Portland State University

PDXScholar

Summer 9-24-2015

\title{
Does Gender Matter? Human Elephant Conflict in Sri \\ Lanka: A Gendered Analysis of Human Elephant Conflict and Natural Resource Management in a Rural Sri Lankan Village
}

Katherine Eileen Griffin

Portland State University

Follow this and additional works at: https://pdxscholar.library.pdx.edu/open_access_etds

Part of the Gender and Sexuality Commons, and the Natural Resources Management and Policy Commons

Let us know how access to this document benefits you.

\section{Recommended Citation}

Griffin, Katherine Eileen, "Does Gender Matter? Human Elephant Conflict in Sri Lanka: A Gendered Analysis of Human Elephant Conflict and Natural Resource Management in a Rural Sri Lankan Village" (2015). Dissertations and Theses. Paper 2533.

https://doi.org/10.15760/etd.2530

This Thesis is brought to you for free and open access. It has been accepted for inclusion in Dissertations and Theses by an authorized administrator of PDXScholar. Please contact us if we can make this document more accessible: pdxscholar@pdx.edu. 
Does Gender Matter? Human Elephant Conflict in Sri Lanka:

A Gendered Analysis of Human Elephant Conflict and Natural Resource Management in a Rural Sri Lankan Village

by

Katherine Eileen Griffin

A thesis submitted in partial fulfillment of the requirements for the degree of

Master of Science

in Sociology

Thesis Committee:

Veronica Dujon, Chair

Margaret Everett

Alex Stepick

Portland State University

2015 
(C) 2015 Katherine Eileen Griffin 


\begin{abstract}
This study is a gendered analysis of natural resource management at the local scale of a poor rural Sri Lankan village in a conservation buffer zone. This village experiences destruction of forests and human elephant conflict. The objective of this study is to gain an in-depth knowledge of residents' use and understandings of environmental resources, and to investigate if gender helps shape these factors. This study relies on a social sustainability conceptual framework. It tracks participation of local women and men in natural resource management, and in conservation within and outside of the Bibile community. Local nongovernmental organizations focus on mitigating human elephant conflict and government policies influence particular farming practices. Unless socially and environmentally sustainable practices are developed, areas within and outside of the protected areas are not sustainable in their current state (Jayewardene 1998). Current interventions are failing to solve this problem in both rural communities and natural ecosystems, demonstrated most clearly by shrinking forest habitats and the frequency of human and elephant deaths (Bandara 2009). By broadening the analysis of natural resource management to examine possible social, economic, and political influences, my research examines how different resource management approaches might be filtered and reflected by variation in local residents' use and understanding of environmental resources. I suggest that gender, household decisionmaking, and equality are overlooked but potentially important aspects in the perception and implementation of natural resource management.
\end{abstract}




\title{
Dedication
}

\author{
For Professor Daniel Monroe Sullivan \\ (1967-2014) \\ in memoriam.
}

To Daniel, for encouraging me to always strive for excellence and integrity as an academic researcher and scholar. Your superior example as an educator, role model, and dedicated mentor, will always be with me. This thesis would not have been possible without your encouragement, foundational support, and loving guidance. Thank you. 


\section{Acknowledgements}

First and foremost, I would like to thank my committee-Veronica Dujon, Margaret Everett, and Alex Stepick-for your expertise, guidance, and insight. Alex, you have generously and kindly taken me under your wing. I could not be more grateful for your mentorship and counsel. Margaret, you have my great admiration. Thank you for your unique and valuable contributions to this thesis. A very special thanks to Veronica: It has been an honor and pleasure working with you. I could not have done this without your knowledge and support. I am sincerely grateful for your long-term investment in this project. Michael Toth, thank you for imparting your theoretical and intellectual curiosity. Professors Sally McWilliams, Michele Gamburd, Bob Liebman, Pete Collier, and Maura Kelly, thank you for your interest and enthusiasm. I would like to also thank my undergraduate mentors from Cornell University_Cynthia Caron, Wasantha Liyanage, Linda Wagenet, Paul Eberts, Parfait Eloundou-Enyegue, Amy Villarejo, Kelly Connison, and Laura Weiss - for your unending encouragement.

Thank you to everyone in Sri Lanka who helped make this project feasible. Achala, my research would not be possible without your profound influence. IUCNVimukthi, Diana, Dilhari and Sajeewa — thank you for the support and collaboration during my field season and data collection. Thank you EFL, especially Manishka, Venuri, and Ruzmyn. To my host-father, Lalith, thank you for introducing me to the project of HEC. Pruthu, your expert opinions and willingness to share them have guided my elephant studies for a decade. Thank you CENWOR, WERC, and Equal Ground, for sharing your resources and libraries. Finally, I'd like to extend warm appreciation to all 
of my participants and collaborators, their willingness to share their invaluable perspectives with openness and trust has been the crux of this project.

Thank you to all of my family, friends and cohort members: Renée, Aaron, Luke, Sam, Alex, Marlon, Beverly, Jade, Jesse, and Bahar, for supporting me during my oral defense; to my cousins, Matt and Megan, for accompanying me cross-country; to Gerry and Michelle, for always providing thoughtful academic guidance; to Noelle, Hanna, Allison, and Christopher, for helping me to believe in myself during pivotal writing blocks, your encouragement has meant everything to me; to Samantha and Kym, for the many months of seemingly endless writing workshops; to Natalie, Sue, and Bill, for the thoughtful thesis-writing care-packages and unwavering votes of confidence; and to my aunt, Marilyn, for the joyous celebration. To all of my Griffin and Game Aunts and Uncles: your unconditional love has made me who I am today.

To my fearless travel companion and indestructible friend, Meredith Talbert: I would never have made it through the summer field season without you. A very special thanks to Dylan Waller, my cohort partner-in-crime: Thank you for always being a wealth of encouragement and giving the tough feedback when I needed it most. Thanks to Marlon, for continuing to remind us that there was "no backup plan."

I give my undying thanks to my dear friend, Megan; my partner, Matthew; and my parents, Tom \& Connie. They have been by my side from the start of my Sri Lankan studies, beginning over a decade ago, through the toughest last-leg of this project. Without their love and unconditional support, this project would not have begun and it certainly would never have been completed. I give my love, my endless gratitude, and many thanks to all of you. 


\section{Table of Contents}

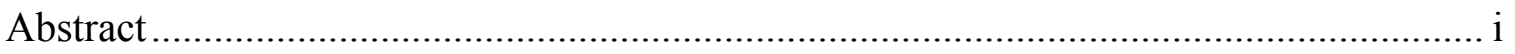

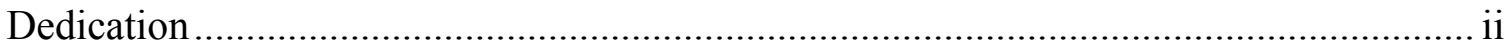

Acknowledgements ................................................................................................... iii

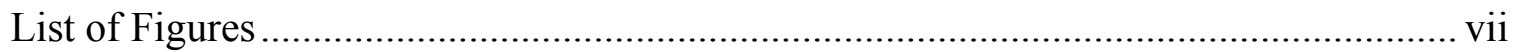

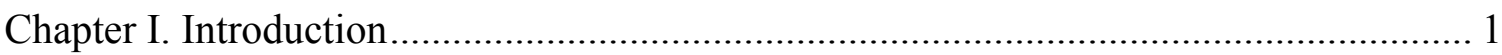

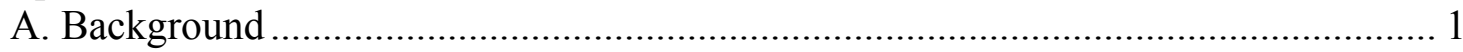

B. Research Questions ........................................................................................ 12

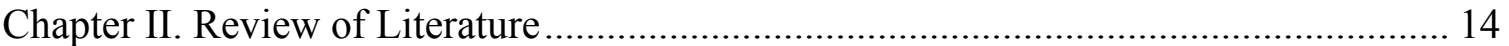

A. Environmental Conservation and Human Elephant Conflict (HEC) in Sri Lanka's

Buffer Zones of Protected Areas (PA) ..................................................................... 14

B. Transnational Feminism \& Female-Led Environmental Movements in the Third

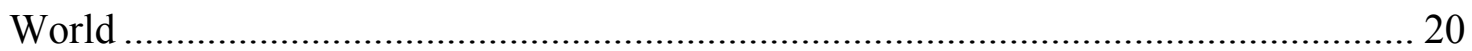

C. Development Alternatives: Exploring the Potential for Social Sustainability

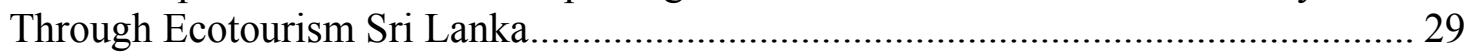

Chapter III. Theoretical Framework …………………............................................... 37

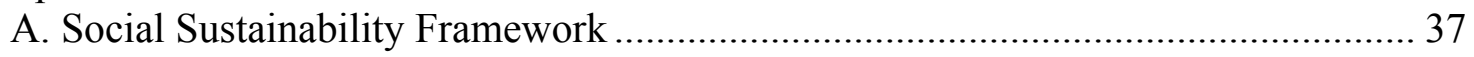

B. Division of Household Labor and the Environment ............................................... 44

C. Feminist Theory on Gender and the Environment ............................................... 47

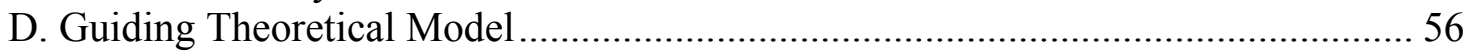

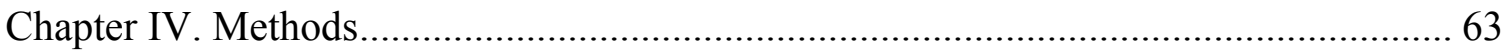

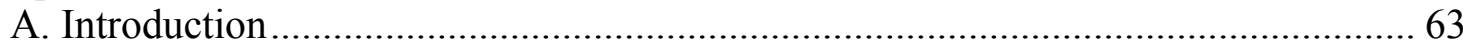

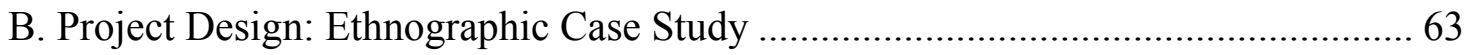

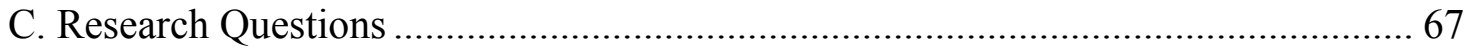

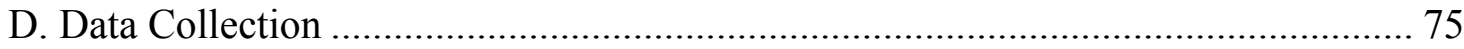

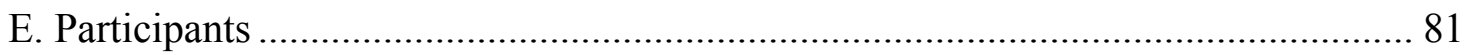

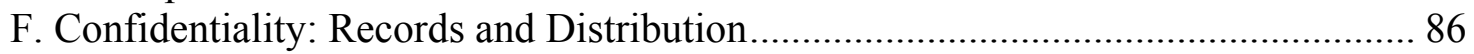

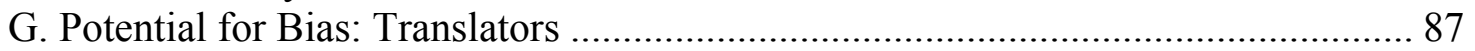

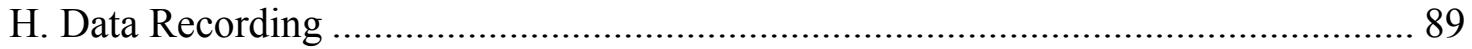

I. Participatory Action Research: Positionality within Applied Feminist Research..... 91

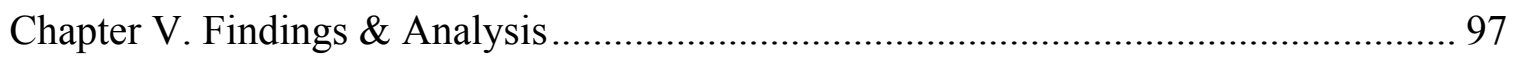

A. Gendered Division of Labor in the Rural Household ............................................... 97

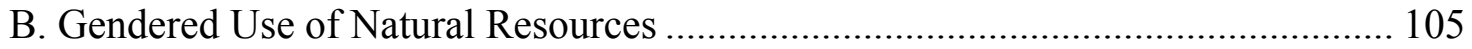

C. Gendered Forest Impact …….............................................................................. 107

D. Gendered Knowledge, Approaches \& Understanding of Natural Resource

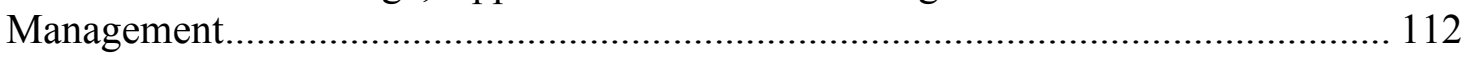

E. Roles of the Government \& NGO Trainings........................................................... 119

F. Alternative Findings: Female Head of Households \& Indigenous Approaches..... 127

G. Elephants, Poverty \& Forest Protection ................................................................ 135 


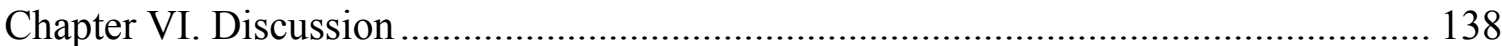

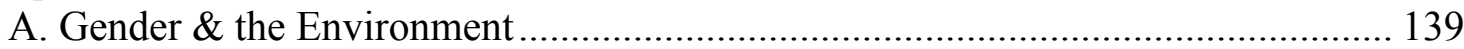

B. Importance of Gender in Natural Resource Management.................................... 140

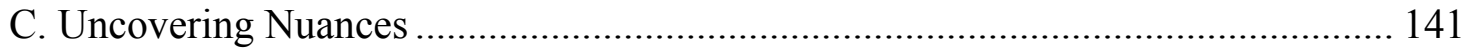

D. Ecotourism \& Community Engagement ............................................................ 143

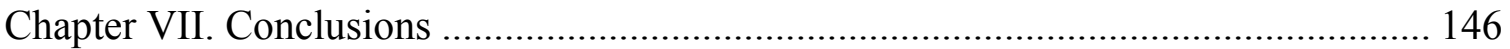

A. Does Gender Matter? ...A Complicated Story ................................................... 146

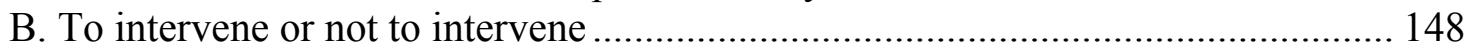

C. Future Research on Gender and HEC .......................................................... 150

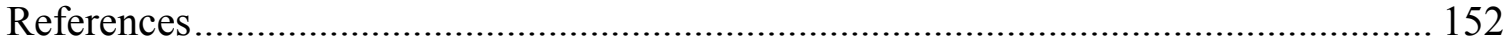

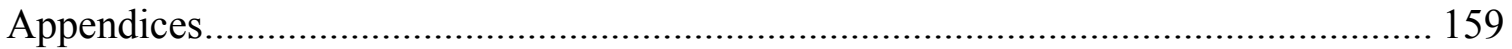

Appendix A. Obtaining Consent .......................................................................... 159

Appendix B. Environmental Impact Assessment of Rural Villagers based on Gender

Appendix C. Interview Guide for NGO staff/ volunteers ................................... 162 Appendix D. Environmental Impact Assessment of Rural Villagers based on Gender

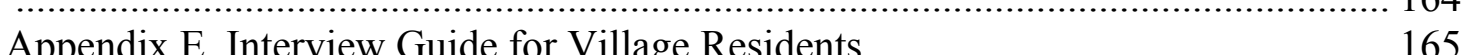

Appendix E. Interview Guide for Village Residents ........................................... 165

Appendix F. Map of Primary Research Site .............................................................. 169

Appendix G. Village Data Sheet: Annual Forest Product Collection/Services .......... 170 Appendix H. Reported Number of People Participating in Forest Collection Activities

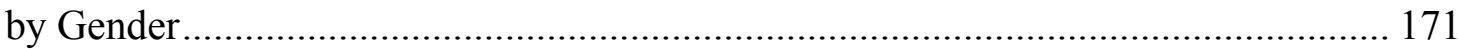

Appendix I. Sample of Evolving Log Sheet: ................................................... 173 


\section{List of Figures}

Figure 1. Gender Institutions within the Social Sustainability Framework.................... 38

Figure 2. Rural Division of Household Labor (DoL) ................................................ 42

Figure 3. Access to Natural Resource Decision Making and Environmental Outcomes . 43

Figure 4. Women's Access to Decision Making and Environmental Choices ................ 48

Figure 5. Stakeholder Authority in Sri Lanka's Protected Area (PA) Buffer Zones in

Bibile-Nilgala National Forest.............................................................................. 57

Figure 6. Stakeholder Environmental Attitudes and Natural Resource Strategies .......... 59

Figure 7. What Socially Sustainable Institutions Can Do: Conservation Feedback Loop

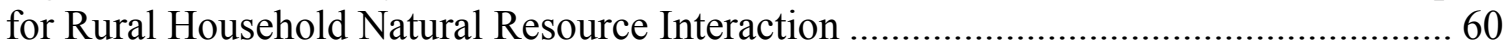

Figure 8. Environmental Needs and Gendered Environmental Uses .............................. 61

Figure 9. Village Interview conducted with Dilhari Weragodathenna ........................... 70

Figure 10. Map of Sri Lanka and Bibile Nilgala Area............................................... 71

Figure 11. Typical Village Residential Structure: A Mud Hut....................................... 72

Figure 12. Dilhari Weragodathenna in a Rice Paddy Field in Bibile-Nilgala ................. 73

Figure 13. Map of Bibile in the Intermediate Zone ..................................................... 74

Figure 14. Katy and Dilhari Examining Ancient Medicinal Plant Book ........................ 79

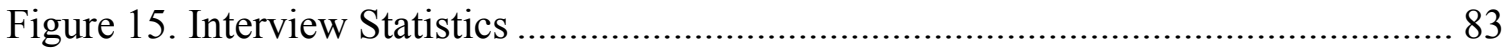

Figure 16. Villager Households (HH): Assigned Names ${ }^{\wedge}$ and Spousal Relationships .... 85

Figure 17. Village Households* (HH): Number of People \& Children's Ages ............... 85

Figure 18. NGO Participants: Assigned Names by Gender........................................... 86

Figure 19. Additional Expert Informants: Assigned Names (Male)............................... 86

Figure 20. Dilhari en route to Bibile-Nilgala Forest Protected Area .............................. 89

Figure 21. Household Activities by Gender: Average Number of Hours Per Week....... 99

Figure 22. Restated: Rural Division of Household Labor (DoL) ................................ 102

Figure 23. Overlapping Household Roles.................................................................. 103

Figure 24. Average Reported Number of Participants' engaging in Forest Collection

Activities by Village Residents............................................................................... 105

Figure 25. Participation in Forest Collection Activities by Gender ............................ 109

Figure 26. Firecracker Provided by the Wildlife Department .................................... 122

Figure 27. Dilhari inspecting village water tank...................................................... 125

Figure 28. Demarcations of Protected Forest and Wildlife Areas ................................ 127 


\section{Chapter I. Introduction}

\section{A. Background}

Sri Lanka is a small island nation in the Indian Ocean with an approximate area of 65,000 square kilometers and a dense human population of almost 20 million people. It is located 28 kilometers off of the southeastern coast of India and is between $5^{\circ}$ and $10^{\circ}$ North Latitude and $79^{\circ}$ and $82^{\circ}$ East Longitude (Jayewardene 1994). The country suffers from environmental degradation, which has been increasing since the end of a civil war that began in the early 1970s and ended in 2009. Most natural areas of Sri Lanka are fragmented and rapidly shrinking as a result of population growth of 1.3 percent per year and associated increasing socio-economic need. (Somasekaram 1997:47). Over the past sixty years, the majority of Sri Lanka's natural areas, especially mature forests, have been cleared for agriculture (Jayewardene 1994). Development initiatives also result in habitat destruction and fragmentation.

Women in rural areas play a critical role in preventing deforestation in areas containing biodiversity (Mathur 2001). The gendered use of natural resources in rural villages may also have an impact on species preservation and poverty alleviation, because the degree of female empowerment may be linked to variation in resource management (Jayaneththi 2000:89). Rural areas are most relevant management sites for preserving biodiversity due to their proximity to surrounding natural environments. Natural resources play a key role in the livelihoods of poor residents, especially women because they are tasked with gathering forest resources to provide food and water to their families. The purpose of this case study is to analyze the gendered use of natural resources among residents of the rural Sri Lankan district area of Bibile, located in the 
Buffer Zone of the Protected Area (PA): Nilgala Forest. The residents of this area suffer greatly from destruction of their crops by elephants native to the area, which has led to killing of elephants and increased encounters with elephants have led to human deaths (Jayewardene 1994). This conflict involving human and elephant deaths as a result of interspecies killings due to competition over limited shared land and resources is known as Human Elephant Conflict (HEC). HEC is particularly acute in Sri Lanka, but it exists throughout Asia and Africa involving both the Asian elephant (Elephas maximus) and the African elephant (Loxodonta africana) (Jayewardene 1994: 2).

Human Elephant Conflict is "one of the serious threats facing the long-term survival of elephants in Sri Lanka" (Jayewardene and Santiapillai 1998: 5). HEC also threatens the social, environmental and economic sustainability of the communities in the buffer zones of protected areas. The Sri Lankan Elephant (Elephas maximus maximus) is endangered largely due to HEC, and other species would be threatened by the possible extinction of elephants (Fernando 2005). The largest threat to the survival of the Sri Lankan Elephant is particularly at risk due to increasing conflict between rural farmers and elephants (Fernando 2005).

In the discourse on the intersection of environmental conservation and social sustainability, the impact on poor residents living in buffer zones and in particular the uneven impact on gender roles is largely unexplored. Previous research has concluded that rural women have specific approaches to environmental and natural resource management within their roles as forest gatherers that differ from those of men who occupy primarily agricultural roles (Wickramasinghe 2000:36). 
In many places in the developing world, the conflict in buffer zones where poor people live is highly charged, but not enough research has been done in unpacking the problems or identifying potential opportunities to determine how one might improve outcomes. Given research that suggests a correlation between gender roles and positive social and environmental outcomes (Mathur 2001), I want to understand what gendered environmental interactions look like in this context. This research uses Bibile as a case study to understand what gendered environmental interactions look like in this buffer zone in an effort to contribute to better theoretical conceptualization of the challenging dynamic of preserving biodiversity while promoting more sustainable and improved livelihoods for poor residents.

According to the conceptual framework developed by Dillard, Dujon and King (2009):

Social sustainability refers to both (1) the processes that generate social health and well-being now and in the future and (2) those social institutions that facilitate environmental and economic sustainability now and for the future.

I use a social sustainability framework developed from that definition to understand the gendered interactions, because doing so will provide a balanced way to understand the environmental, economic and social factors that influence and shape the outcomes that we see. This framework facilitates the ability to incorporate these three areas in an integrated approach that provides in-depth understanding of the dynamics of such contested spaces. I find this particularly useful not only because it facilitates a way of integrating these factors, but it also allows for a focus on gendered interactions between people and nature in this context that seem to present different outcomes. 
The Nilgala forest is of great ecological and social significance: "Sri Lanka's ancient Nilgala forest... [is] known for its medicinal plants...such as Aralu, Bulu and Nelli, [which] are invaluable, rare and have been growing in the area since King Buddhadasa's reign in the fourth century" (Friends of the Earth International 2014). The social sustainability of Bibile communities is threatened on a variety of frontiers. First and foremost, the residents of Bibile suffer greatly from Human Elephant Conflict (HEC). I first became impressed with the importance of the elephant species and the magnitude of the impact of HEC on the people of Sri Lanka in 2005 through my discussions with urban citizens, government officials, village farmers, and environmental agencies. I found the Sri Lankan Elephant (Elephas maximus maximus) to be of historical, religious and cultural relevance to most Sri Lankans across varying class backgrounds. Both wild and domesticated elephant populations are revered. As human populations increase in Sri Lanka, so will interactions between human settlements and wild elephants particularly in buffer zones such as Bibile (Jayasuriya \& Gibson 2013). This will unavoidably lead to greater HEC. Prithiviraj Fernando suggests the best elephant conservation strategy is one that includes traditional land-use practices in methods of coexistence, "where people and elephants have to share resources" (Fernando 2005: 2465). In the interest of more effective approaches to integrate strategies of coexistence, understanding the role of gender and how it can potentially mitigate conflict is fundamental. This analysis of shared resources is needed to determine the importance and relevance of the role of gender regarding HEC and potential mitigating strategies.

In the discourse on the intersection of environmental conservation and social sustainability, the impact on poor residents living in buffer zones and in particular the 
uneven impact on gender roles is largely unexplored. This project explores the experience in Bibile as a case study of these intersections in an effort to contribute to better theoretical conceptualization of the challenging dynamic of preserving biodiversity while promoting more sustainable and improved livelihoods for poor residents. Defining and analyzing this case is achieved through participant observation and formal interviews with local residents of Bibile. In-depth interviews with non-governmental organizations (NGOs), located outside of the village, regarding gendered and environmental attitudes are also utilized. A goal of this research is to develop informed and relevant hypotheses for future research about HEC mitigation strategies. The project seeks to understand the meaning behind particular actions involving environmental resource use and management. This study hopes to provide an insightful analysis regarding the environment and natural resource management as it relates to gender and gender specific roles.

Women's role in development is considered significant by local WID (women in development) scholars as well as by transnational feminist theorists (Bandarage 1998: 17). Selila Jayaneththi (2000) believes that sustainable development "can be achieved through environmental consciousness and, inter and intra-generational equity in resource distribution" and that women are central to family structures in Sri Lanka and therefore key to providing guidance in supporting conservation goals (88). This study adds to a relatively unexplored area by combining an exploration of gender with the mitigating strategies used by villages to manage Human Elephant Conflict. Local experts, including Jayanethi have called for further examination of gender and natural resource management to "create a balance between forestry and agriculture into one forestry model" to prevent 
deforestation resulting from land conversion to other uses (100). This Environmental Impact Assessment model, to date, has not been done sufficiently (Vitarana 2000).

In rural areas of Southern Sri Lanka, many women and men view increasingly prevalent human elephant conflict as a social, environmental, and economic problem. Drawing on three summer-long field seasons to develop familiarity with perceptions of HEC in Sri Lanka, I use holistic ethnographic methods to explore issues of gendered division of labor in the household, natural resource use and management including management of HEC. Currently, conservation programs implemented where people live fail to address gender as a key factor in the complex dynamics of use of resources in buffer zones. According to Jataneththi:

There is a significant relationship among environmental degradation, the status of women, and poverty. The attempts to reconcile the competitive demand of the rapidly increasing population often exclude women everywhere in the world and results in blocking their traditional access to natural resources, economically productive endeavors and food security. (Jataneththi 2000: 88)

There have only been a few preliminary studies in Sri Lanka regarding an Environmental Impact Assessment, which suggest there is an unexplored link between gender and natural resource management (Vitarana 2000). Further exploration has been impeded by political reservations, social restrictions, economic hardship and civil war, all of which forced limited resources elsewhere. Jayaneththi argues that "Whatever the contribution is, women's views and concerns are questionable in the development and policy making. Very often their views on various issues and needs are neglected in formulating plans to meet their social and economic needs" (Jayaneththi 2000: 89) The addition of a gendered analysis of HEC to the analysis of environmental impacts could prove to be vital in innovative solution seeking practices. 
In addition to identifying possible HEC mitigation plans, the issue of equality in local governance is a primary reason to focus on gender-specific relationships to the environment. Alaimo has argued that "Ideally, as part of a crucial sort of utopian political imagining, all environmental movements would be forged in such a way as to repel racism, sexism, heterosexism, ableism, colonialism, as well as anthropocentrism" (Alaimo 2008: 303). Alaimo gives reason to focus the environmental movement on forms of social oppression. This current project is guided using this political imagining. Quisumbing has shown gender to be a main factor in natural resource management, with potential for sustainable community development globally through transnational global alliances and feminist activist organizing (Quisumbing 2003). Integrating larger concepts of capitalization and globalization, this project will imbed this mission into each aspect of the process.

The goals of this project, corresponding to the goals of social research as described by Charles Ragin (1994), include giving voice and authority to those studied, especially women who are not usually represented in environmental assessments (Vitarana 2000:25). This exploratory study hopes to lay groundwork to develop future questions and potential hypotheses regarding gender and environmental resource management in this specific area and in corresponding buffer zones of other protected areas in South Asian regions with elephant populations. Although each buffer zone may have unique characteristics, they also share many similar traits. Their similarities may make the findings appropriately transferable. Regions and countries are diverse in their overall desire to protect or remove human populations in buffer zones due to cultural ideologies, animal habitats, local laws and structural mechanisms for addressing 
environmental issues. These conditions have variant historical and cultural influences on gender and domestic structures. However, findings may correspond to these areas in Bibile due to their similar goals, lifestyles and proximity to nationally protected natural habitats.

Following the end of the civil war, Sri Lanka has become a renowned tourist destination. It was named the number one desired location the top 31 tourist destinations of 2010 by the New York Times (Beehner et al. 2010). According to National Geographic Traveler, a US-based magazine, which focused on the island's hill country, Sri Lanka was among the best destinations to visit in 2012. Another monthly travel magazine in Britain, 'Condé Nast Traveller,' has nominated Sri Lanka as one of the top five destinations to watch in year 2012."

The goal of Sri Lanka achieving a target of " 2.5 million tourists by the year 2016 " (2012) will have dramatic effects on the local economy, with the probability of increased development coinciding with damaging effects on the natural habitats. Following this population trend as well as the current direction of the market economy in Sri Lanka, mitigating strategies become increasingly important. Increased wildlife interactions and the widespread destruction of habitats, in many villages, threaten the survival of the Elephas maximus maximus.

This study will provide a clearer picture of the relationships between people and the environment as it relates to gender and gender specific roles. "The women's struggle for their legitimate share in land can prove to be the single most critical entry point for women's empowerment in South Asia. Irrespective of the country the specific contribution of men and women to agricultural production are divided among themselves 
clearly" (Jayaneththi 2000: 90). In Sri Lanka, and elsewhere there is an increasing research interest in the impact of gender in conservation efforts (Viterana 2000). To my knowledge, prior to this study, gender had not been examined sociologically in Sri Lankan villages in relation to environmental impact and Human Elephant Conflict. This study helps address this deficiency.

A move toward a sustainable future requires not only an equitable distribution of available resources, but also the active participation of women as community members and environmental decision makers (Jayaneththi 2000: 100). The disproportionate sharing of environmental burdens by women is particularly unfair considering that this ascribed group arguably commits less of the detrimental acts against the environment. (Jayaneththi 2000) For my research, a key reason to focus on the role of women as a main factor in natural resource management is due to the potential for sustainable community development. Inclusion of the impact of gender roles is an essential aspect within the framework of social sustainability (Dillard, Dujon, \& King 2009). According to Quisumbing (2003), “equalizing men's and women's education, physical capital and cash inputs could lead to significant productivity gains" (54). With increased productivity, there may be increased sustainability in rural communities.

Rural villages are often located in close proximity to governmentally protected areas and other important natural habitats; the result is that the social sustainability of these communities is negatively affected by resource depletion and human-wildlife conflict. A guiding hypothesis of this project is that rural women have specific approaches to, and attitudes regarding, natural resource use and management that differ from men (who occupy the majority of policy-making and natural resource management 
roles). Should that be the case, gender may prove to be relevant concept when addressing future matters of rural forest management and conservation and HEC mitigation. The possibility of a unique female environmental perspective proves especially useful when women's viewpoints contribute to a conservation method that encourages greater preservation of natural resources. Due to the gender-specific ways in which rural women are affected by the degrading effects of pollution and resource scarcity (Braidotti 1994), policies might also address these gender-specific needs.

For this investigation, it is also useful to examine how environmental projects and governmental policies, developed outside of the village but implemented within it, affect gender relations and the impact on conservation outcomes. This will be useful in determining policy suggestions for agencies whose goal is to conserve forest habitats for the sake of people and elephants.

Habitat preservation is essential for any effort to preserve biodiversity and prevent species extinction. According to Kamini Meedeniya Vitarana (2000), in addition to ecological benefits of environmental protections, the preservation of rural forest habitats is essential to alleviating some of the issues of rural poverty, though often unrecognized as a poverty-reducing initiative. In an attempt to protect Sri Lankan forests and natural habitats, inclusion of rural women may be the next step in sustainable resource management. Women-centered (or at a minimum female-included) decision making regarding natural resource use and policy locally and nationally can potentially have a positive impact. If this should prove to be the case it would have ripple effects of improving gender equity in the household. Development agencies and international funding sources interested in natural resource conservation and sustainable development 
may also have a stake in how gender roles impact the environment. The inclusion of rural women in decision-making is one effort that has the potential to achieve increased conservation and poverty reduction.

The environmental crisis, involving resource scarcity and deforestation in Sri Lanka, is paramount in guiding policy. One aspect of environmental damage worth addressing immediately is the rapid loss of biodiversity. Following in the footsteps of industrialized nations, many natural areas within developing nations have already been destroyed in the interest of economic development. Developed nations have depleted most of their old-growth forests and natural habitats, including charismatic mega-fauna. In countries that we currently consider developed, these mega-fauna, (wolves, mountain lions and other predator species,) threatened human development and agricultural practices, which resulted in them being hunted to extinction or near extinction. Countries working toward development now are experiencing the same issue with rhinoceros, tigers, elephants and others, threatening the survival of these endangered species. Focus must be placed on sustainable development in poor rural areas in order to encourage survival of these species in addition to the preservation of human communities.

The research questions listed below, all of which focus on gender, use a Social Sustainability framework to explore the questions of gender and Human Elephant Conflict in Sri Lanka. Bibile community residents, including men and women, are dependent on the natural resources provided by the Nilgala forest in the protected area. This dependency is in direct conflict with the elephants, thus stakeholders are making efforts to negotiate that balance. The NGOs focused on conservation have one thrust or approach and the people respond in different ways. Some of the people affected include 
farming residents, government officials, indigenous tribes and outside encroachers. Through the information gathered using the following research questions, this project specifically focuses on the relative importance and impact of gender in the matters of HEC and forest conservation. Other work on natural resource conservation has suggested that a focus on gendered interventions will result in better outcomes. Thus, by focusing on these interventions that tend to be gendered, an opportunity exists to explore the intersecting forces of the environment, the economy and the social factors. This expands ways of thinking about poverty. It informs how to think about the elephants and the conflict between rural communities. Based on the evidence of what women actually express combined with what the research observes, effective alternative strategies may be developed. According to the literature, which will be discussed more thoroughly in the following chapter, gender seems to matter. To that end, this research is guided by the following research questions.

\section{B. Research Questions}

Q1: What is the gendered impact of forest-dependent village residents on natural resources?

Q2: What is the gendered understanding of interaction between humans and elephants in buffer zones of PAs? 
Q3: Do men and women have different ideas or approaches to solving HEC? If so, how do men and women consider different solutions to the HEC problem and forest management?

Q4: How do non-governmental organization staff members understand the relationship between gender, HEC, and poverty? 


\section{Chapter II. Review of Literature}

The following sections review the relevant literature related to gender and HEC in Sri Lanka. The literature review begins with an overview of the environmental conditions in Sri Lanka's buffer zones and surrounding Protected Areas (PAs). This overview highlights the social importance of elephants in Sri Lanka and the relevance of gender in this investigation. It then explores transnational feminism through a comparative approach of female-led environmental movements in the developing world. Two movements given particular attention include: the Chipko \& the Green Belt Movements. Lastly, I explore the potential of achieving HEC mitigation goals through moving forward with socially relevant and equitable ecotourist practices in Sri Lanka. The literature suggests that development alternatives ought to include the local-engagement of communities with the ecotourism framework to encourage social sustainability in Sri Lanka.

\section{A. Environmental Conservation and Human Elephant Conflict (HEC) in Sri}

\section{Lanka's Buffer Zones of Protected Areas (PA)}

Human societies exist within and depend upon surrounding natural habitats. Often humans exploit the environment to meet pressing survival needs or to achieve shortsighted capital gains. Societies are increasingly engaged in developing sustainable systems of exploitation that promote the long term health of these environments in order to ensure their own survival. Finding that balance however, can be rather challenging particularly when poverty is juxtaposed with the risk of species extinction as often 
happens in communities located in buffer zones around protected areas. In Sri Lanka, as this project describes, the conditions are particularly difficult.

Given the intersecting motivations to protect both human societies and elephant populations a social sustainability framework that allows for the exploration of the environmental conditions that result in HEC as well as the social institutions, policies, and processes that may allow for a resolution is best suited to guide this research. I begin below with a discussion of the environmental challenges of protecting the elephant habitat and how these intersect with the social, economic and cultural conditions of the residents of the buffer zones that surround the protected areas for these habitats.

HEC occurs wherever wild elephant populations are juxtaposed with human settlements. This conflict is highly concentrated along the boundaries of national forest parks and wildlife refuges. HEC damages human lives and human property, particularly that of the rural poor. Although wild elephants and human populations have found themselves at odds long before the colonial era let alone post-independence, the current intensity is unprecedented. If immediate preventive action is not taken, the population of the Sri Lankan elephant may soon fall below a viable level. (Jayewardene 2003) The populations of Sri Lankan elephants, a subspecies of the Asian elephant, are decreasing at a rate of six percent annually (World Wildlife Fund 2015). This rapid decline is in large part due to deforestation as a result of habitat encroachment and fragmentation of the elephants' normal habitat. The proximity of human communities to elephant populations escalates the phenomenon of HEC and occurs most frequently in the areas bordering governmentally protected areas. According to Jayewardene (2003), “[t]he conflicts between the settlers and the elephants have not abated and continue to cause concern and 
deaths of both humans and elephants" (97). Communities of people residing in forests suffer both physical and economic harm from this conflict (Jayewardene 2003). Although HEC has been identified as an issue of concern by the Wildlife Department and attempts have been made to reduce it, these efforts are often superficial and have little success. Jayewardene concludes that this is most likely due to the lack of understanding of structural societal causes that lead to the conflicts and a failure to implement ecologically and socially sound practices for HEC mitigation (Jayewardene 2003:97).

Sociological inquiries investigating HEC are more complex due to the intricacies of the ties between Sri Lankan culture and the elephant, which is regarded as a sacred icon. Because this animal is so respected and religiously revered, its extinction will affect the entire culture negatively. "Due to close cultural and historical ties between people and elephants, these conflicts have become an important socio-economic and conservation issue" (Jayewardene 2003:164). The local interest and investment in the survival of elephant populations for the religious and cultural values embedded in the species provides additional rationale to use a social sustainability framework to understand the complex social and environmental causes of HEC in Sri Lanka.

From a biodiversity conservation perspective because the Elephas maximus maximus, a subspecies of the Asian elephant, is unique and exists only in Sri Lanka, it is worthy of environmental protection. The Sri Lankan elephant evolved isolated from other Asian elephants and is the largest and darkest species of Asian Elephant (WWF 2015). Its extinction would represent the disappearance of an entire sub category of Asian elephants. According to a long-term study on its population dynamics, "the Asian elephant was once widely distributed across much of Sri Lanka...(yet now) the number 
of elephants in the wild in Sri Lanka has declined from about 12,000 prior to the $19^{\text {th }}$ century to about 4,000 in 1997" (Katugaha et al. 1999: 51). "The latest count places elephant population size in Sri Lanka between 3,160 and 4,405 individuals. Of these, between 2,000 and 2,870 are found in protected areas, however this is likely to be an underestimate. Captive elephants have declined to 400-600 individuals" (WWF Global 2015). The decline of elephant populations in this area, has garnered attention for their protection throughout the country.

Effective wildlife management planning and habitat conservation is considered imperative not only for the sake of elephant but for many other species that also rely on the ecosystem services they derive from elephant habitat. Protecting biodiversity is a high priority in wildlife management (Lele 2010) as it ensures the fulfillment of a greater number of ecological niches for a number of species, creating a more resilient ecosystem. The greater the biodiversity of a habitat, the more resistant that habitat is to natural disturbances, such as disease, climate change, and drought. In an area with high levels of biodiversity, if one organism is negatively affected, other organisms will be able to fill its niche and prevent the crash of the entire ecosystem. When such an organism is a keystone species, if it is disturbed, a large percentage of other species will be adversely affected in a cascading series of reactions. As a keystone species elephants are particularly important to the integrity of ecological structure in their natural habitats in Sri Lanka. Jayewardene and Santiapllai argue that their protection in an area would enhance the survival of several other species sympatric with it thus maintaining biodiversity (Jayewardene and Santiapllai 1998:6). 
The health of a keystone species such as the elephant indicates the health of an entire ecosystem. A healthy ecosystem has a better chance of surviving in the long term and is therefore more sustainable. If elephants become extinct, many other wild species, which share a common habitat and rely on elephant for some other unique forest function, will also suffer from potential extinction or reduced health. Elephants provide a range of benefits to other species such as creation of jungle corridors through herd movement allowing greater mobility for smaller creatures; the removal of certain layers of foliage to allow pioneer plants to access sunlight on the forest floor and the propagation of certain plants since their seeds must be ingested by elephants and pass through their digestive systems before they can germinate. (Fernando 2005; Jayewardene 1994)

Using a basic understanding of population dynamics in ecological systems, once the elephant population drops below a viable number, this subspecies will become extinct. According to Dr. Prithiviraj Fernando (2005), the amount of time it will take for the population of elephants to drop below a viable number is unknown and cannot be determined with any degree of accuracy. Additionally, local experts do not agree on the number of elephants it takes to maintain a viable population. (Jayewardene 1994) Though some argue that it is worth the effort of maintaining this population regardless of predicted population size outcomes in the future. Beyond these environmental concerns however, the extinction of the Sri Lankan elephant would be a socio-environmental tragedy (Katugaha 1998).

"With almost twenty million people and three to four thousand elephants sharing and competing for land in Sri Lanka, conflicts are inevitable" (Jayewardene 2003:164). 
As issues of poverty deepen in rural areas, elephant habitat is increasingly encroached upon. Elephants kill humans because humans encroach on elephant territory, which prevent the elephants from accessing food and water sources. Wild elephants are dangerous to humans and have killed rural villagers at a rate of fifty individuals per year (Jayewardene 2003).

Male elephants need large areas of space, referred to as 'elephant ranges' by biologist and conservationists, to move about, feed, forage, and reproduce successfully. Female elephants have slightly smaller ranges, though herds made up of female elephants still need to be able to migrate freely throughout their ranges in the country to access enough food and water to allow their populations to remain viable. (Jayewardene 2003) The planting of rice paddies and other agricultural products by humans within and near elephant habitat disrupts their range behavior.

In Sri Lanka poaching is rare. People kill elephants primarily to stop them from consuming rural crops and destroying their property (i.e. fragile mud hut residential structures). As farming settlements increasingly encroach upon elephant habitats and push them out of protected areas, elephants visit croplands at a higher rate. Crop damage and property loss in poor rural areas completely devastate household and village livelihoods. HEC and habitat encroachment are the major causes for the Sri Lankan subspecies of elephant to make the endangered species list.

By consuming entire fields of farmer's crops in short periods of time, elephants pose an enormous threat to farming families and agricultural communities. According to personal accounts given to me by villagers in prior years, elephants can destroy an entire farm's annual income through one night of feeding. This obviously can devastate rural 
farmers and, not surprisingly, often provokes retaliation. Based on an assortment of newspaper articles on HEC in Sri Lanka, those who take revenge are almost exclusively men and usually impoverished. This gendered response in human interactions, use and exploitation of natural resources has been the subject of much debate in the search for solutions to environmental problems. In this next section I discuss the gendered nature of resource extraction as well as the social movements and scholarly research that attempt to shed light on these interactions, particularly from the perspective of the developing world.

\section{B. Transnational Feminism \& Female-Led Environmental Movements in the Third World}

Women in developing nations have led grassroots movements that have been effective in changing the landscape of environmental resource management (Brechin \& Kempton 2003). Throughout the world, particularly in the global south, women-led environmental movements are at the forefront of feminist grassroots organizing. The Chipko Movement in India was able to prevent deforestation and the Green Belt movement involved the planting of trees to promote empowerment and fight injustice (Brechin 2003: 328). In Malaysia, women of the Penan tribe in the Sarawak region resisted destruction of their land and culture by leading the blockade of the forest road. In Brazil the Yanomano women led successful resistance to destruction of the rainforests in their region (Brechin and Kempton 2003: 338). Gendered environmental activism in the Third World exists partially due to female household and caretaking responsibilities, which are typically assigned to women. Domestic roles require specific access to 
consumable natural resources, such as healthy food, abundant water sources and medicinal plants. While male's activities also may require access to natural resources, the materials they need are typically used for economic purposes.

According to Naples, "For women in the Third World, destruction of the environment means that women have to spend more time every day to gather wood for fuel, fodder for cattle, and fetch drinking water." (Naples 2002: 24). Globally feminist organizations are incorporating environmental principles into their mission statements and primary activist efforts as they increasingly respond to the importance of environmentally sustainable development practices. Although challenges of access to water, food and forest resources are not typically understood in gendered terms, women's responsibility for providing these, as demonstrated by the Chipko and Green Belt movements, arguably provide them with a unique and meaningful perspective on conservation and forest management.

Can this unique perspective be similarly appropriate for community organizing for resolving HEC conflicts in the buffer zones of protected areas in Sri Lanka? Can the hardship women experience motivate them to organize better conservation efforts? The lessons learned from the conditions of these globally recognized movements may potentially be transferrable to Sri Lanka and might be helpful in providing/developing a theoretical framework to improve understanding of the experience in the buffer zones in Sri Lanka and thereby inform positive change toward sustainable rural developments and promote gender equity.

Viewed from a feminist lens I argue that the active participation of women as environmental decision makers in the Chipko and Green Belt movements, promoted a 
more environmentally sustainable future and the avoidance of global environmental degradation by advocating for more equitable distribution of available resources. Because women in these areas were acutely aware of the connection of forest health to their access to resources and the direct impact on their own well being as well the health and viability of their families and communities, they were motivated to take on the lead in environmental conservation in ways that benefited their entire households. Other scholars have also concluded that inclusion of women in natural resource management, through equal participation regarding approaches to conservation, have resulted in positive outcomes for both conversation and community wellbeing (Rao 1997). The structural inequalities and gendered division of labor rural women experience in households is directly connected with the ways in which they are affected by environmental degradation. This in turn provides them with a unique lens through which to view potential solutions to forest conservation.

The Chipko movement garnered mass participation by women in India who were adversely affected by the felling of trees in the Himalayan Mountains. Women were primarily responsible for water collection and gathering firewood. The felling of trees destroyed water sources and required women to walk greater distances to collect firewood that was no longer easily available (Warren 2000). Weber (1988: 99) argues, "It is easy for the hill women to see what is happening around them. The drudgery and their life as quasi-widows while the men work on the plains below... their heavy and increasing workload means that there is often little time left for care of children." While the women leave their village and are gone throughout the day to conduct their chores/daily work, they often have to leave the children behind. In some cases their 
children have been burned at the hearth, severely injured, or died as a result of having no other choice than to lock them in the house without a caregiver. Weber (1988) reports instances of women's mass suicide by jumping into a river as a result of their dismay at these kinds of travesties "because they could no longer bear the misery of their lives" (99).

The women in the Chipko Movement: broadened the social issues addressed in the movement; inspired and influenced the governmental ban of tree-felling; set up cooperatives to guard forests; produced fodder for local communities at affordable rates; restored degraded lands through tree planting and land rotation; and established successful plant nurseries with selected species. The women, most of them poor, opposed forest exploitation and dam construction by the state forestry policies in favor of supporting subsistence use (Ray \& Katzenstein 2005). Because the women were involved in the hill protests on such a large-scale, some scholars claim that the Chipko was an "ecofeminist" movement (165). Women, who were most affected by the environmental disasters such as recurring floods and landslides occurring in the area, literally stood in the hills with their arms around the trees to prevent them from being cut by loggers (Jain 1984). Women became "front-line soldiers of the andolan" (Weber 1988: 44). Many men were also interested in saving forests, but because they were not available, and also sometimes bought off with the use of alcohol bribes, the task fell to the women. As the movement grew, women were able to provide the needed support to save the trees. Man with similar goals needed the support from women to achieve their shared goals of preserving forestlands. 
The "ecodevelopment camps" to plant trees created by the movement's organizers "from their inception, managed to cross caste and class barriers" (Weber 1988: 94). With many women attending the camps, traditional sex barriers were usurped. These camps with women's participation in the movement have been one of the ways women have been able to begin to change their social situations and start to managing natural resources differently. This resulted in significant changes in the daily management of their lives and thus their individual happiness. By taking care of the wellbeing of their household interests women simultaneously contributed to conservation goals.

This movement has become a touchstone for women's grassroots organizing (Naples 2002). Many women's groups now turn to the Chipko movement to try to learn new ways of addressing their own environmental problems and to better understand the issues associated with gender-specific ways women often suffer from environmental degradation both directly and indirectly.

Today the movement is well known and is often referenced and discussed by prominent activist figures. When women from Pakistan visited India's NGOs, Vandana Shiva (1991) explored the variable conditions that would indicate why a similar movement had not yet occurred in Pakistan. The Chipko movement is one of the original environmental movements that involved an overwhelming number of local women in its grassroots organizing. Thus, women in other areas have become very interested in how women functioned with the Chipko movement. Unfortunately, according to Vandana Shiva, women from Pakistan have not found the possibility for that applicability to their own situation. She states "the group's findings were at the same time sobering and encouraging. It was concluded that movements such as Chipko cannot be transplanted to 
another culture: they are too much a product of local circumstances to be neatly replicated elsewhere" (Shiva 1991: 129).

While the circumstances of the Indian "hill women" are specific to their locality, the findings from the Chipko movement may serve as a model for a comparative approach.

The social climate in Sri Lanka is different from those women living in the 1980s in the Himalayas. However, the ways in which the division of labor in the household places women in a position of greater responsibility for forest gathering as well as fetching water may be comparable to Sri Lanka. Thus, it may make sense to conceptualize a framework in the rural farming villages in Sri Lanka similar to the rural villages of India. This theoretical comparison allows for the inclusion of gender as an essential factor in studying natural resource management in rural Sri Lanka.

Using this same line of argument, the Green Belt Movement may also be useful for a structural comparison with the conditions in Sri Lanka. According to the official NGO website, "the Green Belt Movement (GBM Kenya) was established in 1977 by Professor Wangari Maathai, under the auspices of the National Council of Women of Kenya." (2010). It was created by a forceful women's activist surge in the 1970s in protest of forest degradation. As trees were increasingly logged and the environment destroyed, women's lives were dramatically affected in direct ways that threatened their livelihoods.

Maathai who began her career as an agricultural extension officer and saw a direct connection between deforestation and the quality of women and children's nutrition and lives, organized poor women and encouraged them to plant trees for fuel, shade and food. 
The planting of trees became one form of combating poverty. This practice improved quality of life by providing new food and income sources while simultaneously increasing the health of the environment and the quality of water. The rural women of Kenya had never been in the "business of planting trees" and quickly became successful agents of change.

The changes ranged from micro improvements in the well being of households to macro impacts such as the fomentation of social movements for greater democracy and political accountability that challenged the environmentally destructive export led logging sector and government corruption. What began as a women's movement to enhance the quality of their lives by protecting the environment eventually influenced the political climate of the entire country. Women's contribution to protest movements led to a complete philosophical cultural turnaround.

Previously the government acted primarily as an agent of destruction in its intensive promotion of the logging sector. Through women's political, environmental and social activism, and in alliance with other student and labor groups, the country made strides towards greater democracy. In that transformative process, the military became an agent of environmental preservation as an extension of their role to protect the nation. Environmental conservation activism led to the alleviation of poverty and the improvement of women's lives.

According to the documentary, "Taking Root", (2008) after the movement's efforts the government became a "protector" for the environment as a part of national security. Under Maathai's strong leadership, a leadership that a decade ago earned her the Nobel Peace Prize, the community of women radically influenced a structural problem in 
the country. "Their tree-planting grew into a nationwide movement to safeguard the environment, defend human rights and promote democracy" (Green Belt Website).

The movement has now been institutionalized into a successful international and national non-governmental organization that promotes and safeguards the principles with which the movement began. It increases education, builds community and holds the government accountable for actions taken against environmental wellbeing. Tree planting is the main focus of the project and continues to be a successful strategy today. More trees translated into better lives for women. Women not only had new food sources and income, they also served in meaningful political and community roles. The ways in which the movement has expanded includes involving projects in education, advocacy, food security, ecotourism, women's involvement in economic development and more. The program seems to have been very successful in its goals of "promoting environmental consciousness, volunteerism, and conservation of local biodiversity, selfempowerment, community development, and accountability." (Green Belt Website)

Through an examination of these movements, it is clear that grassroots organizing can be a reaction to environmental degradation that is not being addressed by governing agencies. The movements discussed here grew as a result of the intensity of the women's identification with the effects of natural resource degradation on their lives. It is specific to women and thus clearly motivated by gender-specific needs. Environmental degradation that affects poor rural communities has distinct effects on women in those communities. Women may be driven to protest the degradation while at the same time may lack resources and social status to create change. According to personal reports from local NGO staff in 2004 and 2005, Sri Lanka also suffers from certain governmental or 
mismanagement. Sri Lanka struggles with corruption in dealing with environmental matters. This coincides with lack of concern of governing boards for the well being of the rural poor.

Sri Lanka's governing agencies and institutions do not typically include gender in policies regarding environmental conservation. Given the clear relevance of gender in environmental conservation in other similar developing areas as discussed above, this section considers the relevance of gender in policy making in the Sri Lankan context by drawing on the existing body of literature. As we have seen, women's participation was the basis for grassroots initiatives in some developing nations including India and Kenya. Women were key actors and leaders in local attempts to alleviate issues of environmental degradation and improve the lives of people. These local community initiatives clearly provide effective models for future action of women who face similar challenges in other places like Sri Lanka.

Though the models cannot be applied directly, an investigation that uses an analytical lens informed by a social sustainability approach that integrates social and environmental well being might enhance understanding of the adverse conditions in the buffer zones and consequently how they may be alleviated. How does gender impact the relationship women have to the forest and HEC in Sri Lanka? How does this gendered interaction play out in resource use and conservation strategies?

Ecotourism which is based on the premise that environmentally appropriate economic activities can be developed so that people have access to gainful incomes and the environment is simultaneously protected, has been suggested as one approach that may be a sustainable solution to the problems of HEC and environmental conservation 
and social well being. The following section explores whether an ecotourism effort has potential for promoting economic sustainability, reduce HEC and enhance the livelihoods of residents in the buffer zones, and particularly the well being of women.

\section{Development Alternatives: Exploring the Potential for Social Sustainability Through Ecotourism Sri Lanka}

Sri Lanka offers a rich mix of cultural, geographic, and environmental attractions to tourists from around the world. Although Sri Lanka has had interest in developing its ecotourism sector, more recently it has been an unexplored source of revenue. A twodecade-long civil conflict, in addition to a devastating tsunami that altered the tourist climate, had adversely affected the ecotourism industry (Tisdell 2003). Due to the recent conclusion of its civil war, Sri Lanka may move in a direction of increased development in areas previously occupied by violent civil disputes. Sri Lanka now has potential for increased tourism within the improving political climate. Therefore, it is highly probable for an ecotourist industry to develop, providing yet another reason for attention to be paid to the survival of the Sri Lankan Elephant, as it is more economically vital and timely than ever before.

An ecotourism approach may be a viable potential solution to its ecological problems in an increasingly globalized world. For the purposes of this thesis, I define ecotourism in Sri Lanka as the travel of local residents and foreigners to remote destinations of particular ecological value, including governmentally protected areas, for combined entertainment and educational purposes. 
Ecotourism has been promoted as a strategy for increased sustainable development within the context of developing countries. Evidence from Duffy and Moore (2010), who examine elephant-based ecotourism in Thailand and Botswana, supports that there is also a need for an emphasis on community-benefit and participation in developing "new ways of valuing and conserving elephants". Duffy and Moore claim that community-based approaches have a strong potential to lead to positive outcomes within a neoliberalism framework. Duffy and Moore critically examine the global tourism industry and the possibility of alternative tourisms "such as ecotourism, responsible tourism and nature based tourism [to become a] pathway to sustainable development for the South". They support the need for an emphasis on community-benefit and participation in elephant based tourist practices. Economic gains ought to benefit community conservation efforts, in order to be categorized as a form of ecotourism. Ecotourism provides a potential solution to the elephant population decline in Sri Lanka. It can also provide impoverished rural residents with an alternative livelihood. This can benefit women as well as men. Ecotourism is one way in which people may strive to use conservation values to create economic capital.

In the case of Sri Lanka, the persistence of elephant interactions can be redefined such that the presence of elephants can indirectly benefit the communities they are currently harming physically and economically. As with other forms of tourism, ecotourism is not without its faults and imperfections. If ecotourist practices develop profit-driven large-scale corporate business models, ecotourism ceases to fulfill goals of increasing environmental awareness and affinity. If the government pushes ecotourism to the detriment of environmental factors, the goal of establishing some form of economic 
incentive to preserve the habitats themselves, will also fail. A lack of industry regulation and a disregard for environmental education can cause more harm than good. Wellmeaning efforts in other regions have revealed flawed ecotourist attempts and negative community and environmental outcomes. (Honey 2008)

The exclusion of the local community is another potential problem that should be avoided. If local communities are excluded, rural area populations will suffer from greater social inequities, falling further into poverty. Ecotourist development can move in a direction potentially toward or away from social and environmental sustainability. This pivotal transitional period makes the issue of planning and policy enforcement ever more pressing. Ecotourism can develop a participatory community-focus, rather than a profitdriven focus. By educating ecotourists, ecotourist guides, and other industry players about the science of sustainable interactions with fragile ecosystems environments, there is potential to avoid the pitfall of the exclusion of the local population to the detriment of the ecosystems and forest-dependent communities.

Given the uneven success with attempts at ecotourism efforts especially in buffer zones (Honey \& Rome 2001; Honey 2008), potential ecotourism projects, involving Sri Lankan communities in Bibile, need to be carefully examined for being mindful of goals of social sustainability. While ecotourism is a potential means toward conservation, misguided efforts can thwart conservation initiatives.

Ecotourism involves a complex relationship between travelers and the communities that attract them. New experiences, beautiful landscapes, and environmental awareness all motivate an eco-adventurer's journeys to far-away environments. Global explorers often seek experiences in the developing world. 
As ecotourism has grown in popularity, sometimes resembling traditional mass tourism, its definitions have been expanded to incorporate ideas about ecotourist responsibility, environmentally friendly destination management, profit linkages to conservation efforts, and the sustainable development of local human populations (Campbell 1999: 535).

Because people have begun to include more activities under the realm of ecotourism, concepts such as "alternative ecotourism" have begun to take hold to mean participatory residential benefit in destination areas (Lele et al 2010). The sense of activism surrounding the debates on ecotourism, provides an interesting set up to begin to explore the positive and negative impacts of ecotourism, as it relates to issues of social and ecological sustainability. Within the context of Sri Lanka, it applies to the conservation of the elephant combined with the active and inclusive participation of rural communities.

According to discussions with Sri Lankan biodiversity experts, two strains of ecotourists are most prominent in Sri Lanka. The first is the backpacker who seeks a rustic experience and the second strain is the wealthy tourist who prefers a "westernized" experience. Both strains are said to be welcome in Sri Lanka. This notion is supported by personal experience as a welcome guest in Sri Lanka, while also observing other travelers as warmly embraced, across many facets of Sri Lankan social strata. Regardless of the type of ecotourist, ecotourism results in part from a "growing demand for unique natural and cultural experiences" (Schellhorn 2010:116).

There is an economic push factor in motivating a person to become a tourist and encouraging them to go travel. There is a "pull factor" from the hosting country that desires to earn foreign currency through purchases made by foreign tourists. This is significant in understanding the complex dynamics between host country and visitor (Reisinger 2006). The ecotourist guide is often motivated by a desire to gain revenue 
from local assets, including unique ecosystems, undeveloped natural spaces, and interesting cultural novelties. Socio-political dynamics encourage visitors to travel within a country include and exhibit a need for foreign exchange within the host country (Reisinger 2006).

Arguably, women in rural areas see the least amount of economic and material gain from these kinds of developments. Feminist tourism, as described by Coralynn Davis (1996) in “The Politics of Purchasing Power: Feminist Tourism and Women's Development in Nepal" takes into account the potential and problems of international exchanges of capital. Davis offers interesting insights from a feminist lens into the way certain people are benefited and others are harmed through practices of tourism. Through an incorporation of her analysis, I argue that gender and gendered consequences are relevant in the analysis of social sustainability relating to ecotourism.

Ranjith Bandara (2009) investigates ecotourism policies and practices in Sri Lanka. He is critical of Sri Lankan policies. Bandara claims that the country's policies were initially well intentioned. Unfortunately, in practice, the initial goals currently remain unrealized (475). Current practices emerged through an ecologically minded stance and later translated into inconsistencies and a lack of legislative regulation and enforcement. The article, "The Practice of Ecotourism in Sri Lanka: An Assessment of Operator Compliance towards International Ecotourism Guidelines," outlines the way ecotourism operators throughout various regions of Sri Lanka comply, or more accurately fail to comply, with international standards. Some of the prevailing reasons Bandara cites as the cause for why tour guides in Sri Lanka fail to comply with international standards 
are high costs, an inability to implement commonality from site to site, and a lack of willingness to examine less expensive options (Bandara 2009: 490).

This is not surprising given the somewhat unstable political context in which this industry began in the 1980s. Bandara outlines the directions Sri Lanka will need to take if it is to develop its Ecotourist industry and makes suggestions on ways of going about this development effectively, stating that one way of mitigating ecological damage would be through increased information provided to international travelers regarding the fragility of the ecosystems they come across (481-483).

Unfortunately according to data collected in his interviews, Bandara did not find that there was ample enthusiasm for conforming to international standards. Nor did he find an ecologically-minded regulating force that would strive to protect the ecosystems it markets for its own profit. This negative response to a willingness to adopt "proper" ecotourist practices (490) might play a negative role in developing ecotourism as a means of reaching social and environmental sustainability in rural areas. This is potentially disappointing, as the prospect for alternative means of ecological preservation and poverty alleviation are then less probable.

As a means to mitigate social and environmental conflicts, in part due to Sri Lanka's recent ethnic conflicts, community involvement is key in future ecodevelopment practices. An equitable approach in relation to all stakeholders to avoid further social unrest is well-advised. This is especially the case because of Sri Lanka's history of political unrest. Ecotourist developments that do not take an equitable stance will increase political tensions. This could reignite undesirable violence and fuel HEC. Therefore, it is incredibly important to avoid inequitable distribution of revenue 
generated though ecotourism, not only for reason of equity, but to prevent political violence and civil unrest.

What can the case study examples do to inform the Sri Lankan situation? Regarding local participation in Indonesian ecotourism, in the Schellhorn case study, "Tour operators utilize indigenous resources and cultures in various ways, with indigenous people becoming increasingly involved" (Schellhorn 2010:116). Thus, I hypothesize that there is some possibility for future increased equitability, due to the demonstration of increased local participation in Indonesian tourism. I see potential for Sri Lanka's ecotourism industry to become more equitable through the active inclusion of rural populations and indigenous groups.

All countries will have different experiences with the implementation of ecotourism. Sri Lanka is unique and requires particular investigation and analysis. The success of the projects will be place-specific, as emphasized in Schellhorn's analysis of noting the "importance of recognizing the "specific circumstances" at work within a community" (117). The country-specific relevance of each potential case study supports an investigation of the particularities within Sri Lanka.

An emphasis on distribution, equity and global exchange of goods and ideas might be helpful, in terms of suggestions for future actions and potential research projects. As conservation efforts progress, local communities are sometimes prohibited from activities that were previously used to sustain their livelihoods including "collecting firewood and herbs, growing food and tree crops, hunting and fishing" and settling (Schellhorn 2010, 118). This is true around protected areas in Sri Lanka. Parks then become barriers to sustenance of rural people. Ecotourism, if community-minded, 
oriented and regulated, while not perfect or without shortcomings, can be viewed as a potential source of future income.

Conversely, individuals exploited for the ecotourist industry become further colonized and exploited. Rather than finding viable means of co-existing with wildlife and protected forested areas, local people are instead compelled to create a spectacle of their natural habitats and communities to culturally edit and exhibit for purchase and profit.

While exploitation may allow some rural communities to remain above subsistence levels, it does little to remove larger systems of global and national inequality. Tourism often reinforces notions of the authentic versus the inauthentic. Thereby, patchwork amendments to the problems, through a culture of servitude and hierarchy, result in increasing benefits for the privileged. Limiting community access to economic gain increases pressures on vulnerable communities, especially the rural poor. Alternative sustainability and development models need legislative rigor and grassroots activism to be effective and equitable.

When we address sustainability in Sri Lanka, whether or not ecotourism emerges as a viable solution, the key element is the human aspect. Although there are concerns about natural resource and biodiversity conservation, these concerns are entirely dependent on the people involved. Rural farming communities, suffering from HEC, live in this very sensitive buffer zone. They are in the transition zone between development and forest preserves. Gender is relevant when deciding how to mitigate HEC in the buffer zones. 


\section{Chapter III. Theoretical Framework}

\section{A. Social Sustainability Framework}

According to Dillard et al (2009) "Social sustainability refers to both (1) the processes that generate social health and well-being now and in the future and (2) those social institutions that facilitate environmental and economic sustainability now and for the future." Social sustainability incorporates the processes and institutions in place to generate social benefits and the environmental benefits they depend on. This project, guided by such a conceptual approach takes into account the institutions, policies, and processes that inform and shape the contributions that men and women have to make.

Within that framework, this project assesses if, and how, the social institution of gender matters in decisions about how to mitigate HEC in the buffer zones. The study takes into account the institutions, policies, and processes, which frame resource use and HEC conflict in the buffer zone and how these affect the contributions that women make. The following theoretical discussion lays out the framework that situates women's contributions.

According to the still evolving discourse on social sustainability, the natural environment defines the limits of resources available to human populations for survival. The key way of deciding how we use the environment either through extraction or distribution is through the social institutions we develop. The conceptual framework as developed by Dillard et al (2009) maintains that if we develop appropriate institutions and processes that are also sensitive to equity, we can simultaneously take care of the environment, so it can take care of us. In sum, it is the social institutions and processes 
societies develop that create the conditions to promote human and environmental wellbeing now and in the future. The figure below, developed from this conceptual definition is a visual representation of these connections.

Figure 1. Gender Institutions within the Social Sustainability Framework

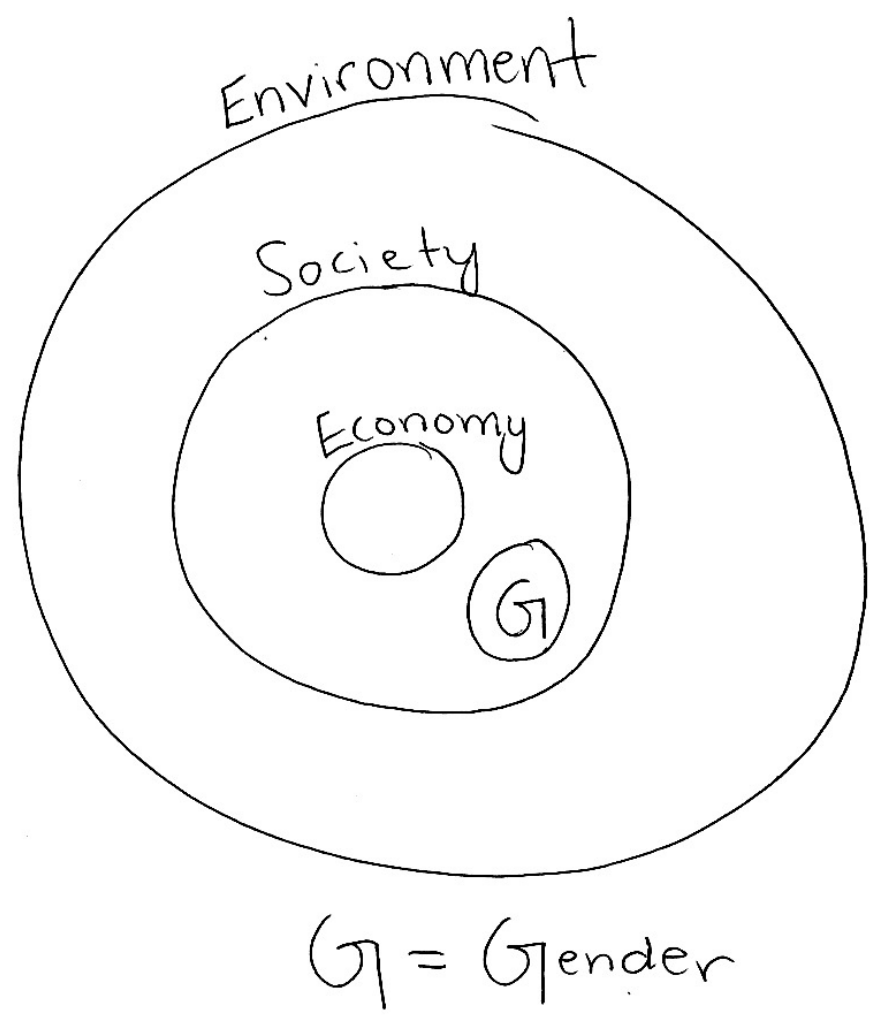

The outermost part of the diagram represents the environment. The next layer represents society. Within society are economic as well as gender institutions, represented by the smaller circles within it. Both the economy and gender are social institutions that shape human behavior around resource use and distribution. Societies are constrained by the environment because people must survive within the resources 
available in it and how they are able to manipulate them. Within these limits society determines the institutions and processes for use and distribution of resources across space, now and in the future. The economic system is one set of social institutions that guide resource use and access. This system encompasses the rules we have defined for determining resource use and exchange. For example, our economic systems, whether capitalist, socialist, or otherwise, determine how we use environmental resources and how to distribute these resources.

The system of gender is another set of social institutions that guide the participation of males and females in economic, cultural and social activity in general. Figure 1 uses the symbol "G" for gender to situate this set of institutions inside society circle in the model. Gendered institutions exist within societies in the form of all of the rules and regulations that dictate roles and behavior based on a person's status as male or female. The gendered division of labor allocates household responsibilities as well as wider social and economic responsibilities.

According to the social sustainability conceptual framework if we can define processes and institutions that promote wellbeing across these levels/circles the outcome will translate into a good life for the future. Democratic institutions that encompass rules and processed for participation help to encourage equal access to necessary resources. The ability for everyone to have some degree of decision making over his or her own life carries the possibility of a better life across time. A strong groundwork of democratic institutions in the present, in turn, ensures that possibility will extend broadly into the future. Additionally, due to communities' shared stake in environmental health, these institutions will also provide guidance when there is a threat of over-use natural resources 
or inappropriate use of the environment. In using a social sustainability framework that focuses on the intersection of the economic, gender and environmental constraints, this research may contribute insights about how this balancing act may be approached in buffer zones where the interactions among these factors seem to have immediate and substantial consequences on human populations and conservation efforts alike.

The conceptual orientation of a social sustainability is substantially different from longstanding understandings of development that have emphasized the central role of only one set of institutions, the economic, as the leading factor in shaping development and consequently well-being. The assumption in the dominant economic framework is that the implementation of appropriate economic policies will provide the incentives for generating economic growth that will in turn produce increasing welfare, both economic and social, for everyone.

The social sustainability model, building on earlier work on alternative development models, challenges this overemphasis on the economic, arguing that economic institutions are only one of many social institutions that can regulate the relationship between resource use and distribution, and that indeed other institutions that define political participation or define gender relations are emerging as quite central in promoting socially sustainable societies that promote social welfare and enhance environmental health.

Indeed there is a long tradition of scholars who examine women's role in development, particularly at the intersection of the gender and the economy, who have demonstrated the central role that gender plays in shaping outcomes of wellbeing at various scales: individual, household and beyond. As Miles and Shiva conclude, 
"Women's increasing underdevelopment was not due to insufficient and inadequate 'participation' in 'development' rather, it was due to their enforced but asymmetric participation whereby they bore the costs but were excluded from the benefits" (Miles \& Shiva 1993:73-74).

As elaborated upon in the literature explored in Chapter Two, gender as an institution is also a key regulating factor that can improve how we relate to the environment and simultaneously improve the lives of everyone, not only women. However, the institutions that carry such benefits tend to only be those institutions, which are democratic, give women more voice, and are more equitable. The essential thrust of the WID approach, according to the Asoka Bandarage (1998) is the integration of poor women in the economy (17).

The gendered division of labor in rural developing areas affects resource use and consumption. Some feminist scholars, as explained previously, have found the division of labor in the household to be a relevant factor in determining environmental impacts (Mathur 2001; Quisumbily 2003; Rao \& Rana 1997). Women and men have different relationships to natural resources due to their differentiated household roles. They consequently can also have differentiated environmental impacts on resources. As is captured in the visual in Figure 2, men's work tends to be focused on economic activity outside the home and in the market place whereas women's responsibilities tend to be within the home and focused on caretaking of the family's reproductive needs. 
Figure 2. Rural Division of Household Labor (DoL)

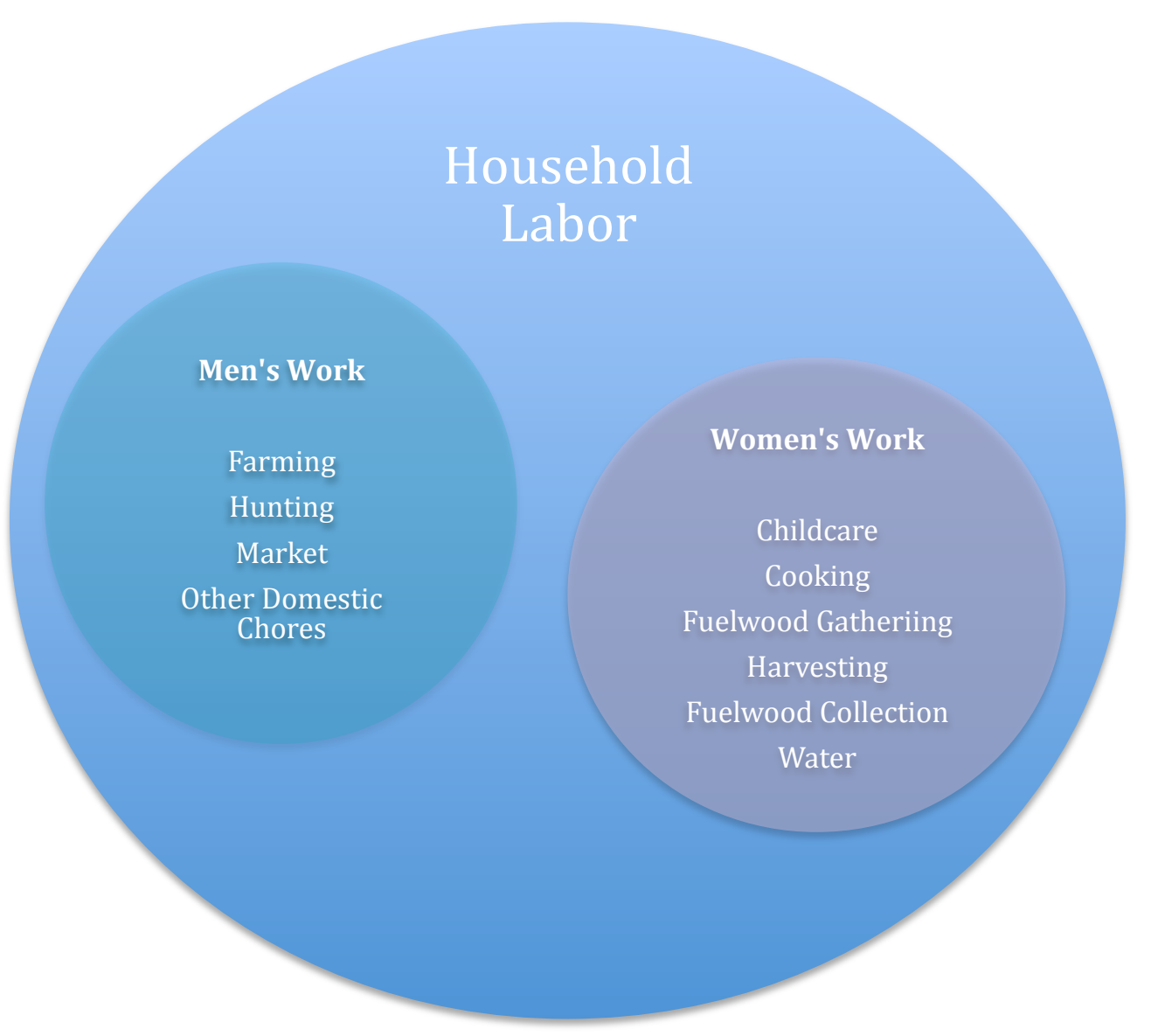

In terms of my research in Sri Lanka, I rely on the work of Jayaneththi (2000), Bandarage (1998), and Wickramasinghe (1994) to explore whether and how gender and the gendered institutions at play is essential to helping figure out the best relationship with nature and use of natural resources particularly in the buffer zones. Amarta Sen (1999) states that "women are increasingly seen...as active agents of change: the dynamic promoters of social transformations that can alter the lives of both women and men (89). The reason to focus on gender and gender roles is because when gender roles are equitable, and generally when women are effectively included in decision-making 
roles, better social [and environmental] outcomes are more likely (Amarta Sen 1999).

Figure 3 is a visual representation of access to decision-making and environmental outcomes. When men dominate in decision-making the tendency is for capitalist goals and economic needs to take precedence in the use of natural resources. Women are then left to function with little influence and consequently also tend to end up using resources in the same way. On the other hand when women have more equitable access to decision making this theoretical framework maintains that the environmental outcomes tend to be better.

Figure 3. Access to Natural Resource Decision Making and Environmental Outcomes

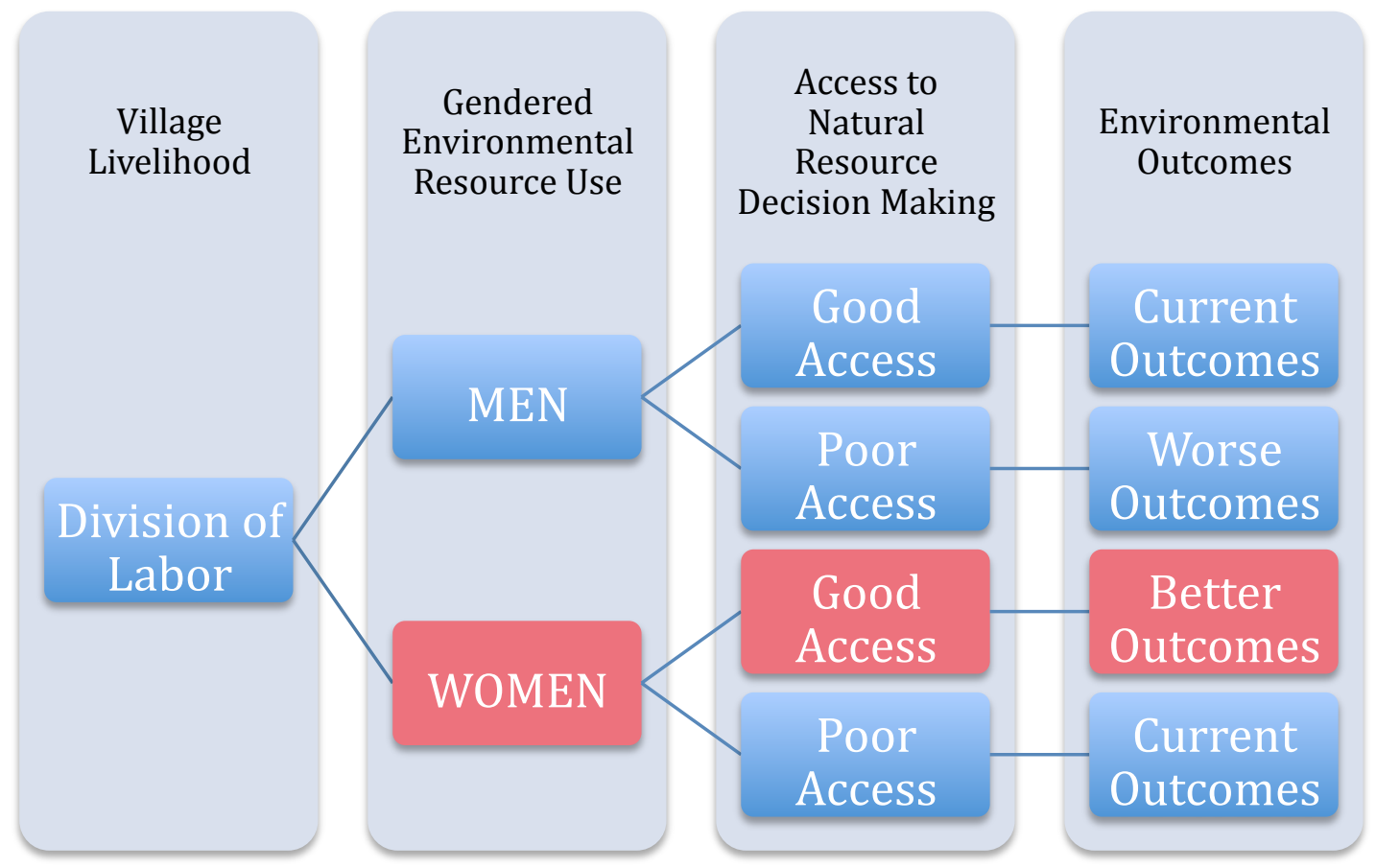

When we have a gender system where women are marginalized, have no voice, and are exploited, we have worse outcomes for the environment and the utilization of natural resources (Jayanethithi 2000:89-90). The interactions occur in a feedback loop. The more poorly women are treated and the less powerful their voices, the less likely they 
are to gain access to the resources they need. In such conditions they will be less likely to speak out with relevant ideas and solutions to institutional organization relating to resource interaction. In these constrained circumstances they are also more likely to end up in situation where they too overuse or abuse the natural resources available to them.

The social institutions that define gender and gender roles, especially in locations with poverty, are a key leverage point for improving environmental, social, and economic institutions with the goals of simultaneously taking care of people as well as the environment (Mies \& Shiva 1993). The next section describes: the connections between the gendered division of household labor, perceptions of the environment, and the use of environmental resources.

\section{B. Division of Household Labor and the Environment}

The impact of environmental degradation weighs most heavily on women and children. According to Humphrey et al (2002), women are the primary actors in the daily care and feeding of their families in the majority of "less developed" countries where firewood is the main source of energy. Humphrey et al.'s research found that "deforestation is directly connected to their ability to play their family caretaking roles" in rural South Asia (10). Finding firewood and other forest products, which women rely on to take care of their families, is difficult in deforested areas. Thus, women have a defining interest in the protection of local resources and are already involved in resource management on the micro-level within their households (Humphrey et al 2002).

According to McMichael (2004), they help promote small-scale biodiversity through gardens they cultivate and are active managers of forest products that they 
harvest (262-266). Women have always been involved in the protection of local resources and community, "but one consequence of colonialism is that this activity has become almost exclusively a women's preserve" (262).

As a result of colonialism, the rights to private property afforded to men also disadvantage women in the commercial sector and labor economy. Men can use their access to property to engage in crop production for the commercial sector and earn income, while women began to specialize in activities involving use and maintenance of the commons, including the gathering of firewood and medicinal plants, and other work remaining outside of the commercial sector. Because of this specific and specialized relationship to forestland, "women assumed a role as environmental manager, often forced to adapt to deteriorating conditions as commercial extractions increased over time" (McMichael 2004:262).

Based on his research, Humphrey concludes that there may be more effective environmental management results if women are involved in the creation and implementation of local solutions to environmental issues of water availability, sanitation and energy. In countries such as Niger, Senegal, Ethiopia, the Philippines, and several Indian states she observes:

Reforestation programs largely fail because of inadequate involvement of local people, especially women, in the design and implementation of programs. They also fail because of social inequalities in village class structure. Owners of large blocks of land can use part of a block for reforestation programs, and the profits forest land owners make from the sale of wood fuel exacerbates village inequality. The antagonistic attitudes of state forest officials toward local people also contributes to program failure (Humphrey 2002: 12).

Unlike men, women more often make household and economic decisions that prioritize maintaining the health and well being of the entire family (Humphrey 2002). 
Given this motivation it is logical to explore whether the empowerment of women to protect their interests would lead to behavior on their part that would decrease the environmental impact on flora and fauna in rural villages in developing countries. And along similar lines one might infer that the empowerment of women in rural Sri Lankan villages has the potential to increase environmental and social sustainability in these areas. Development agencies, whose current practices do not take inequality into account as a serious cause of environmental degradation and unsustainable development, are less likely to be successful in maintaining goals in the long term (Mathur 2001: 5). The “continued exclusion of women from key decision-making processes or institutions ultimately represents a loss of potential knowledge, ideas, and insights that could contribute to new sustainable and locally appropriate approaches to resolution [of humanwildlife conflicts]" (Ogra 2009: 171).

The roles of men and women within the household differentially influence how resources are used. Disregard for that difference leads to policies that miss opportunities to appropriately empower women in management strategies and the potential positive outcomes that may be derived (Quisumbing 2003).

In order to fully address household disparities, there must be careful analysis of the household tasks and how these connect to natural resource use. Quisumbing reports "long hours [are] spent by women compared with men in productive activities, including water and food gathering" (Quisumbing 2003: 55). The way men and women use natural resources are different. There is value in examining these differences when looking for more effective ways to conserve resources and promote social sustainability. 
The gendered division of labor in rural villages does create a gendered specific relationship to the environment that might allow for increased social and environmental sustainability given full participation of women in household and community decisionmaking. Inclusion of women, through equal participation, has been shown to have positive outcomes in situations that have tried these methodologies (Rao and Rana 1997). The purpose of focusing on women's gender specific relationship to the environment includes the potential for discovering innovative ways to manage natural resources in alternative way for better ecological and social outcomes. This research project adds to existing empirical data in this field by engaging in depth-analysis of conservation and HEC in Sri Lanka.

\section{Feminist Theory on Gender and the Environment}

There is debate in the literature about the significance of the relationship between gender and the environment. Theories that support a gendered analysis of environmentalism range from ecofeminism to "feminist environmentalism". Ecofeminism is a western ideological philosophy that claims the "domination of women parallels the domination of nature. This mutual domination of women and nature leads to environmental destruction and gender inequality by the controlling patriarchal society" (Humphrey 2002: 10). Feminist environmentalism adds aspects of social sustainability and incorporates the social need for development. These philosophies differ in that ecofeminism is most often viewed through a western lens, while feminist environmentalism focuses on the broader global needs which include women in the third world. 
Ecofeminist ideologies have traditionally suffered from over-simplification, conflating biological sex with differing views on the environment and natural resource management. Feminist environmentalism attempts to fill these gaping theoretical holes. While there may be attitudes correlated to gender, the sex of a person does not necessarily cause those particular attitudes. The essentialist argument that women by virtue of their biological sex have a more innate sense of environmental issues will be avoided in this research project. Women who have poor access to natural resource decision-making will also make poor environmental choices (See Figure 4). Figure 4 illustrates how gendered use of environmental resources leads to positive or negative environmental outcomes based on access to natural resource decision-making. It postulates that giving women 'good access' to natural resource decision-making will result in 'better environmental outcomes'.

Figure 4. Women's Access to Decision Making and Environmental Choices

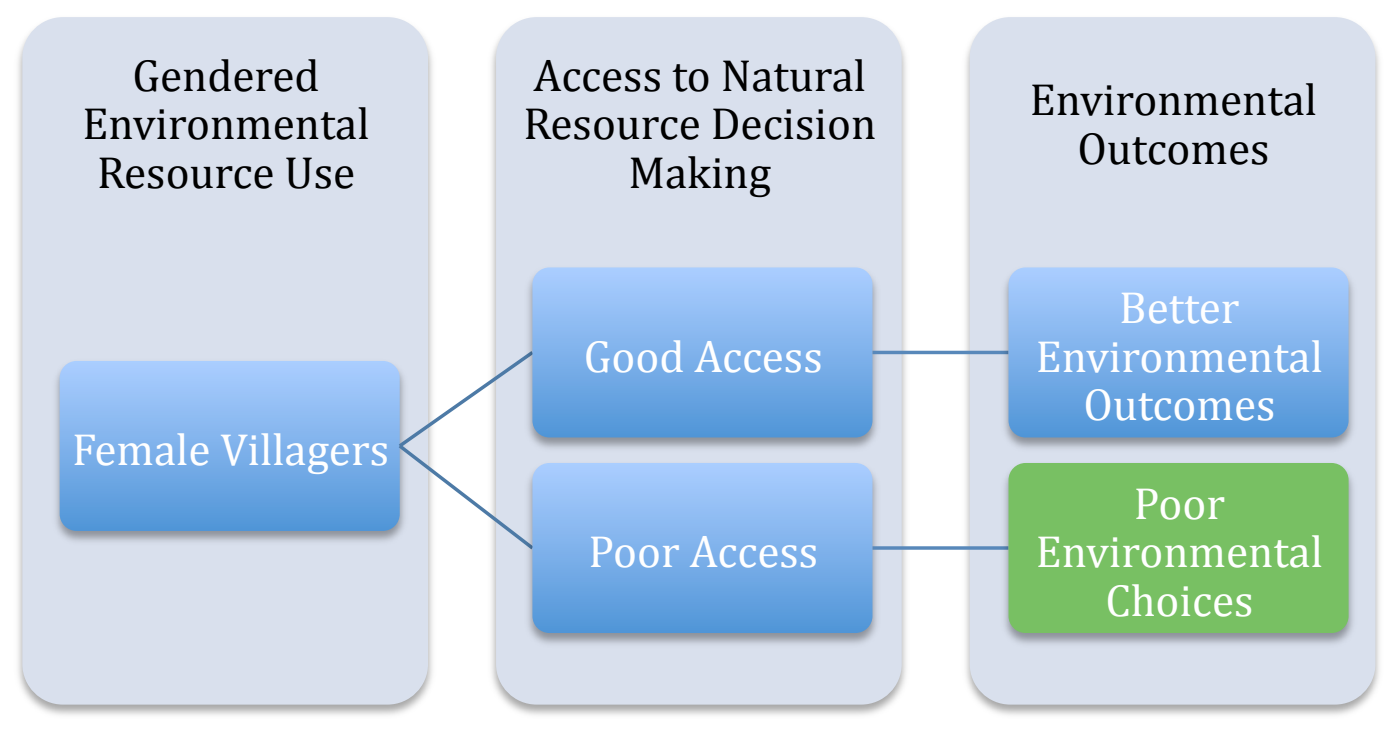


Historically, ecofeminism has also been criticized for having a narrow western focus without much significant change in its philosophical approach over time. Feminist environmentalism widens that approach through exploring the relationship of rural Third World villages to natural resources and conservation and how the gendered division of labor effects environmental interactions in these locations. Western ecofeminism generally fails to account for the significant effects of poverty and colonialism on both women and men in rural households. Men in some areas are equally forest-dependent and therefore may also contribute positively to conservation goals. This thesis seeks to address these specific gaps.

The following subsections focus on three sub areas of debate: Ecofeminism, WID/WED and Feminist Environmentalism. These approaches are useful for informing this project's elaboration of the conceptual connections between gender roles and environmental resource use and management.

i. Ecofeminism

According to Warren (2000:21) "Just as there is not one version of feminism, there also is not one version of ecofeminism. The umbrella term "ecofeminism" refers to a plurality of positions, some of which are mutually compatible and some of which are not" (21). Among those theorists who believe there is a significant relationship between gender and the environment, there is disagreement on the ways in which that gendered relationships matter, particularly for policy formation.

The website, Gender Across Borders (2012), explores two primary types of ecofeminism in popular literature: materialist and essentialist. According to the website, essentialist ecofeminism thought which maintains that "there is an inherent connection 
between women and nature that is encouraged by biological factors and a shared history of oppression" and is problematic in its "feminization of nature" and its alignment with patriarchal views. It falls short as a viable theoretical framework for this project. This project instead focuses on a materialist approach, as it elaborates on the connection between the division-of-labor as it relates to market activity to the subordinate position of women. Schools of materialist ecofeminism explore the juxtaposition between the market economy and the unpaid domestic labor market and how that dichotomy devalues both women and the natural environment. (G.A.B. 2012)

Feminists and non-feminists alike have criticized ecofeminists who believe that women have an innate biological connection to the environment. Others feel that women are connected to nature within their subjugated position in a hierarchy of domination. Among this latter group is Karen J. Warren (2000) who asserts that "there are important interconnections among the unjustified dominations of women, other human Others, and nonhuman nature..." (43). Women are subjugated in their role in a patriarchy and nature is dominated by the majority culture of (hu)mankind. This subjugation results from resource use (and misuse) and a history of non-biodegradable waste creation, habitat destruction, pollution, and mismanagement.

While the relationship of gender and the environment has been explored, the specific issue of gender disparities relating to environmental justice is yet to be developed. There is a significant body of work on gender and development, beginning with Esther Boserup's “Women's Role in Economic Development,”(1970), Lourdes Benería (2003) “Gender, Development, and Globalization: Economics as If All People Mattered" and Irene Tinker's many publications $(1976,1990,1995,2004)$. Though there 
is a significant amount of work that has been done by WID theorists, understandably scholars have not to come to a consensus regarding the role of gender within the framework of development.

Mainstream development agencies and programs for rural areas in developing countries have frequently ignored the issues of gender inequality and gender-specific interactions with natural resources. Feminist critiques of development theories represent many diverse and sometimes divergent viewpoints (Mathur 2001: 6). While some feminist theorists may disagree about structural causes and mechanisms for change, they do, however, share a vision of support for women's empowerment and are critical of women's positions of subservience in their gender roles.

\section{ii. WID/WED}

In the discourse on development there has been a shift in thinking from including women in current development practices to a new goal, i.e., "involving women as decision makers concerned with empowering all women in their various life situations" (McMichael 2004: 262; Benería 2003). The Women in Development (WID) approach includes increasing services for women, including control over finances, access to education, and providing legal agency (Mathur 2001: 14; Benería 2003). WID is a less nuanced argument used by some feminists who want to encourage the active participation of women in the male-dominated process of environmental decision-making involved in the development process (McMichael 2004: 263). The more progressive model, Women, Environment and Alternative Development (WED), encourages a change in the basic practices and ideologies of development toward an expressive understanding of the 
world, rather than simply a market-based rationality (McMichael 2004: 263-264).

McMichael argues:

WED feminism stresses that development is a relative, not a universal, process, and we should be aware of how our ideas shape our assumptions about other societies. Concerns for the empowerment of women in the Third World settings should refer to those circumstances, not to abstract ideas of individual emancipation. In other words, women's role in sustaining cultural and ecological relations is complex, place specific, and incapable of being reduced to universal formulas (McMichael 2004: 264).

This orientation further supports this project's focus on a holistic ethnographic approach to discovering the relationship of gender to the local environment. According to Warren (2000), "All ecofeminists agree that there are important connections between the unjustified dominations of women and nature, but they disagree about both the nature of those connections and whether some of the connections are potentially liberating or grounds for reinforcing harmful stereotypes about women" (21). For example, it is argued, in some schools of "ecofeminism" that women are "naturally" caregivers of people. Therefore, they are viewed as more suited for environmental resource management because of their motivation to provide food and other amenities to their families.

Others argue against the idea that women are closer to nature. They maintain that "dualistic theories such as nature/culture and public/domestic are more solidly rooted in modern western ideology than in ethnographic 'reality'" (Mathur 2001: 11). The essentialist association with women and nature then works to further their oppression. This is due to the subjugated role of nature itself in the nature/culture duality. Merging the idea of "nature" with the idea of "womanhood" further aligns women with yet another subjugated position. 
Braidotti (1994) explores the "essentialism linked with theories which depict men as innately violent, and women as maternal and nurturant...thus reinforcing sexual polarities" (73). Excusing men's "innately violent" nature with a biologically essentialist argument is also dangerous (Braidotti 1994). Reinforcing gender polarities prevents women from escaping their subjugated roles. This reality opposes the notion that aligning women with nature will bestow a "maternal" or "nurturant" power upon their collective gender. This is power that some ecofeminists falsely embrace as theoretical support for their gender equality activism. People of different genders can be supported in equality regardless of their parental roles or associations. While some ecofeminists correctly oppose essentialism, they ignore the issue of women's concern with the struggle against environmental degradation. (Braidotti 1994)

In addition to the goal of increasing women's equality for the sake of social justice, there is logic in the activist stance of women's inclusion in environmental management. I argue that it is not for the reason of their essential and biologically determined association with nature, rather it is due to their experiential knowledge of the environmental due to their household roles. This research seeks to discover whether women are more connected to environmental preservation motivations due to their provisioning role in society. It addresses the question of how women experience the world in particular ways due to their stratified and differentiated roles. It hypothesizes that the role of women in many (particularly rural) households with strict divisions of labor along gender lines, often give them experiential (as opposed to innate or essential) knowledge of the natural world within their direct vicinity. For example, when women are charged with the domestic role of firewood gathering, medicinal plant use, or fruit 
gathering, I hypothesize that they will better understand some of the outcomes of particular environmental stressors on these much needed resources.

McMichael (2004) suggests that an intellectual turn toward the feminist debate, regarding Women In Development (WID) and Women, Environment and Alternative Development (WED), may be the next step in preventing a global disaster. An inquiry into women's roles in the household, and their corresponding relationship to natural resource management may provide one avenue in the search for creative solutions that will be increasingly effective in solving this environmental crisis.

In some developing nations, grassroots initiatives have already incorporated women in local attempts to alleviate environmental degradation. These local community initiatives can potentially provide effective models for future action. As an extension of the current literature, this thesis argues that the global environmental movement, incorporating women's specific relationship to the environment, might be utilized to encourage a more sustainable approach to natural resource conservation. (Agarwal 1992: Braidotti 1994; McMichael 2004)

There are more than one hundred million people in grassroots movements and organizations in the rural areas of poor countries today (McMichael 2004). According to McMichael, "Collective movements go beyond remedying development failures. They restore women's access to resources removed from them under colonial and postcolonial developments" (266). Women's exclusion from natural resource management in the Third World was often a result of Western practices forced upon their culture. Womenled development initiatives toward sustainable environmental interactions fight against 
Western notions of dominance over nature as well as a history of colonial imperialism over their native heritage.

iii. Feminist Environmentalism

However problematic as a theoretical framework, the ideas of ecofeminists "feed into the formulation of a Third World perspective on gender and the environment" (Agarwal 1992: 120). While Western "Ecofeminist" philosophies may be somewhat flawed in their oversimplifications, they have impacted women's ideas and forms of activism related to the environment in the Third World. "Feminist Environmentalism" was coined by Agarwal (1992) as alternative approach to issues of unsustainable resource management in rural areas of third world countries. According to Agarwal (1992), poor rural women are both the victims of environmental decline, as well as actors in preservation and conservation movements in Third World countries (119). Issues of conservation and natural resource management are inextricably linked to development practices.

Theories regarding Third World environmentalism must take into account issues of development. Often there is conflict between the desire to develop and the need to preserve natural resources. When there is local need and interest in both areas, efforts should be made to combine them. Building on this orientation and initial observations in Sri Lanka, it is clear that there is conflict over the need to preserve natural resources and the need for economic development and it is particularly intense in buffer zones. Using a Feminist Environmentalism framework that maintains that women are key to conservation due to their direct relationships to natural resources, this research is shaped by the theoretical models developed to inform this project. 


\section{Guiding Theoretical Model}

The gendered division of labor affects resource use and consumption in rural areas. Many scholars have found the division of labor in the household to be a relevant factor in determining environmental impacts (Agarwal 1992; Garcia 2001; Martino 2008; Quisumbing 2003). As discussed in sections above there is some consensus that there is a significant relationship between gender and rural natural resource management. Among theorists who believe there is a significant positive relationship, there are many ideas regarding the ways in which these gendered relationships should or can be harnessed.

To guide this research I developed conceptual models to theorize the behavior, activities and perceptions of residents in the buffer zones. I formulated these diagrams through a synthesis of the research literature. Together, these diagrams combine the theoretical framework within which resource use will be explored. These theoretical conceptualizations drive my exploratory hypothesis.

The following diagram, Figure 5, outlines the institutional structure of all of the invested stakeholders who are involved, in some way or another, with HEC or conservation within buffer zones of nationally protected forest habitats. Each of these entities has different goals, motivations for, and effects on, environmental management.

Non-governmental organizations, often funded by international sources, focus on environmental conservation and 'hot-button' issues fueled by global political interests and economic needs; government agencies, predominantly forest and wildlife, which are expected to maintain the national laws limiting use and access of protected areas (PAs) and protecting endangered species; community-based organizations consisting of the 
Environmental Society, the Development Society, and the Funeral Society, which aim to maintain the social and ecological sustainability of rural villages often located in the buffer zones and near other PAs, as well as provide for the social well-being of village areas, and rural village households comprised of men and women who farm crops and gather water and other resources in the area.

Figure 5. Stakeholder Authority in Sri Lanka's Protected Area (PA) Buffer Zones in BibileNilgala National Forest

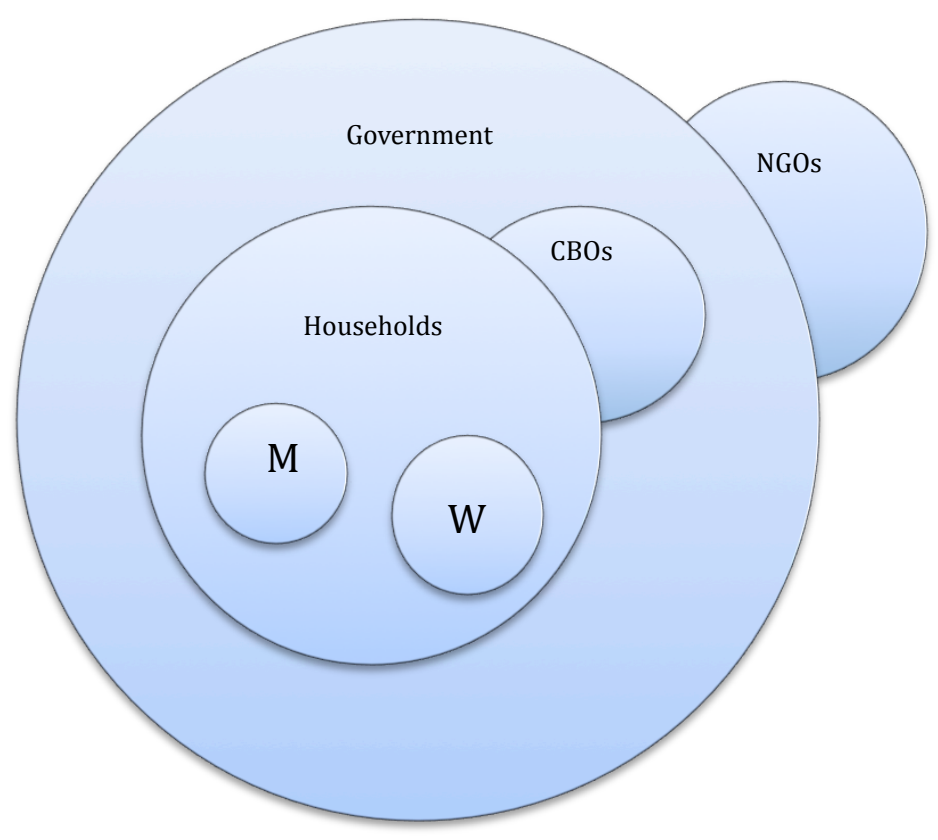

NGOs= nongovernmental organizations (includes international influences)

$\mathrm{CBOs}=$ community-based organizations

PAs $=$ protected areas 


$$
\begin{aligned}
& \mathrm{M} \quad \text { = men's work } \\
& \mathrm{W} \quad \text { = women's work } \\
& \text { Government = Forest Department, Wildlife Department }
\end{aligned}
$$

The project explores the attitudes of stakeholders to discover whether their respective strategies have potential for better social and environmental outcomes. These theoretical connections are captured in Figure 6 below. This research focuses on the roles of women in particular. The research questions investigate the interrelationships between Column 1, "Stakeholder Authorities in PAs", and Column 2, "Environmental Attitudes" (Figure 6). The project seeks to discover for example, whether women in the area have pro-conservation attitudes or do women view nature as a commodity? What are the attitudes of men? Subsequently how do gendered attitudes lead to natural resource strategies? How do these differential attitudes impact environmental outcomes? As laid out in this conceptual framework, this research hypothesizes that attitudes that promote conservation and long-term environmental uses will lead to socially sustainable practices. This diagram illustrates the theory that socially sustainable practices have the potential to reduce HEC. 
Figure 6. Stakeholder Environmental Attitudes and Natural Resource Strategies
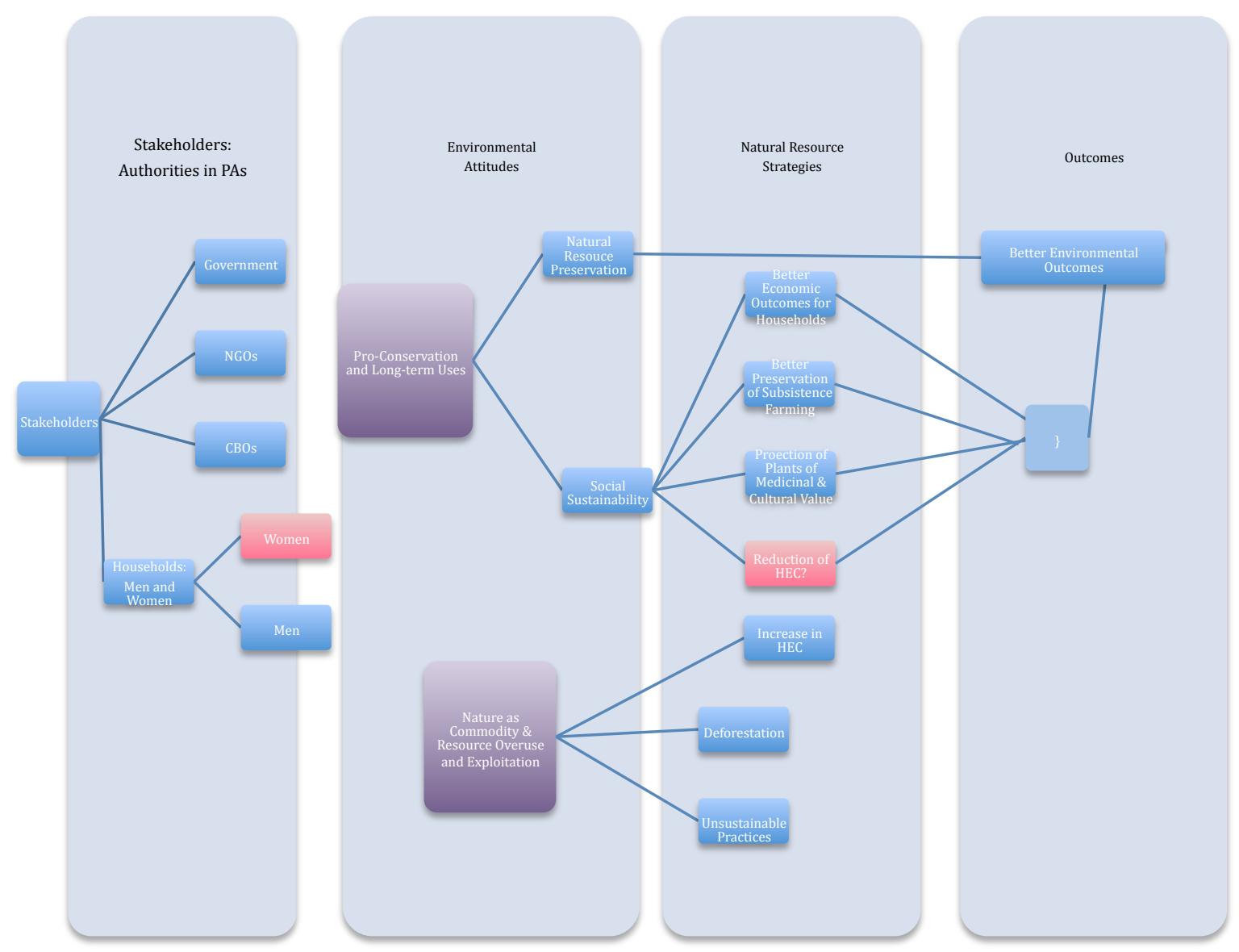

Though this project proposes to examine only one aspect within the flow chart of these this theoretical models, Figure 6 "Stakeholder Environmental Attitudes and Natural Resource Strategies", there is ample possibility for future study relating to the remaining portions of these models.

The following flow chart (See Figure 7), "What Socially Sustainable Institutions Can Do: Conservation Feedback Loop for Rural Household Natural Resource Interaction" gives a general sense of how environmental interactions lead to environmental awareness, which shapes attitudes which then have significant effects on strategies and approaches to environmental management and thus heave policy 
implications which can influence sustainability. This process continues to cycle over time.

Figure 7. What Socially Sustainable Institutions Can Do: Conservation Feedback Loop for Rural Household Natural Resource Interaction

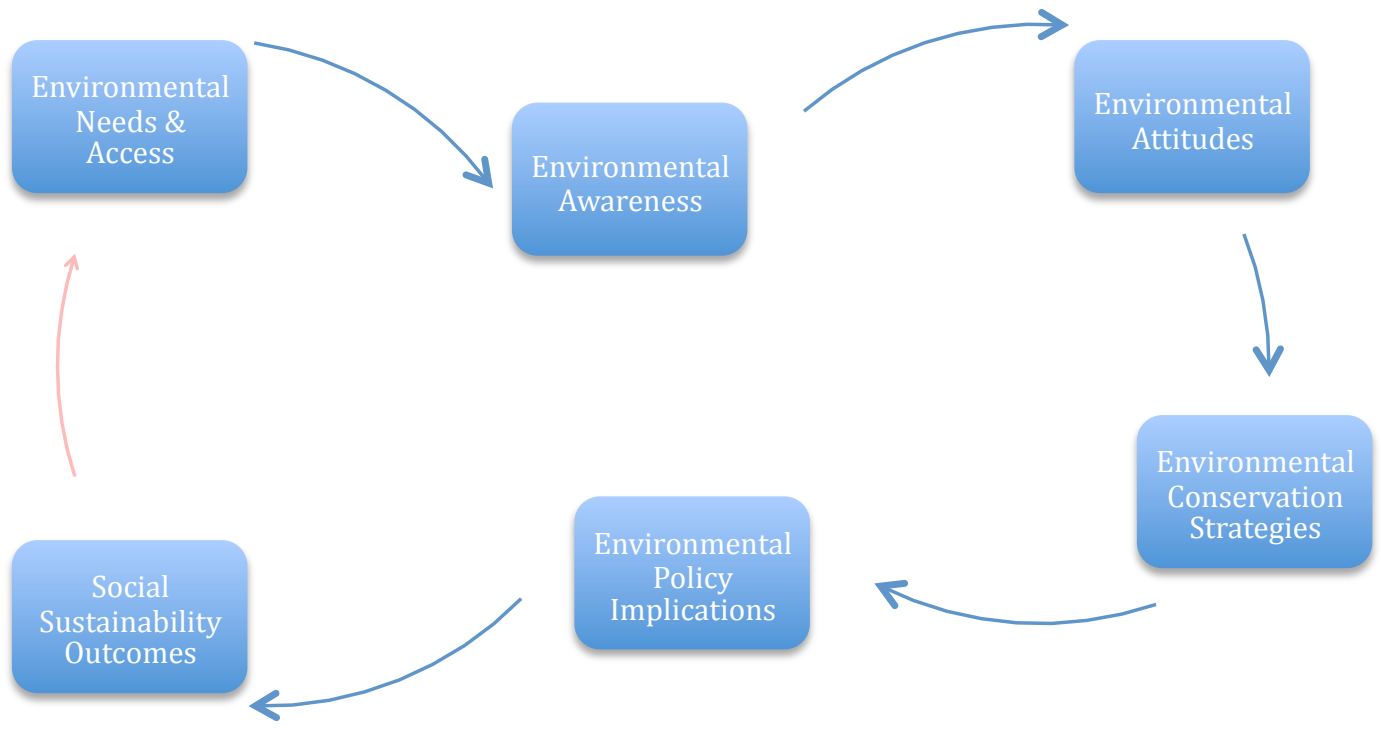

The key access point of this research is the causal relationship between the gendered use of natural resources and environmental impact. The household division of labor creates gender specific roles, which lead to specific natural resource interactions (Quisumbing 2003). The following diagram (Figure 8) illustrates how the gender of labor impacts environmental needs and thus differentiates the environmental focus of men and women in rural households. 
Figure 8. Environmental Needs and Gendered Environmental Uses (Social and Economic Outcomes)

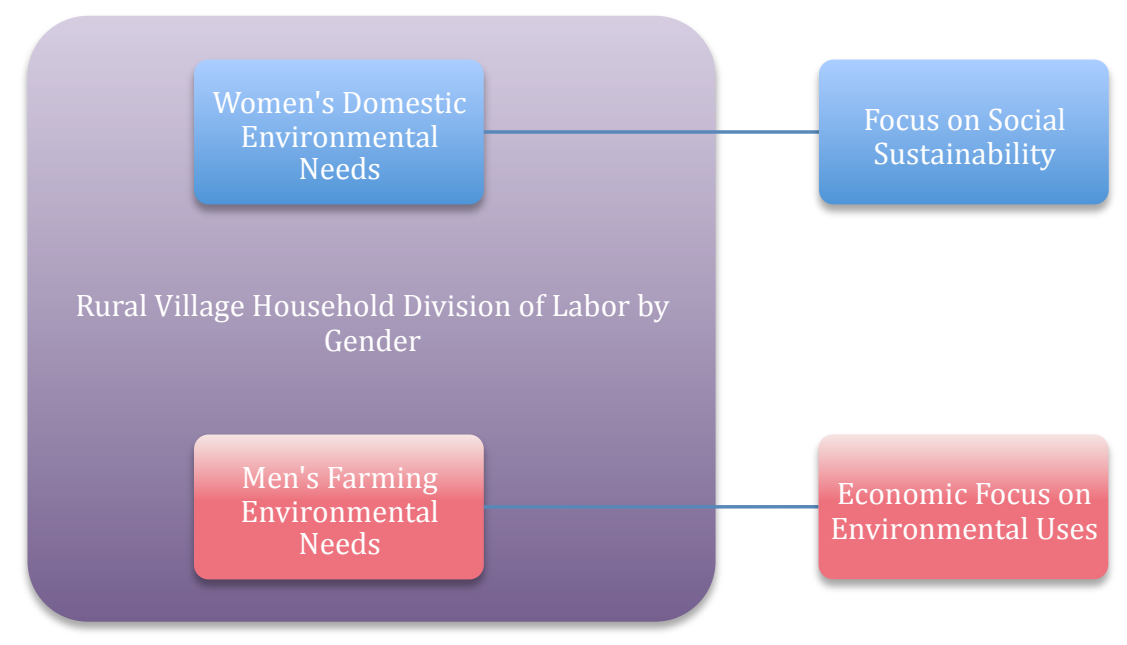

A gender differentiated environmental impact has a number of future policy implications regarding environmental resource management. Gendered access to natural resource decision-making determines power relationships and environmental authority as well as gender-specific environmental needs and thus may predict conservation attitudes. Differing attitudes lead to the potential for men and women to strategize solutions differently.

It is also hypothesized that due to the proximity of women and their relationships to the responsibility roles in the household and their specific knowledge of the environment, women's voices may reflect particularly ecologically minded choices, and giving them influence may have beneficial outcomes. If that hypothesis were supported, women would need to be equitably included in household decision making processes and community organizing for the purpose of achieving community ecological goals and simultaneously household well being. 
Though there is not an 'essential' characteristic of being female which would lead them to have these traits, women's gender specific needs, experience and insights may need to be taken into account by development agencies, because equitable development brings with it greater social sustainability irrespective of environmental conservation. In summary, it is hypothesized that the gendered division of labor in rural villages creates a gender-specific relationship to the environment and that if women are given full participation in household and community decision-making, the outcome would be increased environmental and social sustainability and reduced HEC. 


\section{Chapter IV. Methods}

\section{A. Introduction}

This research pursued a gendered analysis of natural resource governance for the rural poor in Sri Lanka, through a case study of six Bibile villages located in the buffer zone of Nilgala Forest. The project traced women's and men's roles in the localized use of natural resources to determine whether gender roles influenced perceptions and management of the natural environment. Women's and men's roles were examined for purposes of determining how these gendered differences in experience potentially influenced different attitudes toward elephants and the habitats in which they reside. Evidence of these differences might influence solutions for human elephant conflict (HEC).

There is a small amount of quantitative sociological research regarding gender and environmental attitudes in Sri Lanka, but such research has been devoted primarily to urban attitudes with less attention being paid to rural areas. This study was exploratory in nature because it was an initial investigation of rural attitudes.

\section{B. Project Design: Ethnographic Case Study}

The study was designed as an ethnographic analysis of an archetypal Sri Lankan Sinhala Buddhist impoverished rural farming area in the border areas of nationally protected forest habitat. An ethnographic case study method was appropriate for exploring and understanding this relatively unstudied area, because it facilitated access to 
a holistic understanding of men's and women's behavior in resource use and as well as their perceptions of HEC.

i. Project Site

Based on my NGO work and theoretical deduction from the literature review, forest dependency and direct effects of HEC were revealed to be the most important conceptual pieces of this investigation. The field research site, therefore, was selected because it possessed two characteristics: (1) a community that depended directly on governmentally protected forest resources; and (2) individuals who were personally and/or economically affected by HEC.

The first criterion is theoretically important in part because of the role of poverty and how it contributes to forest dependency. When people depend on forest resources in order to meet basic needs, the stake that they have in the preservation of that habitat will naturally be higher. Paradoxically, their levels of poverty may force those same individuals to deplete or degrade those habitats in order to meet their basic immediate subsistence needs. Thus forest-dependent residents may have an awareness of the health and well-being of their surrounding habitats without being afforded the luxury of preserving habitats to meet their own future needs. The second criterion required a direct connection to HEC. Residents' directly impacted by HEC have the highest stake in HEC mitigating strategy outcomes from an ecological and social standpoint. The interconnected relationship between forest dependency and HEC in the Bibile-Nilgala area created a unique and theoretically interesting situation, in terms of resident experiences. 
The situation juxtaposed the immediate survival needs of individuals against future village environmental and social sustainability. The actions and the attitudes of individuals, who are dependent on forest resources, while simultaneously injured (economically and physically) by the wildlife that is needed to maintain the health of that same habitat, are particularly salient when seeking long-term management strategies. It is the paradox of these actions and attitudes that were explored through this thesis investigation. The opinions of those most affected by degradation became most theoretically pertinent, not only because they are the individuals who are dealing most with the problem directly, but they are also most in need of immediate long-term solution implementation. Their survival and the survival of their children depend upon it.

The area chosen was theoretically relevant because its residents lived in the buffer zone of the Nilgala forest, an area that is open to residential use. Although the residents relied on the adjacent wildlife and forest areas for their livelihood and daily subsistence needs, the forest itself was protected by law from human use and development. The sole exception to use of protected areas was the Vedda community, the indigenous group of Sri Lanka. The field research site represented a community experiencing the paradoxical phenomenon this project seeks to understand.

The people in Bibile-Nilgala are almost entirely dependent on the health of the forest habitat for survival, including a reliance on collection of medicinal plants. The Bibile district is a typical, impoverished rural farming area located amidst governmentally protected forest habitats. The population of the area is majority Sinhala Buddhist. Their predominant livelihood is chena farming, a slash and burn method of agriculture. "Both the cultivation of cardamom and the practice of chena cultivation are 
today banned within the protected area in direct conflict with the locals' traditional way of life" (Lindström et al. 2012: 683). Residents are both impoverished and regionally bound. It took roughly a half of a day on windy, rarely traveled roads, to drive to the villages of Bibile from Colombo. The project was designed to be a multi-dimensional ethnography supplemented with interviews and participant observations with both household and village activity logs. This approach allowed the inclusion of multiple perspectives, including village residents, local experts, government officials and NGO staff.

The supplemental activity logs consisted of a survey that I conducted collecting self and spousal-reports on the daily activities of men and women and the connection of their household activities to conditions in the buffer zones and protected areas (PAs). Conditions in both were affected by the legal and illicit destruction of forested areas, elephant deaths and killings, conservation efforts from within and outside the community, the influence of the local nongovernmental organizations (NGO) efforts to implement mitigating strategies, and the effect of government policies on particular farming practices.

This project was an exploration of environmental impact and attitudes as they related to the gendered division of labor. The concept of environmental impact captured the influence of villagers on natural resource use. This impact was defined as the way natural resources were used and how these uses affected the environment. The rationale for this methodology was shaped by the kind of data required to address the research questions. 


\section{Research Questions}

The first question sought to understand the gendered impact of forestdependent village residents on natural resource use. This question captured individuals' impacts on the environment, stratified by gender. This was viewed through the different household roles of men and women as they pursued a subsistence living in rural farming villages.

The second question focused on the gendered understanding of interaction between humans and elephants in buffer zones as a way to identify explanations of environmental and social attitudes toward elephants. This question asked both men and women how they felt about the environment and attempted to uncover how they understood the role of elephant populations in their shared forest ecosystems. It allowed me to gather self-determined meaning related to a person's role in the household and their potential effect on particular interactions with the environment.

The third question sought to discover whether men and women had different ideas or approaches to solving HEC, and if so, to identify their different solutions to the HEC problem and forest management. The data collected for this question sought to uncover suggestions for gender-specific approaches to mitigating HEC. The intent was to gauge both positive and negative reactions of men and women to natural resource management strategies, alternative livelihood methods, and HEC solutions.

The fourth question sought to identify how non-governmental organization staff members understood the relationship between gender, HEC, and poverty. It facilitated exploration of a connection between household roles, natural resource use, and poverty in 
the buffer zone of nationally protected areas through the lens of key informants and expert stakeholders who actually may influence what policies are implemented.

The data collection - which consisted of in-depth interviews and logs of activities by gender - and data analysis utilized a qualitative approach to allow for the emergence of themes as they became apparent. There is little sociological research on the gendered division of labor and the gendered relationship to natural resource use and management in Sri Lanka, although some local women's non-governmental organizations (NGOs) that conduct research have indicated that this inquiry is timely and necessary.

I rely upon semi-structured quantitative self-reporting in addition to holistic ethnographic methods (Ragin 1994). The semi-structured quantitative self-reporting included the self and spousal reported hourly weekly log sheets, as well as the household $\log$, reporting on the number of male and female villagers participating in each forest activity and the number of hours spend collecting various forest materials. The ethnography consisted of in-depth interviews with village residents, local experts and NGO staff members. With this combined data collection approach I could begin to further understand the tensions that exist between husbands and wives in the rural areas and the urban and rural tensions that exist between stakeholders located in and out of the metropolitan areas.

The narrative data will expose potential interpersonal dynamics, which would not be detectable through other forms of sociological investigation. These connections, in the form of a narrative, demonstrate more than the numbers associated with: "how many men and women die from HEC each year" for example. The most valuable information is in the stories and the underlying realities for people, which one can only learn through 
direct participation and observation. The lived experience of a village residents, and NGO staff can be best comprehended through my shared interpersonal experiences with them. Through talking, sharing meals, sharing labor, assisting one another with task, only then can the cultural barriers be broken and meaningful knowledge be conveyed.

The kind of data required to answer the questions of gender roles, perceptions and attitudes posed by this investigation was best accessed through open-ended, in-depth interviews; field observations; and daily logs regarding participant use of resources. Through semi-structured in-depth interviews, I explored the different activities relating to natural resource management, use, and impact performed by women as compared to men. Other data that I gathered from the interviews included: household roles, family structures, household decision-making power, gendered division of labor, typical daily activities, roles in village activities, interactions with natural resources including water collection, gendered forest interactions in the village, destructive forest behaviors, participants' experience with HEC, socio-economic data, and participants' understanding of local conservation and ecology. 
Figure 9. Village Interview conducted with Dilhari Weragodathenna

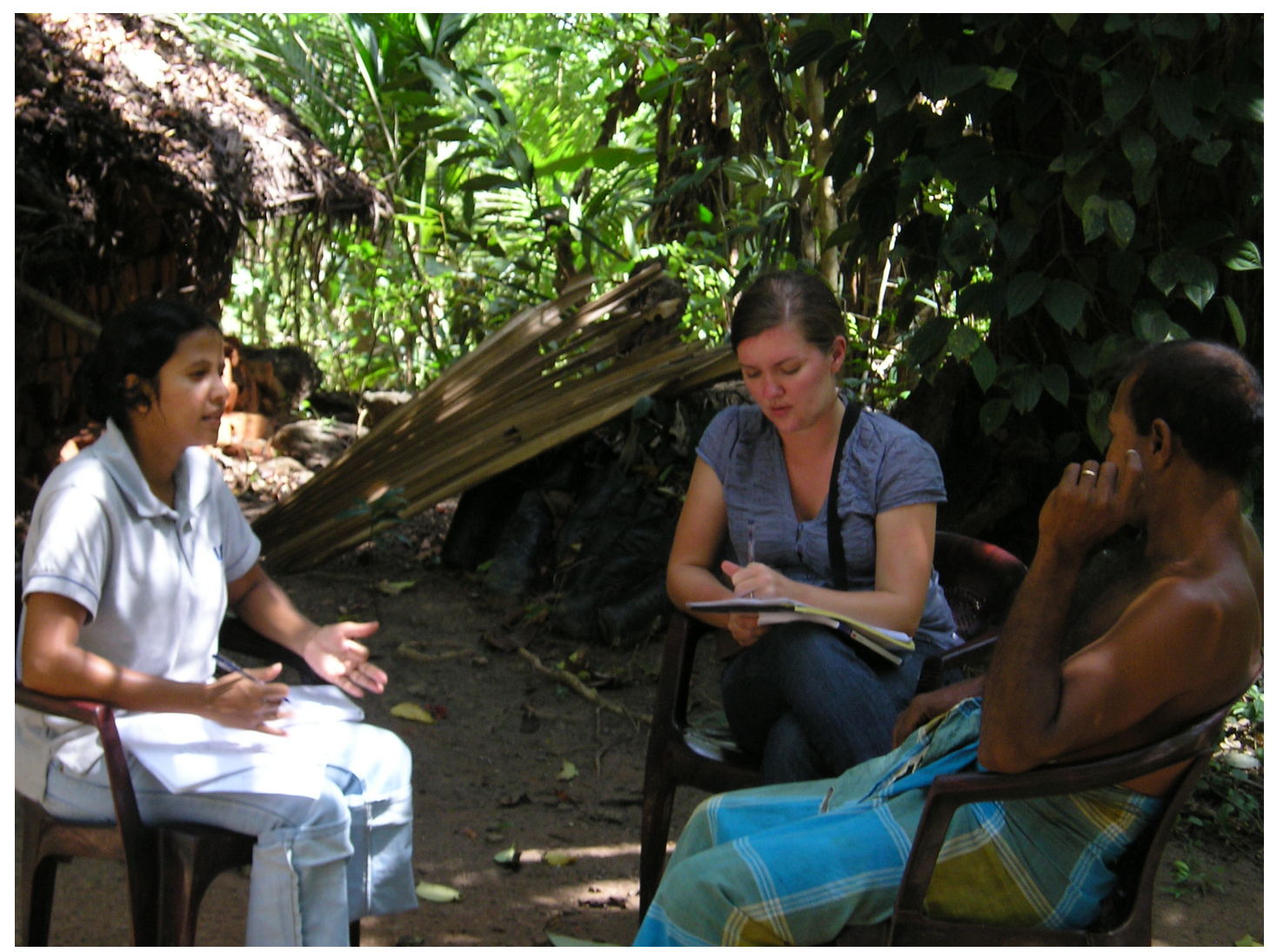

i. Fieldwork

This thesis project was conducted over three months of field research in Sri

Lanka, performed in one interval: mid-June through late September 2010. In the summer of 2010, I was fortunate to have the ability to participate as a volunteer in an internship within the local Sri Lankan chapter of the International Union for the Conservation of Nature (IUCN). IUCN-Sri Lanka is a non-governmental organization (NGO) driven to address pressing environmental and development challenges. The organization operates with the goal of conserving biodiversity, for the sake of addressing climate change, 
sustainable social and economic development and food security through equitable governance and improving 'people-nature' relations (IUCN 2015).

Through the organization I was able to conduct research independently with guidance from a supervisor at IUCN, with additional translation provided by IUCN. A research associate was present at interviews to facilitate and translate when needed. In past years - 2005 and 2006 - I performed preliminary oral surveys of villages similar to Bibile including villages surrounding Uda Walawe National Forest. The governance project entitled "Gender, Poverty and Natural Resource Governance" was done under the collaborative direction of IUCN employees as a service to IUCN for their reports. BibileNilgala is located in an intermediate zone forest. (See Pin A. on Google Map Below.)

Figure 10. Map of Sri Lanka and Bibile Nilgala Area

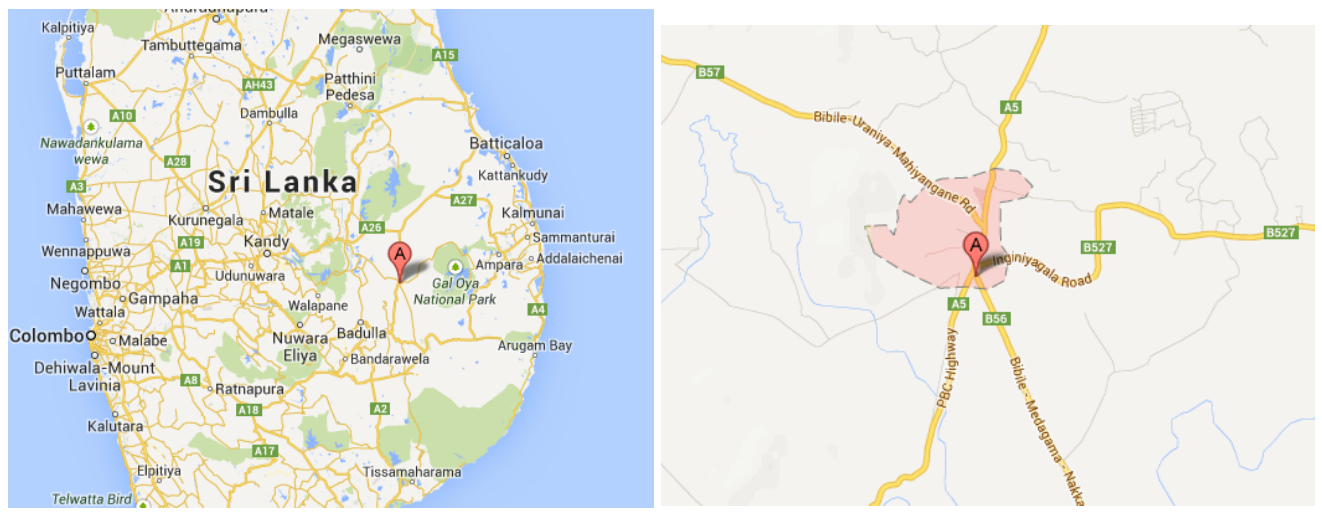

Map Source: (C) maps.google.com 9/2/13 
Figure 11. Typical Village Residential Structure: A Mud Hut

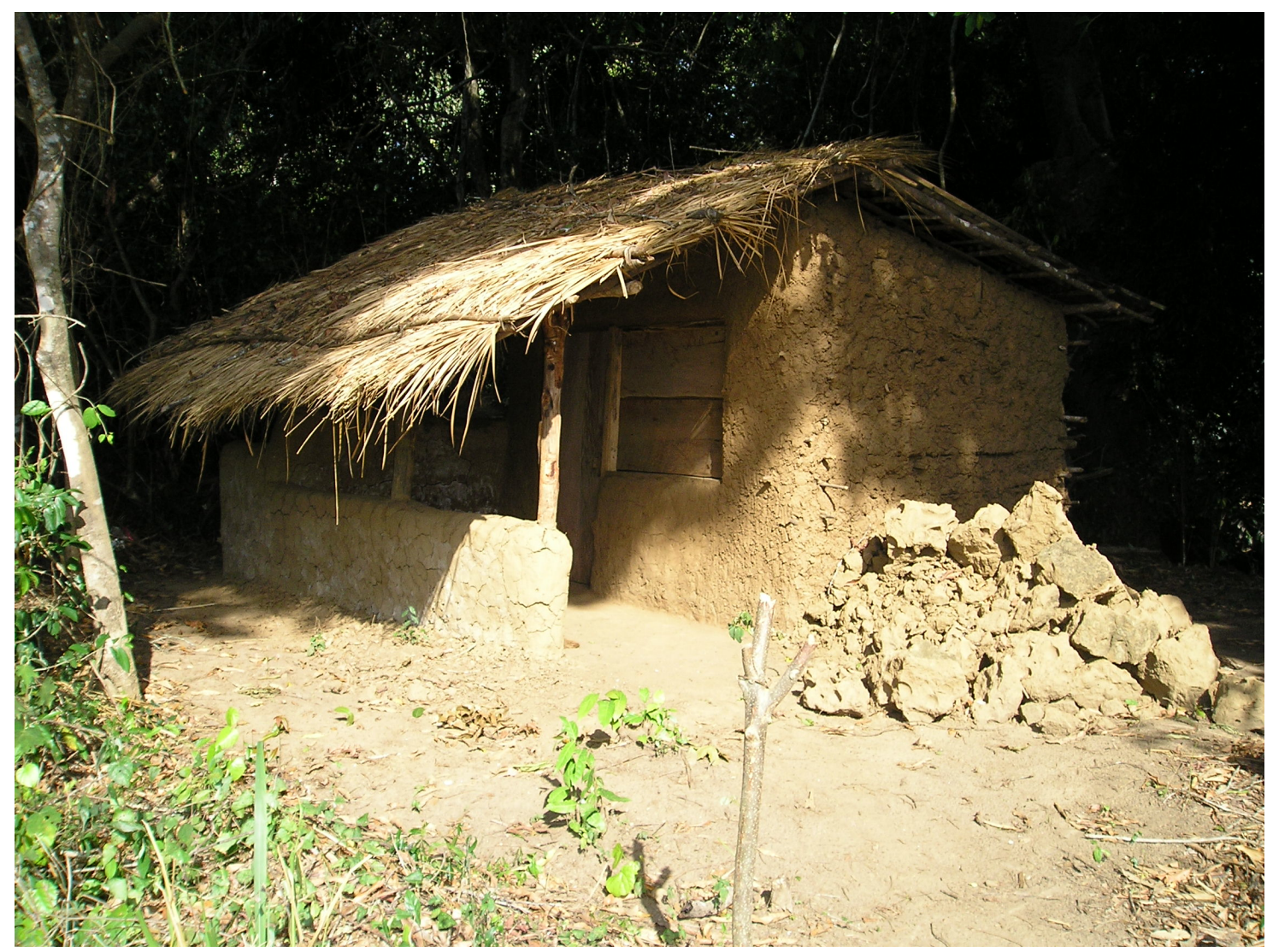

The district is roughly in the southeast central part of the country. Protected areas from both the Wildlife Department and Forest Department jurisdictions surround the villages I sampled, with one village (Vedda) residing within the protected areas, as a protected class status due to indignity. Veddas (Sinhala: $\left.\partial_{\imath} \varepsilon^{p} \mathrm{\varepsilon}\right)$ were granted indigenous status and therefore allowed to reside in protected areas where all others are prohibited. According to the Living Heritage Trust (Website):

Sri Lanka's indigenous inhabitants, the Veddas -- or Wanniya-laeto ('forestdwellers') as they call themselves -- preserve a direct line of descent from the island's original Neolithic community dating from at least 16,000 BC and probably far earlier according to current scientific opinion. Even today, the surviving Wanniya-laeto community retains much of its own distinctive cyclic 
worldview, prehistoric cultural memory, and time-tested knowledge of their semievergreen dry monsoon forest habitat that has enabled their ancestor-revering culture to meet the diverse challenges to their collective identity and survival. With the impending extinction of Wanniya-laeto culture, however, Sri Lanka and the world stand to lose a rich body of indigenous lore and living ecological wisdom that is urgently needed for the sustainable future of the rest of mankind (Living Heritage Trust 2015).

The study was conducted in the following villages: Thunatota, Dimbuldena, Pamweldeniya, Thungalthota, Galahabedda and Rathugala, in the Bibile area. Interviews were conducted with eleven village families with twenty village resident interviews.

These twenty interviews were supplemented with eight interviews with NGO activists and expert researchers.

Figure 12. Dilhari Weragodathenna in a Rice Paddy Field in Bibile-Nilgala

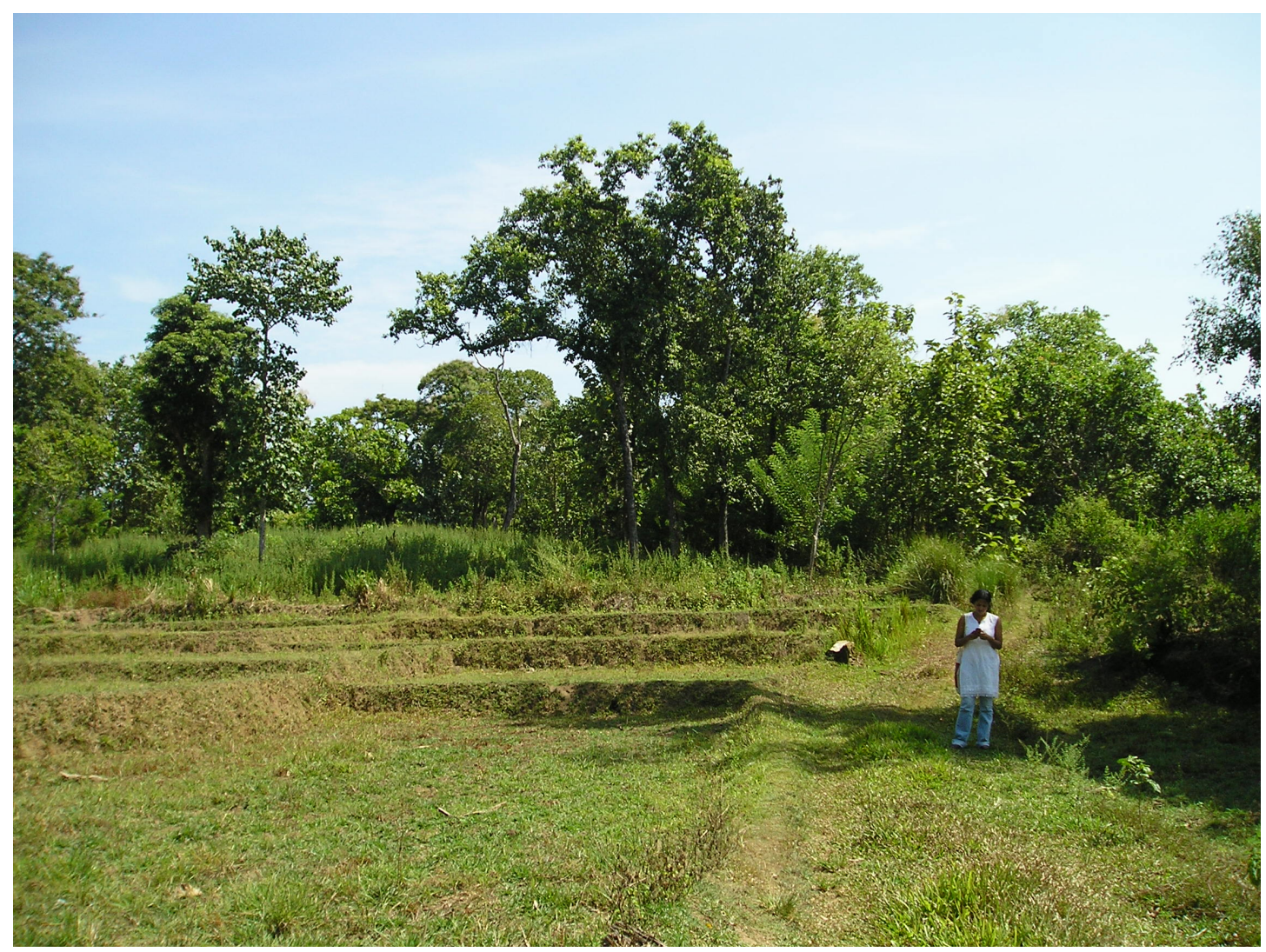


Please refer to Appendix F, of the sampled area below, for a visual representation of the spatial relationships of the rural homes to the protected areas. A GPS recording of each household in the Bibile villages was taken and has been manipulated to create a map of the area traveled, and which displays the sample of villages.

Figure 13. Map of Bibile in the Intermediate Zone

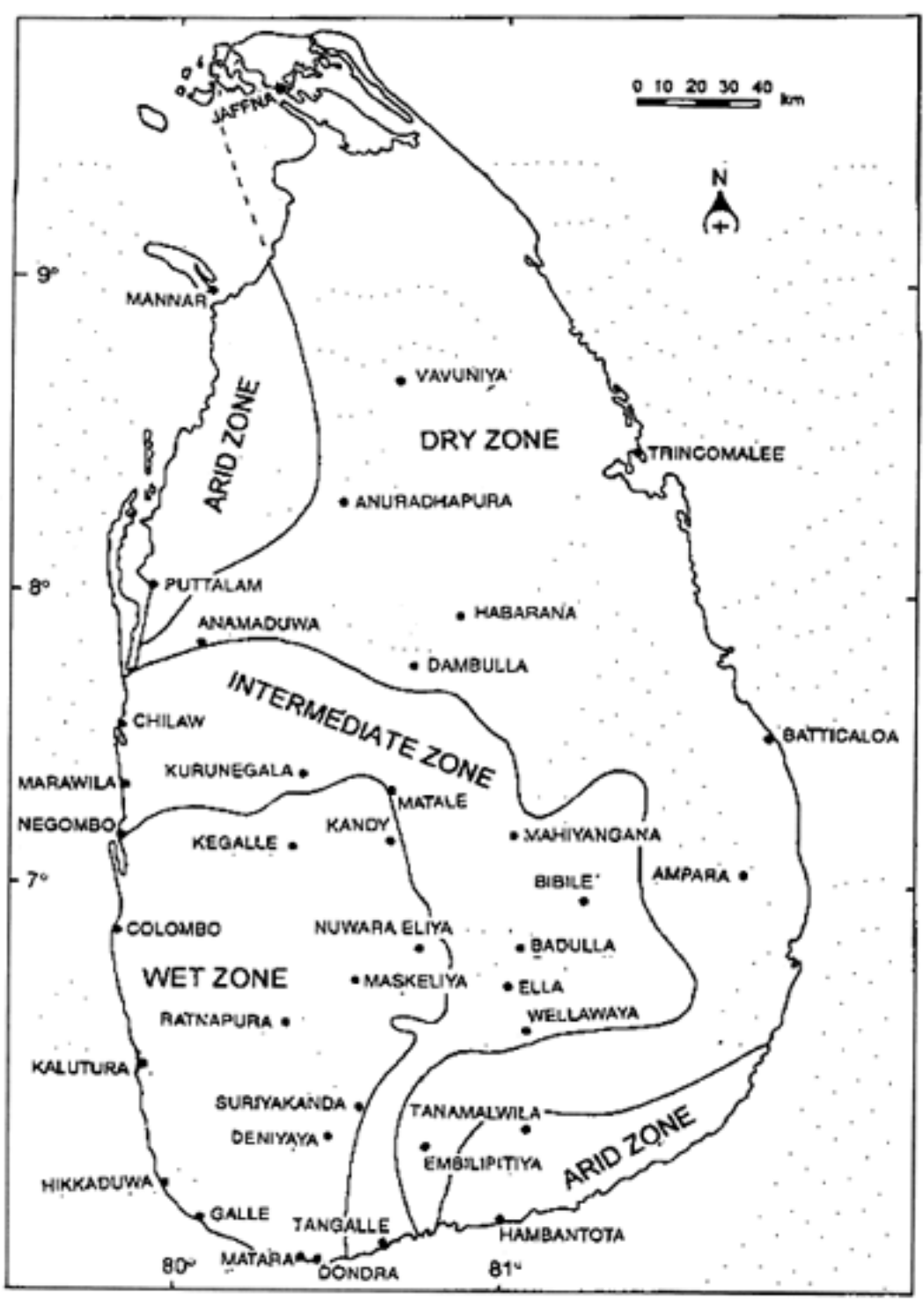

Map Source: FAO (1999) "Fig. 1. Generalized Map of Sri Lanka." 


\section{Data Collection}

Participant observation of NGO policies and practices, observations of village life and behaviors, and interviews with both groups were used to generate data about natural resource use by gender in local village households and in the village communities. The data for this research was derived from five original sources: (1) twenty in-depth openended interviews undertaken through a translator with rural residents including one government official. The twenty interviews (across 11 households) were conducted with ten men and ten women - one man out of the ten was interviewed in his resident capacity as a Wildlife Official and was not considered a "household"- (2) eleven rural household surveys recording household and village forest collection activities by gender, through semi-structured logs (3) self and spousal reports of hourly weekly activities capturing division of labor and natural resource interaction (4) eight formal in-depth interviews with NGO staff and other wildlife experts from state agencies and academic institutions and (5) observations of various events in the research field as a volunteer with IUCN- Sri Lanka (International Union for Conservation of Nature).

The names of all interviewees, utilized throughout this thesis, are pseudonyms to protect participant's anonymity. Interview subjects included local farmers and their families, regional activists, members of environmentally based NGOs, key informants and a representative from the Wildlife Department. Additional data collection methods included participant observation and document analysis of local media sources and publications from non-governmental organizations.

As Charmaz (2006) describes, the size of my dataset yielded a level of "saturation". With these interviews I was comfortable that the information gathered 
seemed to cover the essential conditions of the area and social phenomenon that I was exploring. I continued conducting interviews until they began to yield few new insights. That was how I determined saturation (Charmaz 2006: 113). Key informant and researcher observations supplemented the interviews by confirming elements that emerged from the interviews. They also uncovered critical information such as the legality of certain behaviors in village areas, and the contradictions between what was reported and what actually occurs in the area, that did not emerge in the interviews.

\section{i. Original Recording Tool}

I explored the environmental impact of rural village residents, by examining their daily use of natural resources through the Weekly Log Sheet (see Appendix D). Prior to each in-depth interview with rural residents, I asked each resident for an hourly breakdown of how they spend their time per week. I also asked for an hourly report of their spouse's time as a cross-reference. These numbers were supplemented with estimated numbers of men and women in the village who participate in each forest collection activity. The forest collection sheets were provided by IUCN and can be found in Appendix G. These numbers are a rough estimate of how their time is actually spent and can serve as a general guide for how division of labor exists within the household, particularly how this division of labor is perceived by each husband and wife interviewed.

I postulated the effect of natural resource use on the environment, based on my basic understanding of ecological systems and environmental awareness. I examined questions that might allude to resource extraction, consumption and pollution, though it was difficult to gain accurate responses to those questions in self-reports. Important 
examples of environmental interactions included: water use, farming, foraging, collecting fuel wood, energy use, deforestation, disposal of waste materials, extraction of renewable and non-renewable resources, collection and harvesting of food, and management of wildlife interactions. The gendered-use of natural resources was documented in a weekly $\log$ sheet. The initial Log Sheet coding categories were determined using previous knowledge of village natural resource use. The following categories were used to initially inform my creation of the initial Daily Log Sheet.

\section{Categories of Observation:}
1) Water Use
5) Household Maintenance
2) Waste Disposal
6) Wildlife
3) Utilities
7) Farming
4) Resource Extraction
8) Food

Through the interviewing process, various discourses and policies surrounding gender and the environment are identified. The Daily Log Sheet was modified along the way and became the Weekly Log Sheet during the data collection process. I created the initial log sheets in an earlier period before the research began for this project to be organized documents to measure gendered household activities and natural resource interactions. I developed this original observation-recording tool as a part of a study resolving human-elephant conflict with the residents of this same village. The tool evolved throughout the process. A copy of the original and the final versions are included in the appendix (Appendix B: Daily Log Sheet \& Appendix D: Weekly Log Sheet). 
This original recording tool was created to assist in structuring daily activities and observations in an organized fashion. The gendered division of labor was defined as the set of specific and stratified roles within the household that were utilized to manage daily activities commonly ascribed to either men or women along gender lines. The categories were based on general findings of natural resource use reported in local journals, combined with reports of the division of labor in households in surrounding countries. (Agarwal 1992; McMichael 2004; Quisumbing 2000; Vitarana 2000).

An example of one of the local pieces of literature that reports on gendered use of natural resources is Kamini Meedeniya Vitarana's Environmental Assessment published by CENWOR (Center for Women's Research) located in Colombo, Sri Lanka. Specific potential interactions with gender roles and division of labor are most often related to water use and land use (Vitarana 2000).

The "Weekly Log Sheet" (see Appendix D) evolved from the "Daily Log Sheet" (see Appendix B) following the first few interviews with village residents. Other examples of environmental impacts that were measured can be seen in the first column of the Daily Log Sheet (see Appendix B) entitled "Type of Natural Resource Use" and include: resource extraction, consumption, pollution/ waste, soil depletion, farming and soil erosion, deforestation, wildlife destruction, land use and energy use. The tasks related to environmental impacts were calculated per hour per each adult individual in the village. [I asked about the daily schedule of villagers, including the number of individual participants per day involved in each activity. I documented their time according to the coding tool]. This tool continued to be useful and relevant as it evolved throughout the 
process. I tallied all of the responses and presenting the findings in the form of graphs that I created based on the raw data.

Figure 14. Katy and Dilhari Examining Ancient Medicinal Plant Book

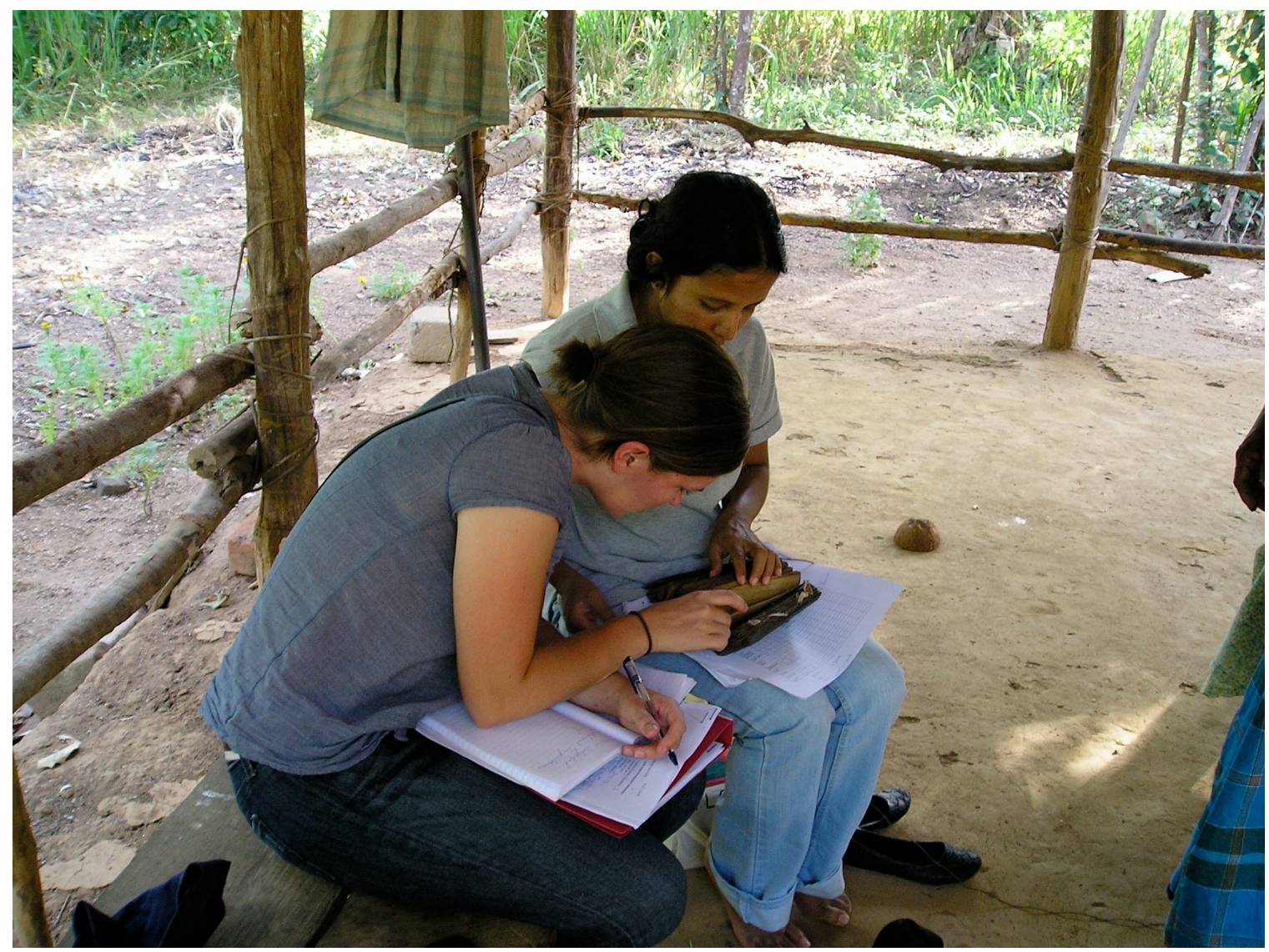

\section{ii. Access}

I gained access to key informants through my volunteer service with the most prominent local environmental NGO in the country, IUCN-Sri Lanka. Without access to the village communities and sufficient interpretation from the educated English-speaking activist community, the information that I needed and theoretical models I wished to explore would have taken an exponentially greater amount of time. In order to have the same amount of information conveyed in the time I had available, I needed to convince 
the "gate-keepers" that I was worthy of the causes in which they shared interest and show that I came with integrity, knowledge, perspective, and good intentions.

This investigation required acknowledgement of the cultural attitudes and perspectives of the area, with particular sensitivity regarding political structures and the socially valued aspects of environmental resources. In order to understand the perceptions of local people regarding wildlife conflicts and natural resource management, trust needed to be established amongst participants. This could only occur through a demonstrated commitment to the serious issues affecting Sri Lankans, as well as a cultural sensitivity to meaning within social interactions. This bond had to be established, between the researcher and the participants, to effectively employ this ethnographic methodology. One way of demonstrating commitment to the issues that affect Sri Lanka was through an established investment in a language rarely spoken outside of Sri Lanka.

I acquired Sinhala, the majority language of Sri Lanka, during two years of academic instruction at Cornell University and two prior summer field seasons of research and local internships in Sri Lanka. My intermediate knowledge of the native language made it possible to build rapport amongst village residents who are isolated from English speakers. Additionally, my previous field seasons in Sri Lanka, gave me an opportunity to absorb unique gestures, behaviors, customs and practices, all of which better facilitated participant observations and rapport amongst village residents. My acclimation surprised many participants. It is rare for them to interact with foreigners, especially outsiders who have invested so much time in national issues at a young age. My practiced language skills, including reading and writing in Sinhala and my 
investment in cultural norms and behaviors clearly demonstrated my investment in the country to the people and built trust between us. This trust and my national connections were necessary to effectively conduct ethnographic inquiries.

\section{E. Participants}

The sample selection process was based on a myriad of theoretical and practical criteria. Residents were selected based on key informant and peer recommendations. These recommendations were based on levels of cooperation, forest-specific dependency and community involvement in the community-based organizations (CBOs). The interview availability of both the husband and wife within the household was also taken into consideration in order to provide a household gender comparison. Both proximity to forest habitat and dependency on forest resources were taken into account. Theoretical Sampling, based on grounded theory was used (Charmaz 2006).

Grounded theory is "a method of conducting qualitative research that focuses on creating conceptual frameworks or theories through building inductive analysis from the data" (187). Each interview couple was selected based on the theoretically interesting criteria listed above. "The movement back and forth between category and data in theoretical sampling fosters raising the conceptual level of your categories and extending their reach" (121). This movement was utilized throughout the data collection process.

Grounded theory involves analyzing data while it is being collected in order to better inform choices regarding future collection of data. The lines between data collection and analysis were intentionally blurred in this project, as advised by Charmaz 
to achieve the goals of moving away from preconceived ideas and uncover new patterns and fresh categories. (187)

This study sought to incorporate institutional perspectives regarding rural poverty, gender and HEC, while focusing primarily on gaining insight from rural residents themselves and the NGO staff members most connected with providing aid and educational training to these residents. Twenty interviews were conducted in eleven households, with an even number of men and women living in the Bibile area including one key informant and one local government official.

For purposes of this study, a household was defined as all family members residing together in one housing structure. Of the eleven households that were interviewed, husband and wife pairings were interviewed in all but three households. The three households that were not able to include husband and wife combinations included: a widow, the president of the community based-organization (CBO) Environmental Society and the Key Informant who facilitated the interviews. Ten women and ten men were interviewed in the rural area.

NGO staff members were recruited as well. Three men and three women from NGOs participated in the study. Two additional men were interviewed in their capacity as local environmental experts, both professional and academic. A total of twenty-eight interviews were conducted. Village participants ranged from twenty to sixty-eight years of age.

Drawing on background material regarding changing government policies on nationally protected areas and trends in Human Elephant Conflict, I interviewed nongovernmental organizations regarding gendered use of natural resources in rural villages. 
I discussed gender and environment with key informants. I conferred with scholars at the local universities in Colombo and Kandy concerning current research on gender and the environment in Sri Lanka. Consulting with scholars gave me the opportunity to explore the pertinence and perceived relevance of local academics. The consultations were informal and preliminary.

Information about the background and purpose of the research project was presented to each interviewee. Consent was obtained orally, in accordance with Human Subjects Review requirements. Interviews were recorded when permitted and confidentiality was assured. In the oral statement to establish informed consent, we described the nature of the research. This discussion included the absence of risks and lack of benefits involved to participants, the provisions made to preserve confidentiality, and the rights to end the interview at any time.

\begin{tabular}{|c|c|}
\hline Figure 15. Interview Statistics & \# \\
\hline Total Number of People Interviewed: & 28 \\
\hline Total Number of Key Informants: & 2 \\
\hline Total Number of Households: & 11 \\
\hline Participant Gender & \\
\hline Number of Men: & 15 \\
\hline Number of Women: & 13 \\
\hline Participant Categories & $\#$ \\
\hline NGO Staff: & 6 \\
\hline Government Officials: & 1 \\
\hline Academic/Research Experts: & 2 \\
\hline Village Residents: & 19 \\
\hline
\end{tabular}


A combined total of 28 people were interviewed for this thesis. All of them were Sri Lankan nationals currently living and working in the country. Fifteen (15) were men and 13 were women. Twenty (20) of those interviews were rural village residents. Of these, 9 were with men and 10 with women. An additional interview was conducted with a tenth male resident in the village but in his capacity as a government official. Nineteen (19) out of the 20 resident interviews spanned 11 village households. Eight (8) of the 11 village households interviewed consisted of married couples. One of those households was a married couple from the only indigenous community in Sri Lanka, the Veddas. One head of household was a widow. An additional 6 interviews were conducted with environmental NGO staff: Three (3) with female staff and 3 with male staff. The last 2 in-depth interviews added additional male expert viewpoints: one (1) with the preeminent academic elephant researcher and conservationist in the country, and another (1) with an individual with over thirty years experience in the environmental sector. Lastly, 2 separate, informal interviews took place with the project's two key informants.

Religious attitudes often influence attitudes toward nature and wildlife. In Sri Lanka, Buddhism considers the elephant a sacred animal. Many would agree that elephants are, in fact, the most highly religiously revered species in the country. Because it is so highly revered, the religiosity of village residents was considered during the interview process. It may have had an influence on attitudes toward elephant conservation and strategies for HEC mitigation. All resident respondents were Buddhist, except for three who reported not having any religious affiliation. Of those who claimed to be Buddhist, the average attendance at the temple was one to two days a month. Most claimed to attend temple activities during Poya (Full Moon) days. The majority of 
respondents claimed to have agricultural forms of income production, which are very unstable, especially during the dry season. Water access is a major issue for the wellbeing and livelihood of all village residents during this season.

Figure 16 describes the husband and wife spousal relationships in each household. Figure 17 provides the household number, children's ages, and village name. Figure 18 and Figure 19 illustrate the gender and assigned names of NGO staff and other experts.

Figure 16. Villager Households (HH): Assigned Names` ${ }^{\wedge}$ and Spousal Relationships

\begin{tabular}{|l|l|l|l|}
\hline HH & \multicolumn{1}{|c|}{ Husband } & \multicolumn{1}{|c|}{ Wife } & \multicolumn{1}{c|}{ *Role/Livelihood } \\
\hline 1 & Ashane & Yuvani & Paddy Field Farming, Animal Husbandry, Milk \\
\hline 2 & Baba & Vidula & $\begin{array}{l}\text { Chena Farming, Animal Husbandry, Medicinal Plants, } \\
\text { Milk, Honey }\end{array}$ \\
\hline 3 & Chatura & Shoba & $\begin{array}{l}\text { Farming, Animal Husbandry, Poultry, Milk, Medicinal } \\
\text { Plants, Honey, Beedi Leaves }\end{array}$ \\
\hline 4 & Gihan & Renuka & Medicine Man/ Farming: Paddy \& Chena, Gardening \\
\hline 5 & Hetuwa & Prema & $\begin{array}{l}\text { Agriculture, Paddy Cultivations, Chena, Bananas, } \\
\text { Home Gardening }\end{array}$ \\
\hline 6 & Iranga & Nimala & $\begin{array}{l}\text { *Veddas/ Chena Cultivation, Forest Food Collection, } \\
\text { Hunting, Gathering, }\end{array}$ \\
\hline 7 & Jegan & Mathy & Farming, Forest Food Collection, Animal Husbandry \\
\hline 8 & Kiribaba & Lakmini & $\begin{array}{l}\text { Farming: Paddy, Chena, Animal Husbandry, Home } \\
\text { Gardening }\end{array}$ \\
\hline 9 & N/A & Hashini & $\begin{array}{l}\text { President of Environmental Society (CBO)/Farming: } \\
\text { Animal Husbandry/ Milk }\end{array}$ \\
\hline 10 & Sena & N/A & *Key Informant \\
\hline 11 & N/A & Amanthi & $\begin{array}{l}\text { *Widow/ Farming: Paddy Field, Chena; Home } \\
\text { Gardening: Medicinal Plants }\end{array}$ \\
\hline
\end{tabular}

${ }^{\wedge}$ Names have been changed to protect the identity of participants

Figure 17. Village Households* (HH): Number of People \& Children's Ages

\begin{tabular}{|l|l|}
\hline \multicolumn{1}{|c|}{ Number in HH } & \multicolumn{1}{|c|}{ Village Name } \\
\hline $\begin{array}{l}\text { 7 (children: 24 years, 22 years, and 15 years; grand- } \\
\text { children: 2 years, 2 months) }\end{array}$ & Dimbuldena \\
\hline 4 (children: 18 years, 13 years) & Dimbuldena \\
\hline 5 (children: 20 years, 16 years, 11 years) & Galahabedda \\
\hline 5 (14 years, 12 years, 4 years) & Galahabedda \\
\hline 4 (children: 16 years, 13 years, 9 years) & Nannapurawa \\
\hline
\end{tabular}




\begin{tabular}{|l|l|}
\hline 2 (children: 32 years, 30 years) & Pamweldeniya \\
\hline 6 (children: 20 years, 15 years, 13 years, 10 years) & Rathugala \\
\hline 12 (children; 3 years, 10 months) & Thunatota \\
\hline 4 (children; 3.5 years, 2.5 years) & Thunatota \\
\hline 5 (children: 20 years, 18 years, 17 years) & Thungaithota \\
\hline
\end{tabular}

*Households have been randomized and alphabetized by village

Figure 18. NGO Participants: Assigned Names by Gender

\begin{tabular}{|l|l|}
\hline NGO Women Interviewed & NGO Men Interviewed \\
\hline Menika & Hasitha \\
\hline Dayani & Ruwan \\
\hline Dilipa & Srihan \\
\hline
\end{tabular}

Figure 19. Additional Expert Informants: Assigned Names (Male)

\begin{tabular}{|l|l|}
\hline \multicolumn{1}{|c|}{ Participant } & \multicolumn{1}{c|}{ Role in Sri Lanka } \\
\hline Priya & Academic Researcher \\
\hline Ukkuwa & NGO \& Private Sector Consultant \\
\hline Lasantha & Government Official (WL Dept) \\
\hline
\end{tabular}

\section{F. Confidentiality: Records and Distribution}

Research materials consisted of handwritten notes and digital auto-recordings.

Notebooks used during interviews were locked securely when not in my immediate possession. Research notes and digital recordings were stored on a password-protected computer and backed up on an external hard-drive kept in a locked cabinet in a locked room after return to Portland State University. At this time, there are no official sanctions against research in Sri Lanka. I did not ask questions on politically sensitive topics. I minimized any risk of confiscation of my research materials. In all public documents and presentations, the names of the people involved have been removed or changed to protect 
people's privacy. Strict confidentiality of all information and the cloaking of identities will continue to protect participant's privacy.

\section{G. Potential for Bias: Translators}

Because I possessed a basic intermediate knowledge of spoken colloquial Sinhala, I needed a translator to improve my accuracy of understanding. The importance of the translator cannot be overstated. "The focus on generating accurate and meaningful data through the translation process is paramount" (Marshall \& Rossman 2006: 111). The translator can be considered an asset rather than an impediment if treated with due respect, diligence and authority. In addition to viewing the interviewee as an expert on their experience, the translator ought to be viewed as an expert as well. Translators can provide additional insights and are closer to the "insider" knowledge. While it can be a problem that translators may filter the language used by participants through a biased lens, they can also provide their own interpretation through initial coding, during the ethnographic process, within grounded theory. This role thus assisted the process while simultaneously posing obstacles.

Translators can provide a buffer for questions posed by the researcher, which they recognize may be inappropriate in a given situation. They can assist by detecting the appropriate time to leave an interview, or home, and can signal when it is best to stop questioning. A translator's autonomy and authority during the research process, when dismissed or disrespected, can have detrimental effects on the validity and reliability of any research project. Therefore, it is not only respectable and considerate to incorporate the translator's viewpoints; it is essential to the research outcome. 
Sri Lankans are extremely hospitable and pay extra kind attention to guests. Thus it is important for a non-native research to have someone who can detect subtle cues about appropriate and inappropriate behavior. Only then will the researcher know the socially appropriate conduct behaviors i.e. the correct time to leave following the interview or when to stop asking a certain line of questioning. The translator can provide this, especially when the translator has both and educational background in the field(s) as well as village ties, connections or experiences. Thus, for these reasons and more, it is essential for researchers to have a trusting and respectful relationship with the person who is performing the difficult task of translation.

I was very fortunate in my data collection due to the fact that the person assigned to my project was able to have clarifying discussions with me following each interview to increase my understanding of what was said. Some of post-interview discussions and self-reflections were audio-recorded to retain observations for comparison in the final analysis. They were also used during the data collection process to informing continuations, adjustments and corrections to future interview questions and theoretically relevant points of inquiry.

Dilhari Weragodathenna was helpful as a translator and key informant. Her role as a Programme Officer for the International Union for Conservation of Nature (IUCN) during my internship with the program, allowed me the fortunate opportunity to work with her on my thesis data collection. Through the generosity of her time, assistance, and knowledge of both Sinhala and the English Language, I was able to access regions and individuals that I would never have had the opportunity to encounter otherwise. 
Dilhari became a collaborator for the duration of the interview process in Bibile. Dilhari assisted me with translations throughout the interview process. She also played a pivotal role with initial interpretations and analysis. She played a significant role when it came to decision-making regarding who were appropriate people to interview and when certain interview questions should or should not be asked.

\section{Figure 20. Dilhari en route to Bibile-Nilgala Forest Protected Area}

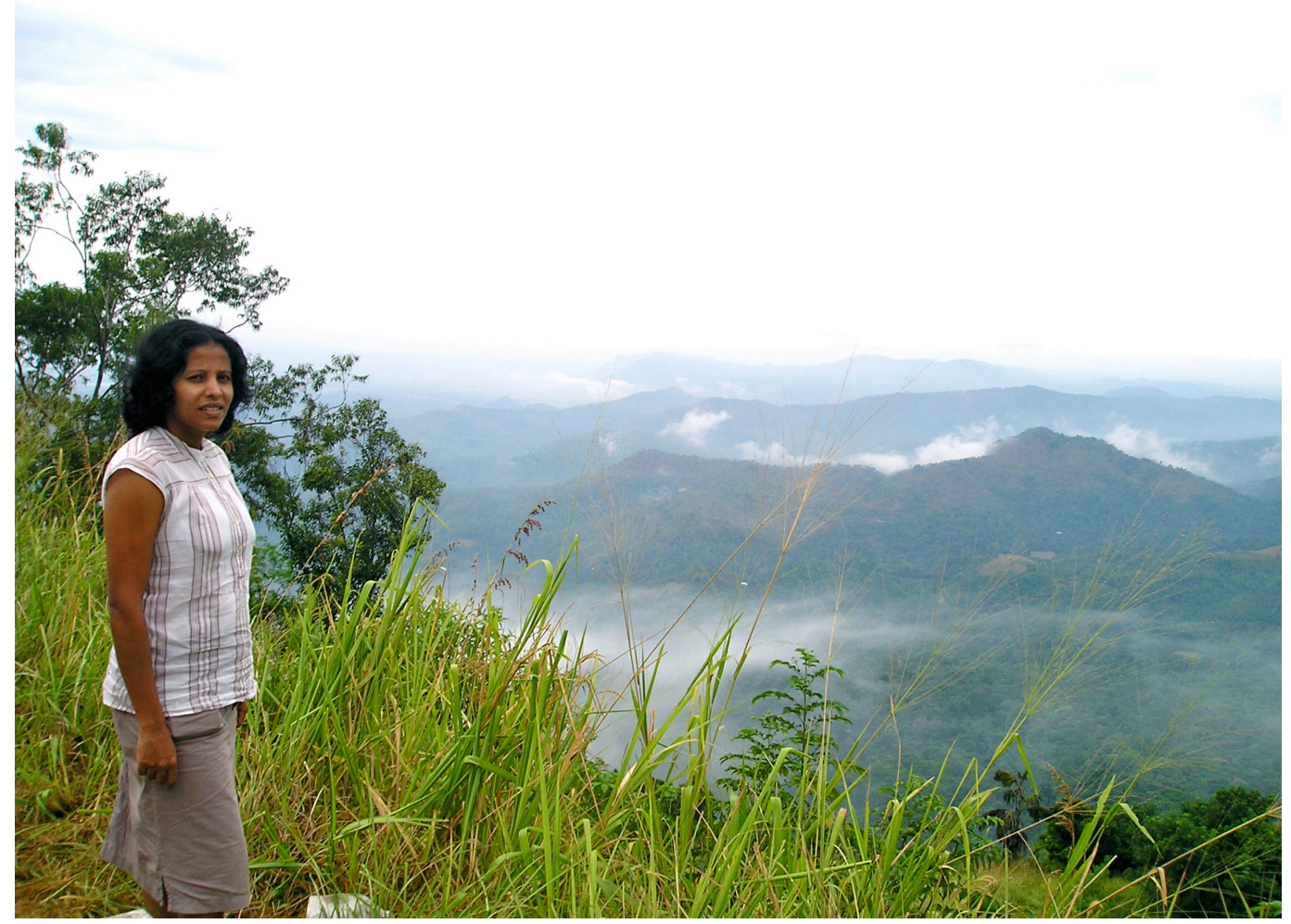

\section{H. Data Recording}

Data collection on household activity has been documented on the weekly log sheet (See Appendix D) by giving each participant a number; half of the individuals fall within the column labeled "Number of Hours Wife Participate in Activity" and twelve individuals under "Number of Hours Husband Participate in Activity". This research tool 
was continually amended, using grounded theory, throughout the interviewing process to allow for more relevant data recordings. This was done with collaboration with Dilhari Weragodathenna, who, as previously mentioned, translated the questions into Sinhala for the participants and then repeated the respondent's answers in English.

Following each interview Dilhari and I discussed the answers to account for missing areas of translation and to remedy potential cultural misinterpretation or language miscommunication. This proved to be an effective mode of operation for this project and allowed for increased relevance of questions as well as increased speed of the project.

Permitted audio recordings were referred to during data analysis. Many recordings were inaudible due to the noise of the surrounding jungle environmental, loud insects and interrupting village members, including neighbors, family members and children. Other recording did not pick up the translations, which were quietly relayed following each participant's response.

Notes were hand recorded by the researcher and collaborator and then shared post interview. In some cases it was socially and politically inappropriate to record via audio due to potential government corruption and potential for punishment related to illegal resource use. Open-ended questions regarding natural resource conservation and importance of habitat health and viability shed light on the meanings behind natural resource use of men and women in the village relating to their gendered division of labor.

The self and spousal reports illuminate how villager residents impact natural resources. These reports also serve to increase our knowledge of how their understanding differs based on gender. Through the ethnographic approach, every participant is viewed 
as an expert on their experience and a wealth of information. Each person in Sri Lanka is invested in the issue of HEC and many will be directly affected by the approaches taken to ensure their survival. The maintenance of Sri Lanka's natural habitats and the survival of the flora and fauna inhabiting these ecosystems, affect the countries ability to develop economically.

This integrated approach allows me to unfold the layers of a culture that I have been slowly understanding with greater exposure over the last decade. Thus, the basis of my analysis stems from the narratives that I collect and the narrative I construct based on my collation of themes and stories from the many viewpoints. The narratives become my raw data, supplemented by the numbers individuals residing in the village self report. I carefully combine the information given and analyze it into themes, ideas and connections with full explanations of a phenomenon that one individual experience could not fully describe on its own.

\section{Participatory Action Research: Positionality within Applied Feminist Research}

"Participatory action research methods including oral history and multi-media projects, which empower poorer classes of women and men, need to be more widely experimented with" (Bandarage 1998: 27). It is important to examine the specific situation within a community regarding HEC. The literature suggests using "analytical frameworks that address differences in society and propose a gender-aware research approach" (Schellhorn 2010:117). This supports my decision to focus on HEC through a gendered lens using a community focus. 
Conversely, Davis reminds us that feminists can get caught up in positions of attempting to help women in developing areas, while at the same time "othering" them. A feminist stance can increase the distance from women whom the researcher is trying to sympathize with. Another danger is refusing to take a look at how the researcher's own actions both objectify and subject local rural populations of women to exploitation.

In my research process, I have made every effort to not increase this form of othering and distance. This involves emotional and intellectual choices and claiming biases and positionality while also including women and men's voices from villages and organizations that alters them to claim their autonomy and own their positions without exploiting them. I empathize with participants rather than sympathize. I do not view my differences as the most salient aspects of our human experience. Through my use of Sinhala, I bridge the language barrier to some extent and prevent physiological feelings of isolation and emotional barriers.

i. Role as Researcher

This section will specifically address my role as the researcher. Identifying my particular perspective and potential biases is in line with my feminist approach to this project. I have a growing interest in the socio-political significance of environmental conservation and how all of our lives are affected by the health and viability of the global ecosystems upon which we depend. I am particularly invested in the ways in which all societies have a gender-specific division of labor. I seek to uncover how these roles give men and women particular relationships to the environment.

These particular relationships have the potential to inform future policy actions to increase social sustainability. Policies that promote conservation and human rights goals 
have the potential to improve the livelihoods of many people living in rural poverty, especially women. Organizing strategies incorporated by global feminist organizations may have transferable applicability to the country of Sri Lanka. From a transnational feminist point of view, I focus particularly on the local activism surrounding the issues of India and Africa. I review the information available regarding gendered environmental activism cross-culturally, paying particular attention to its potential applicability in Sri Lanka. I develop an analysis of how these two environmental movements in vastly different countries, which are led by women, can inform my understanding of what is, and is not, happening in Sri Lanka. This is done through an examination of women-led movements related to the environment in other countries.

My positionality in this investigation must be addressed in order to understand motivations for exploring this issue and my potential for contributing to the body of knowledge on global development and transnational feminism in congruence with environmental movements. As a feminist researcher, it follows that I disclose the lens through which I view the world. By stating all of the potential biases that I may encounter, I become aware of both my privileges and forms of structural or internalized oppression that shape the way I approach data analysis and theoretical critique and structuring of research approaches.

I must be aware of, and make others aware of, my theoretical frameworks and positionality if I am to give an honest and credible account of what social forces have shaped my thinking and understanding of the world. Considering which group memberships have the most influence on me, the more salient influences come from 
identification with various ideological frameworks, including feminism, environmentalism, and egalitarian tendencies.

I approach the world looking for ways to usurp power hierarchies and imbalances. This is particularly relevant in terms of the environment. This lens influences my understanding of transnational politics and the causes or stimulations of global environmental movements. It also informs my approach to research on feminist activism. This framework applies to my interest in the social structural inequalities that exist globally and the ways in which our actions influence them. I am interested in the ways in which global feminist movements rise from grassroots organizing. Additionally, I wish to interrogate how this kind of organizing can be successful and ways in which it might be implemented elsewhere.

I approach my work from an understanding of a global community. My time in Sri Lanka during the summers of my undergraduate internships and research have shaped and molded my international perspectives in overt and subconscious ways. I am still uncovering some of these connections. Living in Sri Lanka as a young adult has profoundly influenced my views. My understandings of education, culture, and the global economy have all been affected. The significance of Sri Lanka's influence on my life is partially due to the fact that my ability to frame the externalities I encountered existed without many filters. As a teenager, I was still in the process developing notions of reality. This has altered my views and my understanding of self. My interest in the Sri Lankan socio-political environment, and the relationship between gender norms and environmental preservation, stems from my experience living in the country as a very young adult. 
I am aware of my lack of "insider" knowledge relating to the socio-political environment of Sri Lanka. A lack of "insider" perspective might be a reason to not study a particular subject area. This has been an internal intellectual and emotional struggle. Uma Narayan (1997) would request that I remain within a forum for critical debate, as to not insult the intelligence of those I am attempting to give agency to. If education is importantly something that trains us to be intelligent and critical citizens of our nations as well as informed participants in a world where many issues increasingly cross, and cut across, national boundaries, what we need are institutional structures, pedagogical perspectives, and political visions that will help to develop and sustain robust, credible, and genuinely enriching forms of multiculturalism, both within and without academic institutions (157).

I am not Sinhalese or Sri Lankan Tamil, nor did I grow up in this nation. I did not experience Third World poverty or Sri Lankan civil war strife firsthand. I have had no family member lose his or her livelihood, limb or life due to this conflict. I have not experienced severe lack of resources and access to information in a way that is often experienced in rural Sri Lanka. Nevertheless, this is a community that I feel attached to on a visceral level. I experienced the aftermath of the Tsunami peripherally and Human Elephant Conflict in the position of an observer. Because of my involved experiences in Sri Lanka, especially as a young adult, part of this identity has imprinted into my consciousness.

My personal understanding of poverty is through an American lens, raised in an economically distressed "rust-belt" city of upstate New York. I also bring with me forms of privilege and education, which has a racial, cultural and class-based lens. Though I am 
interested in discovering a place for empowerment and equity, I recognize the history of colonialism. I know there exists a point for its potential perpetuation in my examination of social phenomenon that exist there, especially relating to feminist inquiry, and my own imposed systems of value that relate to empowerment, equity, conservation and equal distribution of resources. That is the least of my intentions. When exploring the possibility for an integration of larger transnational feminist principles, I do so while also cherishing and strongly identifying with this particular area.

By developing the tools to understand the lens through which I study and view the world, I can potentially alleviate the problems associated with my position as outside academic investigator. I do not wish to create additional harm to those who I study. The participants of this particular project lack the forum as well as the time and luxury to voice concerns and understandings of the world. This lack of voice overlaps with the physical and economic hardships they face. These hardships are a result of political violence and lack of basic needs met through adequate resources.

I am keenly aware of the possible risk of contributing to the very oppression I hope to alleviate. This potential risk is supported by Aili Mari Tripp (2006), who states, "sometimes outsiders do not feel the need to consult with local actors about their facts or strategies because they believe they are providing an unquestionable 'good' in taking action on behalf of another group of people" (297). Not only does this project actively avoid removing agency of participants, it seeks to provide a forum for expression and empowerment. 


\section{Chapter V. Findings \& Analysis}

Note: Because interviews with village residents were conducted with the aid of a translator, such interviews are quoted herein using third-person pronouns, consistent with a direct transcription of the translator's account. NGO staff and experts are quoted in the first person. All names have all been changed to protect participants' identities.

\section{A. Gendered Division of Labor in the Rural Household}

It is clear from the interviews that while men and women share some of the same domestic and income earning roles, some roles are distinct and stratified. Men are responsible for farming activities outside of the home, while women function in a supportive domestic role as childcare providers, in food preparation, and in performing other chores such as shopping and household management. As a male NGO staff member explained:

In terms of other natural resources, if you take the basic things, the small things like firewood and biomass, the women would you know, go out and collect it. It's all related to things they do at home, you know, like cooking, washing, so women are mostly associated with that kind of interaction with natural resources, in rural villages, whereas the men would divert water to their paddy fields they will be doing things like that. You know, it involves more labor, more hard work, so men would generally take part in that. So in terms of wildlife and in terms of hunting, it's almost always the men. You know, maybe [they will] do something illegal.

He went on to elaborate:

If you take chena cultivation, or slash and burn [agriculture], probably the men would work more on things like that. [This is because] it's going away from your home, it's going into the jungles, it's cutting the forest, it's a lot of hard work involved, you burn it, sometimes you stay about two or three days out of your home, so the women wouldn't do that. The women would stay home with their children. But say, sometimes men would go into the jungle and stay the night and come quite late, so women wouldn't go into something like that, but once the area is cleared out, then they would bring their contribution - in seeding the place or 
adding fertilizer or things like that. With water and stuff, it's either wells or rivers or something, so I don't think it has an impact, but in terms of providing, anyway, natural resources for that, maybe there is a slight difference, initial preparation for that, and I think the men would decide where to go from that. -Ruwan, Male NGO Staff Member

Men are predominantly farmers and spend the most time conducting activities in the forest. While both men and women utilize the forest for the common goal of providing for their families, their divided roles (both in and out of field-labor) affect the ways they individually impact forest resources. This has direct and indirect implications for forest management. The following graph (See Figure 21) was developed from the weekly log sheet. Figure 21 displays the combined self and spousal reports of men and women relating to daily activities as they are expressed in hours per week. Men and women occupy different roles in rural villages, with some overlap. This gendered division of labor has direct and indirect implications for forest management. Figure 21 was created using data provided by the weekly log sheet, which can be found in Appendix D. 
Figure 21. Household Activities by Gender: Average Number of Hours Per Week

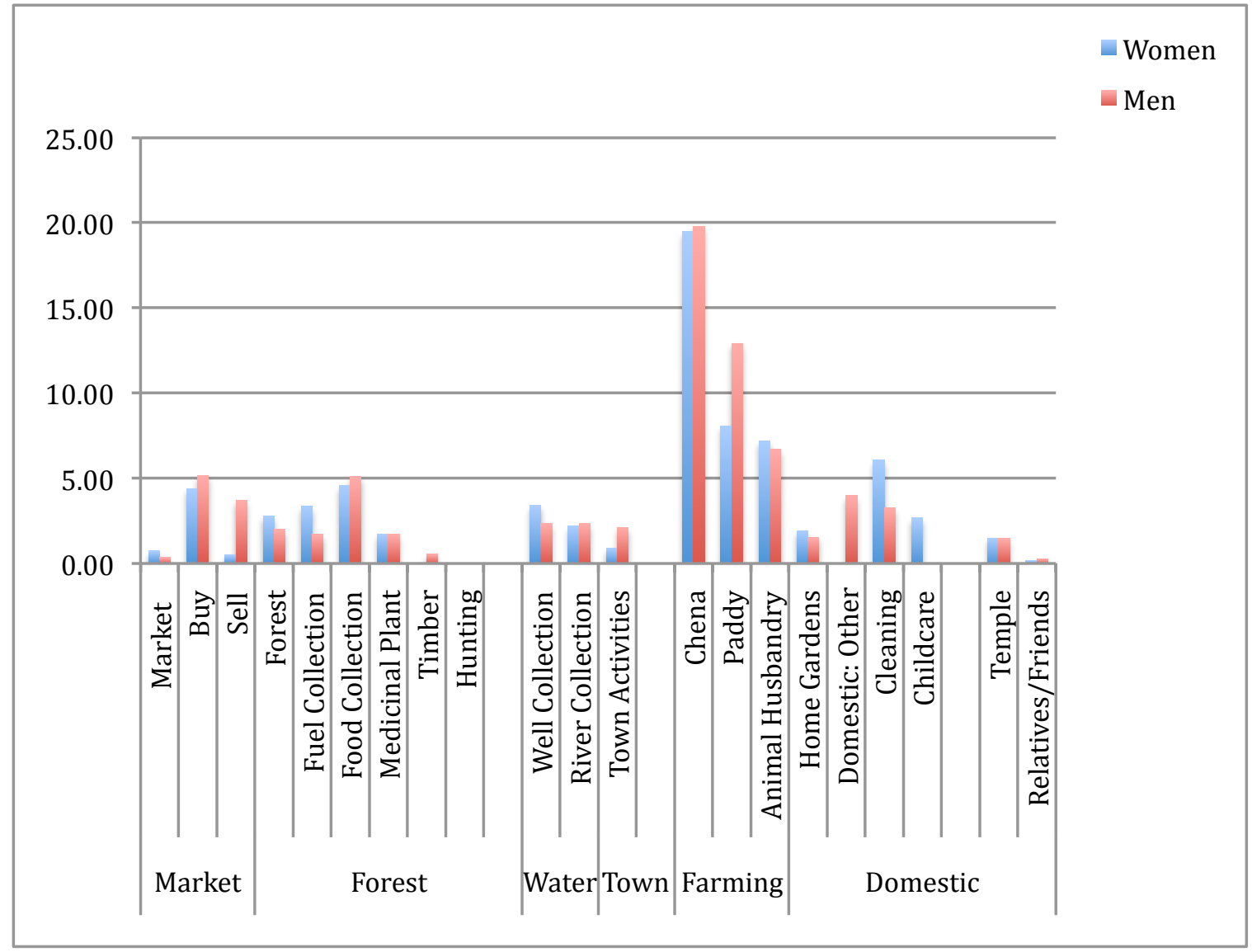

The above chart divides household activities by gender. Figure 21 measures the average of self and spousal reports of the number of hours per week each individual conducts an activity. Women dominate activities such as childcare, fuel collection, cleaning, and time spent in the forest. Men and women both spend most of their time per week chena farming, and do so at a similar rate. Men spend more time paddy farming than women. Men and women both attend temple activities at similar rates and spend time in the forest, though the kinds of forest collection activities are differentiated by gender. Men spend much more time selling at the market, and slightly more time buying. Women share more responsibility for water collection. (Figure 21) 
It is evident from Figure 21 that women conduct more domestic activities and that fuel collection takes up quite a bit of their time. However, it may be surprising to see how high women's participation in Chena farming is in this area. It is only 0.33 less hours per week. The numbers do not account for the fact that men and women both stated that "men" in general are the only laborers who burn and cut the forest. There is a disconnection between what actually happens as evidenced in the weekly logged hours and what interviewees reported.

Women were reported as sharing many of the farming duties and roles with their husbands. Women reported that they were going to the field and helping in certain ways, such as by spreading seeds. They also shared forest duties with men, similarly collecting resources from the forest. A major gendered difference, however, involved cutting trees and setting fires — tasks performed exclusively by men. While the residents shared a few different explanations as to why women shunned these activities, such as the dangers of getting caught or being alone in the forest, or that women viewed them as unsustainable, the interview subjects unanimously expressed that women did not participate in activities that damage forest habitats.

Srihan (Male NGO Staff) acknowledges gender specific roles, however, by stating: "on the supply of water, they [women] are the ones to take much of their time." Another interesting observation is that farmers did not specify the arduous and dangerous tasks involved in chena farming which may explain why women do not perform them. The NGO staffers however, did expose these activities. As Ruwan (Male NGO staff member) claims: "In terms of clearing forests, cutting down and burning, even that, there 
is a lot of risk and women don't usually get involved in that hard labor, you have to work hard, you stay overnight, this is what I feel."

The evidence collected in this study suggests that natural resource management is key in the daily lives of impoverished rural farmers living in buffer zones of nationally protected forest areas. Baba is a confident and friendly father of three, in his late forties, literate, from the village Dimbuldena. He makes his livelihood primarily from chena farming, and animal husbandry; he supplements income from 20 chickens and 10 cows with bee honey and medicinal plants. When Baba was asked how he and his wife selected which $\mathrm{CBO}$ meetings to attend, he replied that:

They [are] both going, they both attend meetings. [The determining factor is] time and for some meetings [his] wife should go...only women at the Environmental meetings and the Selling Committee, for the Development Committee, both they should go, [the] husband and wife both.

When asked why is it divided that way, Baba states:

[For the] Selling Committees, they believe only women can do sale. [It has] Always [been] that habit, [it's tradition for] only the women, that's why they are expecting only the woman [to go].

Hasitha, a male NGO staff member, is aware of the division in household labor

and reports it in the following way:

Especially in water collection; it is 80 percent responsibility [of] the woman. Fuel collection yes. Farming fifty-fifty. They come to the farm and do some work. [In the] planting period they are active. Some land preparations, yes they are active. Food yes. Bringing the food is fifty percent responsibility, operations and everything. Everything is women's role in Sri Lanka, [however], when you are dealing with wildlife, I think it is mostly men's role. It's not the women's role. MOSTLY. -Hasitha, Male NGO Staff Member

Another male NGO staff, Ruwan, commented further on the division of labor in the Sri Lankan rural household: 
Men and women both work a lot, related to agriculture, the men would probably do the stuff that's harder and requires more energy, but it doesn't mean that women don't help, especially in harvesting, women help a lot. Gathering water... [providing] food for their husbands. So I think there is an equal sharing of it. -Ruwan, Male NGO Staff Member

The gendered division of labor in the household significantly impacts the ways men and women utilize and manage natural resources from the forests and surrounding areas. It is clear that the original theoretical model based on the literature (See Figure 22 below, restated from Chapter III. Figure 2), is more complicated than the literature would have suggested, according to my findings on the division of labor.

Figure 22. Restated: Rural Division of Household Labor (DoL)

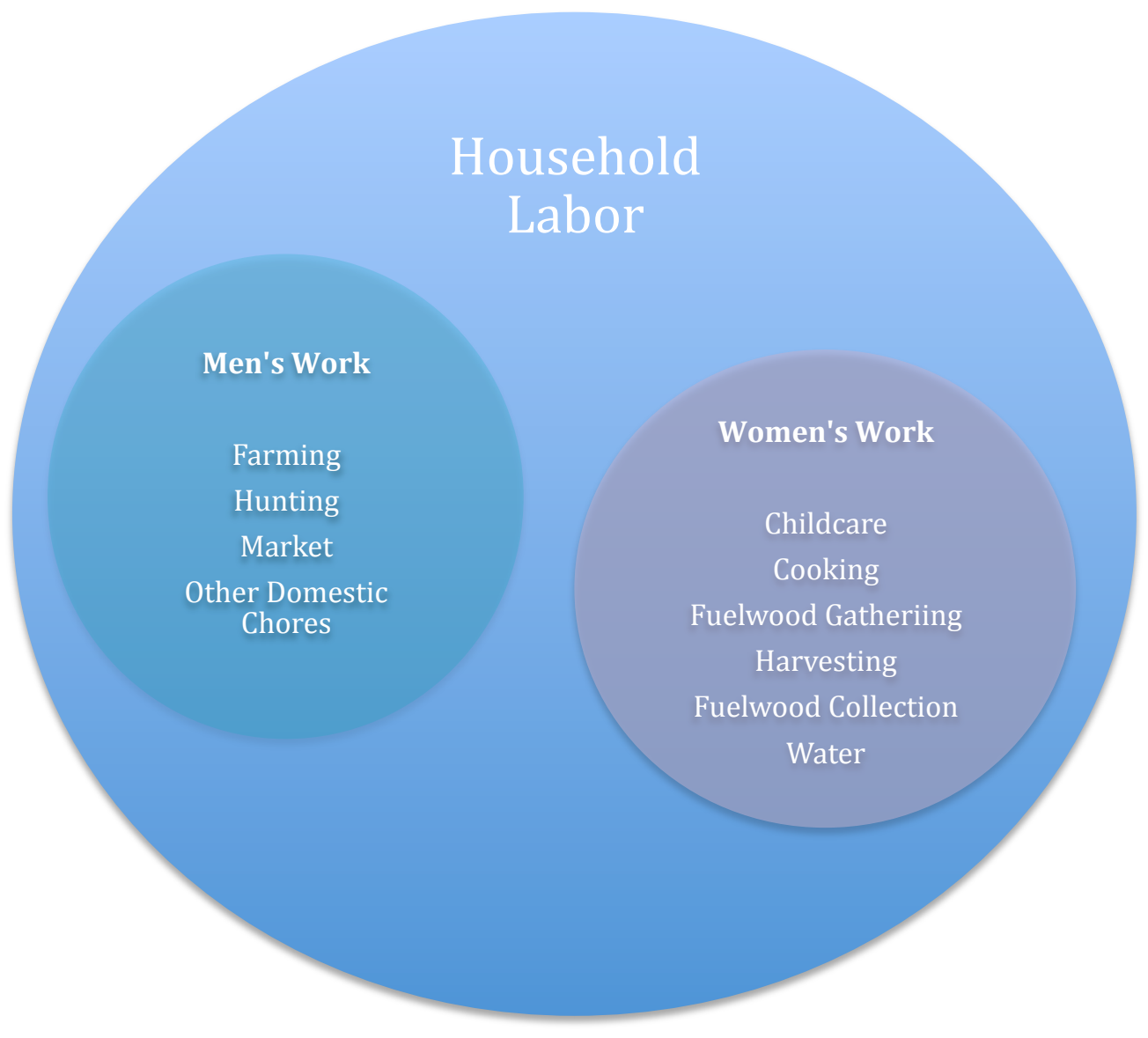


A more accurate model of the gendered division of labor in the rural household would be best represented through an overlapping Venn diagram, showing the men and women in the buffer zones of Bibile-Nilgala with shared forest collection and agricultural roles, including chena farming.

Figure 23. Overlapping Household Roles

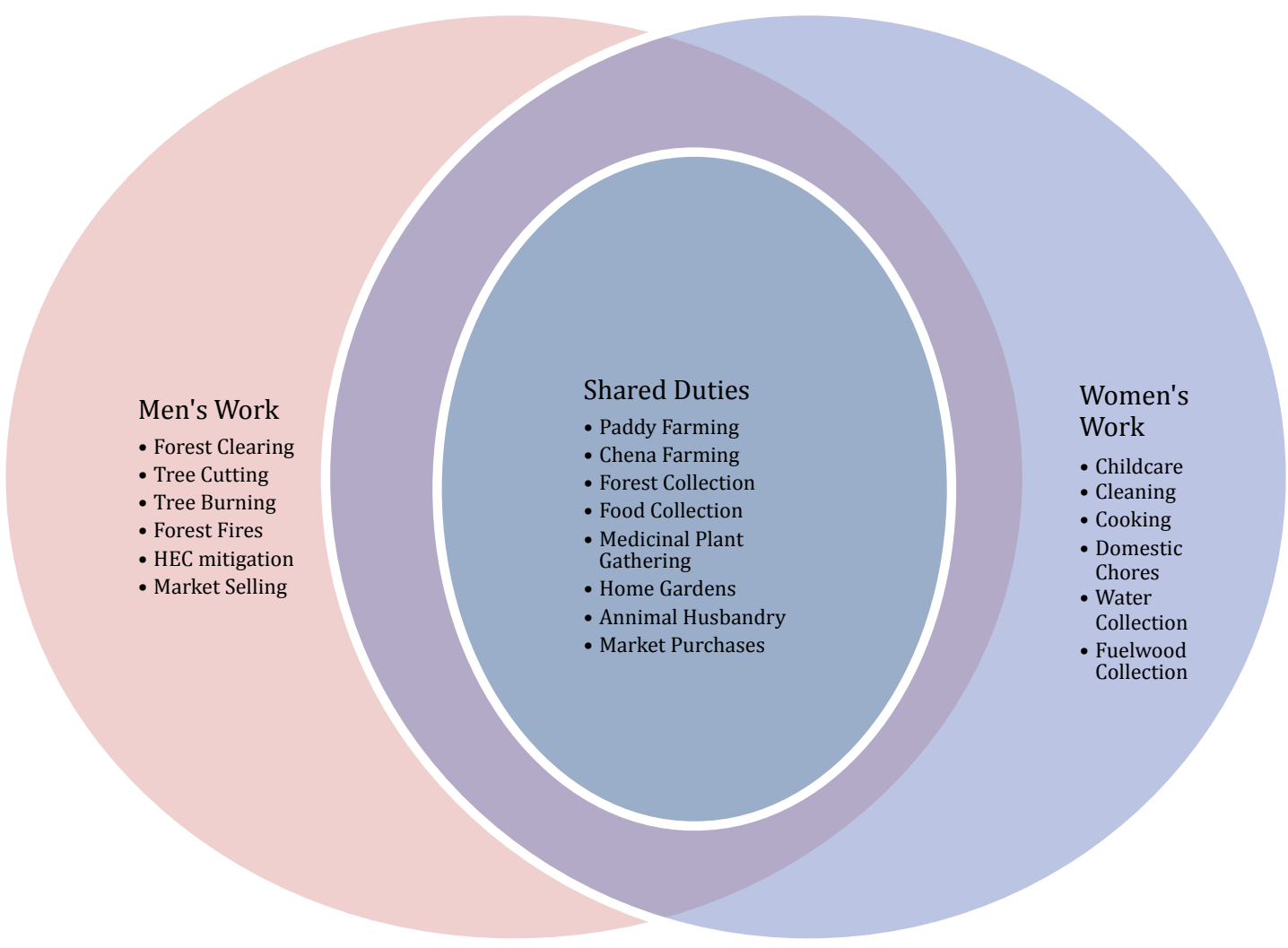

i. Division of Labor \& Decision-Making Power: NGO Perspectives

In terms of capturing the gender dynamics around decision-making, Ruwan, a male NGO staff member tries to explain why things are the way they are: "In villages people discuss a lot. But finally when it comes to the decision, it's the husband. It may seem unfair, but that's the way it is here. If you ask a woman "Do you want to be alone 
and get rid of this guy, they will say no, I don't want to do that." It's not wrong; it's the way they are". There is a deeply entrenched cultural understanding of gender that extends to the urban NGO staff members. Even Ruwan as a NGO representative seems to accept that uneven power relationship as he states:

Generally the decision comes from the man. I guess it's the culture combined with the livelihoods. Mm, it's an agricultural based society, it would involve a lot of hard labor and traditionally the men would take the decision. Our society is that. Even in towns, even in cities. Generally the man would decide. -Ruwan, Male NGO Staff Member

When a male supervisor in one of the most prominent environmental NGO's in Sri Lanka, was questioned regarding how he saw the gendered division of labor in the rural household, he described the following: "I think in the rural settings- - [men and women] do things in harmony and always both have a role to play in everything. So when it comes to farming — so you see they have very nicely divided their roles and finally it's their combined effort when they take a certain amount of paddy harvest, it's a combined effort of both, so I think it's, for them they don't have any... a certain amount of issues. For them, I don't see a major problem in that." Srihan views the gendered division of labor as functional, harmonious and unproblematic.

Similar to the two other male NGO members, Srihan's own understanding of gender is entrenched in the idea that the gendered division of labor is inherent and an inevitable state of being. He cannot imagine a different way of being. 


\section{B. Gendered Use of Natural Resources}

The data collected in the village forest collection logs, represented in charts below capture activities villagers engage in as well as the number of villagers (Figure 24) and a breakdown of these activities by gender (Figure 25).

Figure 24. Average Reported Number of Participants' engaging in Forest Collection Activities by Village Residents

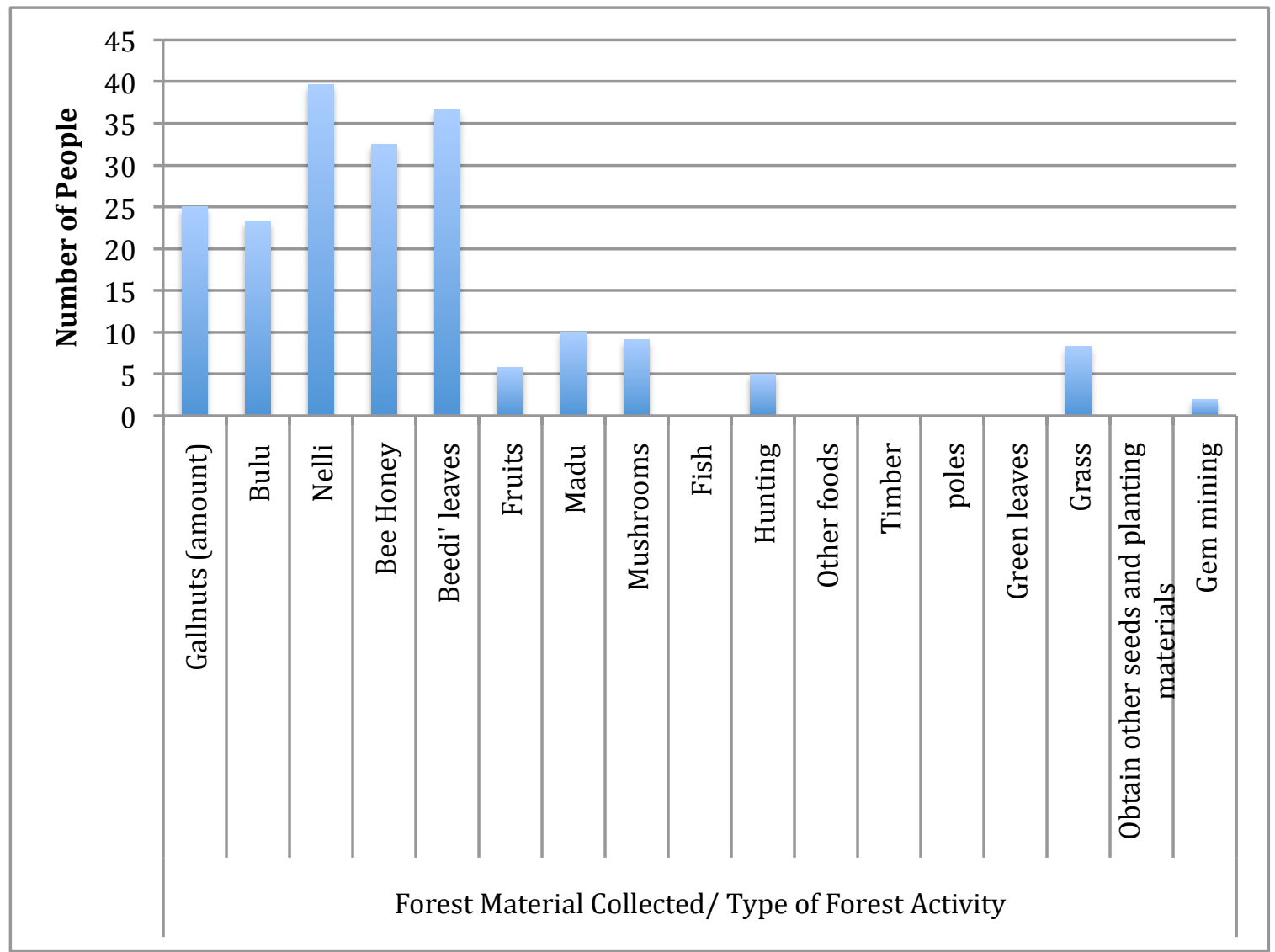

The most common forest activities in the village include the collection of nelli and beedi leaves. These plants are a popular nutritious tree-fruit and a plant that produces 
a tobacco-like substance, respectively. The collection of bee honey is also very common. These three activities provide items both for household consumption and for market sale. Bulu collection is also very popular in this area. Bulu grows on trees. The fruit and seeds of bulu are used for medicinal purposes. Gallnuts are also a popularly collected medicinal plant in this area. Mushrooms, madu and "other fruits" were collected for household consumption. Grass is used for animal husbandry.

Hunting and cutting trees for timber use is illegal in the protected areas, so it is probable that whether or not it occurs in the daily lives of men and women, people did not report high rates of these activities when describing themselves or their neighbors. When asked in open-ended interviews, residents were willing to discuss these behaviors as activities of "outsiders".

There are categories such as fishing, collection of green leaves, and seed collection for which there were no activities reported by residents the households in the Bibile-Nigala area, but were theoretically relevant according to IUCN staff because they occur in other rural areas of Sri Lanka's buffer zones. (See Appendix G. Village Data Sheet: Annual Forest Product Collection/Services)

Participants did not self- disclose risky or environmentally damaging activities during the weekly log sheet question session. It is logical that both men and women would be unlikely to report illegal activities. It does not make sense to incriminate their spouses or themselves. However, those activities were alluded to, or shared indirectly by revealing neighbors' activities and sharing knowledge of activities that are not known to be illegal as occurred in the communication below: 
Both men and women use the forest. They use the forest similarly. However, only men do the tree cutting. Women only do the collecting of the medicinal plants etc...Men create the fires. Women only collect. Men also collect, but only men create fires for chena farming and do the tree cutting" -Shoba (Female Village Resident).

Srihan continued to add that it is "not the females, but the other parties" that have adverse effects on the forest. Nimala agrees, "Men are burning the forest. Men do that... to clear roads." Hetuwa, another village resident, offered the following clarification:

Men and women both use the forest. Men do most of the destructive things. Most done by men -Because of the money. They cut trees and sell. Because of that these do these things. - Hetuwa (Male Village Resident)

During interviews, issues of water collection did not come up as a major time constraint for women. Female Bibile residents were able to spend more time collecting forest products and assisting in agricultural duties due to the presence of wells near their homes. During the dry season, watering crops was reported as difficult in Bibile.

\section{Gendered Forest Impact}

Villagers and NGO staff members adamantly and universally agree about the disparate environmental impact of men and women. They all reported that women did not engage in destructive forest activities. Men were entirely responsible for forest and wildlife destruction.

Men and women use this forest similarly. No difference at all: But destructionthings [are] only [done by] men -Gihan (Male Village Resident).

Srihan, another male NGO staff member, outlined his professional understanding"

So going back to the natural resource management and gender aspect, so the adverse effect on nature is mostly caused by the - not the females, but by the other parties [men]. -Srihan, Male NGO Staff Member 
Interviewees reported that tree cutting increased elephant visits to their croplands and homes as well as decreasing the water supply:

Both men and women use the forest, but men there is a tendency to destroy the forest. That is men who do this. Mostly men destroy the forest. Not women. -Chatura (Male Village Resident)

The average number of male participants who reported conducting forest collection activities was higher than the average number of women (Figure 25 below). This can be somewhat misleading as the number of hours women spend in the forest is greater than the average number of hours men spend in the forest overall (Figure 24). Men and women share in forest collection activities at similar rates when the resources that are collected are used for household consumption.

Men participate in forest gathering practices at a higher rate when those resources collected are used for market/commercial purposes (i.e. bee honey, beedi leaves, nelli). Women and men collect medicinal plants (i.e. gallnuts, bulu) at about the same rates. Women do not participate in strictly proscribed activities such as hunting, tree cutting, or gem mining. The collection of Beedi leaves is associated with forest fires and hunting is illegal in the protected area. (Figure 25) 
Figure 25. Participation in Forest Collection Activities by Gender

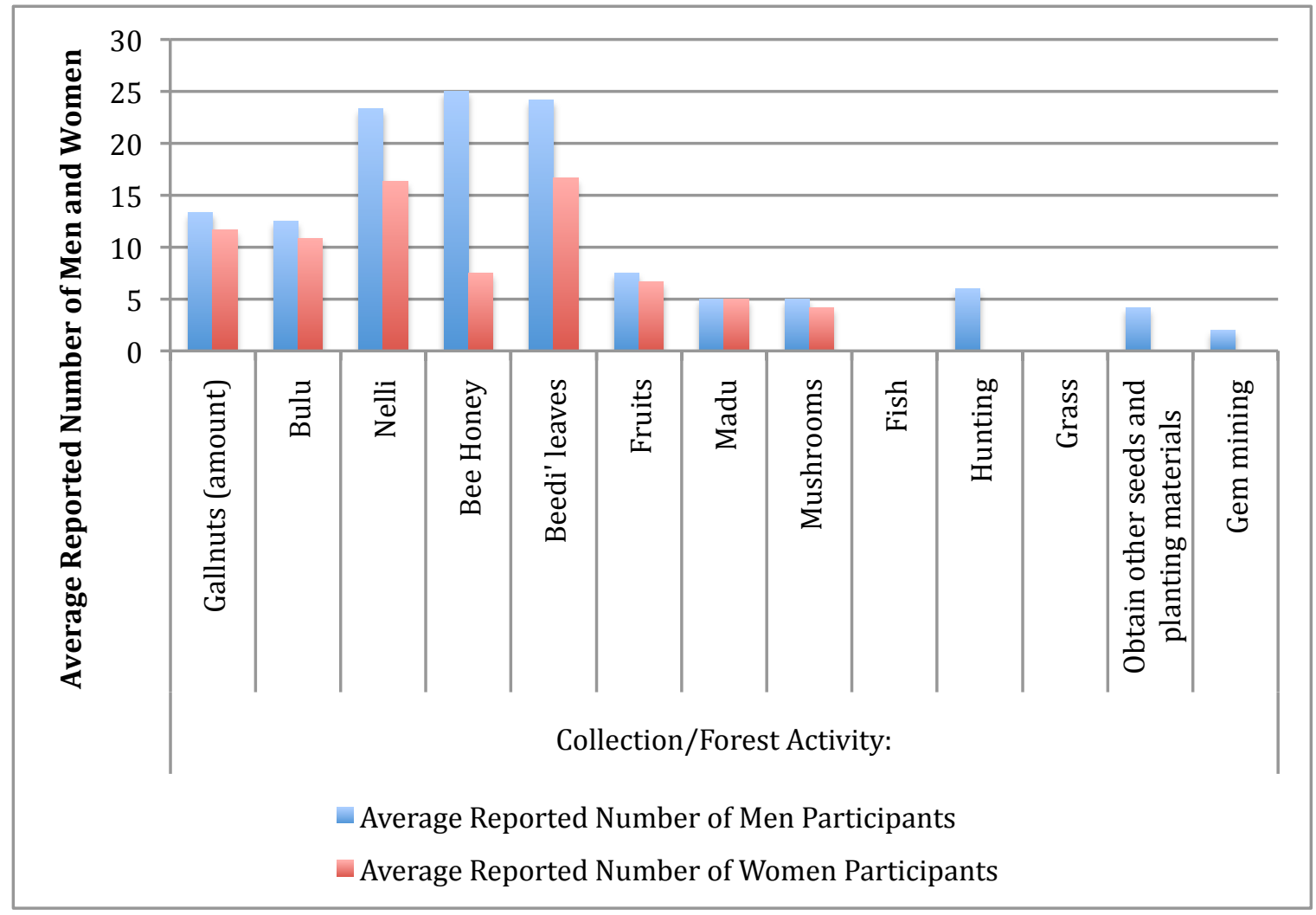

As previously mentioned, Bibile residents engage in a direct extractive relationship to the surrounding ecosystems. Residents rely on the forests for food collection, fuel wood, and medicinal plants. Only one household interviewee claimed to engage hunting and timber collection. Others denied their own participation in such activities. Villagers note that forest fires have damaging effects on the forest. No respondents claimed to participate in forest fire initiation. Nevertheless, almost all participants had a shared knowledge of their duration and initiation. 
According to respondents, on average forest fires were said to last two to three days. They usually occur once a year. The two major motivations behind forest fires include clearing the land for easier wildlife access when hunting and the collection of Beedi leaves to sell on the market. Respondents agreed that forest fires were more harmful than beneficial. They cited issues of water availability. Most village residents felt that the implementation of a sustainable and stable income source would allow people to use the forest differently and in less destructive ways. One household actively participated in putting out the fires. They would look for fires and smother them. This was a family with an income source based on gathering seed, fruits and other materials rather than farming. Because they were hunters and gatherers, they would not benefit, in any way, from slash and burn agricultural techniques.

According to the government official and key informants, many forest activities are illegal in the buffer zone. The legality of activities and the enforcement of forest protections remain ambiguous in practice. There are many forest and agricultural activities that have become habitual for villagers. They are not viewed as unlawful by the perpetrators. Those who have been educated through environmental trainings are of the few who have been informed of the legality of many of these forest activities. Nondestructive collection activities -i.e. small-scale sustainable collection of medicinal plants - as well as some minimal impact activities -i.e. as hunting small game...minor water diversion techniques, etc-were passively permitted, according to village resident reports. 
Government Officials permit resident entry, despite the fact that entry into the forest itself is prohibited in some areas. In other areas, demarcation is not explicit. In demarcated areas, all forest collection activities in those areas are illegal. Very few participants reported engagement in gem mining. Gem mining while potentially profitable is government regulated and is not legal in many areas without a permit. While gem mining is illegal for village residents, it was also not reported as significant source of income in this area.

Financial rewards and the need for basic household sustenance drive most forest collection activities. Beedi leaf collection, a plant that produces a tobacco-like substance, is the most profitable. It is also one of the most destructive forest activities because forest fires are used to condition the habitat to become conducive to Beedi leaf growth and collection. These forest fires, in addition to killing flora and fauna, clear areas in such a way that encourages elephants to inhabit the area.

People did not self-disclose collection of timber (Figure 24). Tree cutting activities are illegal and damaging to this area. All residents stated that timber collection was completed by someone "other" than themselves, specifically groups of men outside of their village communities. The men who cut trees are claimed to be outsiders. This is also true for some of the elephant killings. According to Baba, a villager, "Habitat encroachment [is] happening because of the tree cuttings," He explains that these cuts are for "Fuel wood and building materials. You can see these things. They got them from the forest." When this husband is asked who is cutting the trees, he replies "Outsiders are doing that. Not villagers actually. Outsiders [are] doing tree cutting things." 


\section{Gendered Knowledge, Approaches \& Understanding of Natural Resource}

\section{Management}

NGO Staff, in the process of thinking-out-loud during our open-ended in-depth interviewing process, generally came to the conclusion that women are closer to the environment. Srihan reflected on the connections and concluded:

So that's my view about the gender and-let's say-environment. Yeah, if we just take the role of - men and women in natural resource conservation-- I think they have defined ways of doing their work. Usually, the, females, they, are more closer to the environment and they say, I am talking about the rural setting, Where they are dealing very directly with the nature and maybe on the supply of the water for their daily requirements-- So they are the people who take much of their time in order to provide these things - so they are very well aware of the settings and they have been living in harmony with natural setting. -Srihan, Male NGO Staff Member

Dayani, a female NGO staff member concluded that men on the other hand, are concerned with their commercial livelihood, which takes their focus away from sustainability concerns:

Yeah, there is a difference. [Spoken definitively.] Men always, their motivation is harvesting. Because their main thing is to make their livelihoods. So, women actually, they are more nature-concerned. On nature because they don't involve in these livelihood activities a lot, because of that they have different perceptions. Maybe not because of any other thing, but their understanding — will be a little bit different, but the main reason is that, their livelihood. The motivation for making their livelihood is different. So their involvement is different. -Dayani (Female NGO Staff)

\section{i. Gendered Environmental Attitudes in the Buffer Zone}

Although this research examines women and men's roles in the village household as they relate to the gendered division of labor, the study also finds that villagers have different gendered environmental views, which may be in part based on their access to 
environmental information through environmental trainings, how they conceptualize issues of environmental degradation, and project life expectations for themselves and their children.

When asked if men and women hoped that their children remain in the village, responses varied. Many women agreed with Mathy, a female village resident who "likes if the children have government jobs and live in the town area." Compared to men a majority of women, wanted to see their children move to the "city" and someday obtain government jobs, rather than maintain a farming lifestyle. According to Sena, a male key informant residing nearby Bibile, who overheard and observed many of my village interviews:

Men don't think about the future. Most men don't need the future. Also, men need only money. They make money to... only care about money. They don't care about the environment. Women care about the children and the children's future. -Sena (Male Key Informant)

As discussed earlier, there was one exception to this trend amongst participants. Hetuwa, who, having been injured by an elephant himself, has had some time to think about the future of his children and "likes if his children can go to another town area. He would hope for them to do a government job" (Male Village Resident).

All interviewees demonstrated a sense of the importance of the forest habitat for the wellbeing of the village and their own livelihoods:

This forest is a well because all of the villages depend upon it. -Gihan (Male Village Resident)

However, some participants felt that many men expressed that poorly through their destructive activity in the forest. Also, some individuals emphasized a greater 
concern than others. According to Hetuwa "they are very much aware about these things. They get water because of the forest. All villagers are aware of these things. He considers natural resource to be extremely important, to him, his family, his livelihood, the village and the forest, all these things" (Male Village Resident).

While conducting interviews, Dilhari and I realized we were missing a significant variable in our hypothesis. That factor was education, specifically in the form of environmental training. This was not a focus of the original recording tool, or my interview guide. By adapting the interview guide we were able to discover that those individuals with prior exposure to environmental NGOs educational efforts had increasingly heightened awareness of ecological viability and socio-ecosystem connectivity. While those with trainings were better able to articulate their desires and motivations for protecting the ecosystems, it was a priority for all participants in this study.

According to Mathy, a villager:

Mostly women participate in the meetings [environmental trainings], only a few men participate because, you know, they are doing some agricultural things, no? All the women in this village agreed to do something for forest protections... some, most men, agree [that the forest ought to be protected, [however] some men [do] not agree with them. All women agree [that the forest should be protected].

When asked why men and women disagree on the importance of forest protections, Mathy replies that it is "Because of the knowledge, the lack of knowledge [cause men to disagree]."

Hetuwa, who was rendered unable to farm due to the elephant attack, was one of the few men to attend the environmental trainings. His attitudes reflected positively 
toward forest protections, likely because of those trainings. In his recounting he describes his participation in the following way:

He hear[d] about the government roles, laws and regulations. Laws and regulations. Forest Department did some workshops in this village. That's what he is aware [of]. He participated in a training program conducted by NGOs like IUCN. He learned the importance of nature. After the training he had an awareness about the roles and regulations of the law and the importance of the environment. [Regarding the role of residents in forest protection he is] aware of the importance of the environment and resources. What he can do, when there are people coming into the forest, is call the Wildlife Department to come and catch them. He has their contact numbers, of the government. -Hetuwa, Male Village Resident

The majority of respondents rated the health and viability of the forest ecosystem the highest choice of "extremely important" for the sake of the survival of wildlife species as well as for village welfare. Elephants were a major problem for those villagers in closest proximity to boundary demarcations. Almost all interviewees cared deeply about the wellbeing of the elephants and determined that "they should be there". One participant went as far as saying "this is their land".

Lakmini a 35-years-old married woman, came to this area fifteen years ago, and now has three children. She has completed school up through O-Level exams and is very literate. Her major household source of livelihood is chena farming and animal husbandry. Though Lakmini does not collect beedi leaves, she feels that "the good thing about the Beedi leaves is that they can earn more, the bad thing is that it destroys these trees and animals." When asked if she prefers to stop or continue Beedi leaf collection, she says, "Most people depend on that, therefore it should not be stopped. If it is stopped they will have nothing to earn some money." 
When asked about her feelings regarding the elephants in the forests, Lakmini "said that the elephant is a valuable resource for Sri Lanka and therefore people should protect them, they should be protected." Given the significant damage to her crops, and income potential, it's surprising that she says "Elephants should be in forests because they have roles in the forest." "If the forest cleared, then elephant will be extinct."

Although the respective husbands and wives in each household adhered strongly to the notion that they shared similar viewpoints with one another - at least while within earshot of their spouse - their answers do not appear to tell the entire story. This was made clear in a comparison of later interview questions, wherein men's and women's understanding of environmental conservation were compared. It became clear that men and women have different ways of executing forest management. All respondents claimed that men were the sole contributors to environmentally destructive behavior, including tree cutting, forest burning and human encroachment.

Baba said of his community, "[The] forest is very important for [our] life." $\mathrm{He}$ adds, "Water is [also] very important." This shows men share an understanding of the importance of forest protections. Baba, a male village resident, holds leadership positions in three of the CBOs (community-based organizations) of Bibile-Nilgala and lives in a mud hut with an asbestos roof, a TV, a radio and a cell phone.

Gihan, a 68-year-old medicine man in the village, did not experience negative effects from the elephants in the area. This might be due to the fact that his location was slightly farther than the others in the buffer zone, four kilometers from the forest boundary. "He saw forest fires as a problem and he tried to catch them" (Gihan, Male 
Village Resident). Gihan reported taking an active role, both in volunteering his ancient medical practices, and safeguarding the forest from intruders, though this has proven difficult. The translator said of Gihan's account, "He tried to catch those who were hunting and collecting Beedi leaves in the forest but he could not.” The forest provides the resources needed to sustain this household and others. Gihan goes on to say that "Because of this, forest [conservation and preservation of habitats are] extremely, extremely important for [our] livelihoods and for the village." (Gihan, male village resident)

Gihan recognizes the value of the forest and the importance of its viability in the everyday lives of the villagers. His knowledge of forest conservation is extensive. His knowledge seems to be due to the direct and negative impact of forest exploitation and degradation on his livelihood as a medicinal care provider. "Because of the forest fires, the medicinal plants dried and burned. So it's very difficult to find medicinal plants because of theses forest fires." He goes on to explain, "[I have] to wait more than two years to collect medicinal plants because of this fire." When discussing issues of forest management Gihan claims, "The only natural resource scarcity concern [I have] is species extinction due to the forest fires. Because of the forest, water, food... everything [we] can get from this forest.” (Gihan, male village resident)

Men have ... a short term type of view, but [women] are always looking at the good [of the] environment... as one of the, you know... they have a great respect for the environment. I don't know why, [but] it is there. [In any case], if you give ... decision making power to women, they will make the right decision, in terms of the long term... looking at the long term things. -Hasitha, Male NGO Staff Member 
Respondents across all the different villages perceived an intimate connection to forest extraction and resource sustainability. These perceptions were distributed between men and women:

[Men] understand anyhow. Generally [villagers] understand. Not because of their knowledge actually. Knowledgeable people. People are a bit education and aware of the things. The thing is their struggle and livelihoods and making their livelihoods. -Dayani (Female NGO Staff)

Men and women alike, have knowledge of their surrounding natural environments. Men and women both have an understanding of the importance of their environment, but because of the roles men have in their households- the major role being to earn a livelihood, --women are in a position to better understand the reality of conservation needs. A male NGO staffer explained in the following way:

But in today's context, the Human Elephant Conflict issue yes. There, you know, woman have also raised their issues, raised their voices, this thing. So it is there now, because they also get affected, no? -Hasitha, (Male NGO Staff)

\section{ii. Participants in Support of Female Empowerment}

Many participants in this study have supported female specific influences in rural villages. Female NGO staff members were especially supportive of the goals and hypotheses of my project. For example Dayani, who is a supervisor at one of the leading environmental NGOs in the country, also highly educated with an advanced degree and soon to receive scholarships to study abroad, says:

I think in the conservation. The giving leadership to women, would be one good option to be considered. That is one thing. Involving women. Women focused and leadership for women and using them for education and things like that. They can change the attitude of family members, women can be involved in that way. -Dayani (Female NGO Staff) 
After listening to a few of the interviews with other women, Mathy, a tall fortyone year old mother of three living in the buffer zone of Nilgala forest, chimed in that she has some different ideas about our questions. She had followed us throughout the interview process and wanted to share her own thoughts with us, and so requested an interview. Mathy reported on tree cutting and other destructive activities. She expressed her support of NGO trainings in reducing environmental degradation and her understanding of the significant role of gender in village forest interactions. Details of her interview are provided in the sections below.

\section{E. Roles of the Government \& NGO Trainings}

There is much controversy surrounding the fate of the villages surrounding PAs in Sri Lanka. There are also conflicting views regarding management. According to Ruwan, the government is "not handling it good enough I would say, initially it's a result of their bad planning, they are continuing to do that. But I don't know, maybe they don't have a choice, maybe you can't put a village that far from a water source also- but at least maintaining the corridors and leaving the protected untouched." Ruwan says at a minimum, encroachment of the PAs must be stopped, our data shows that village residents are reporting very high rates of encroachment, this minimum level of conservation is not being properly maintained, though trainings have begun to improve this through the villagers awareness of the role of the forest and the importance of calling the Wildlife and Forest Department officers to come and stop people from damaging the forests. 
Questions regarding environmental conservation and ecosystem health did not seem to be an unfamiliar concept to anyone interviewed, including those who reported lower education levels. Those who reported having had environmental trainings clearly showed an increased knowledge of environmental processes. Women were reported to have higher attendance at trainings that were open to both men and women and in some circumstances women were expected to go exclusive of men. For example, according to Baba (a male village resident), "Men and women have separate meetings as well as joint meetings. My wife attends Environmental Meetings and we both attend Development Meetings". Women held a particular role in this community, which required them to go to environmental meetings.

Mathy recalled that "They called some tree cutting thing, and they called those people [participating in the tree cutting] to those meetings and now tree cutting is rarely happening in this area, because of their meetings" (Mathy a female Resident). "Now the villagers are aware of the laws and regulations and why we should conserve the forest and natural resources" (Mathy). Thus, by bringing those violators into the meeting, environmental destruction was significantly reduced.

According to Lasantha, a male key informant and Wildlife Official, "People are often helpful in catching intruders, both men and women sometimes call to alert officers of people entering the forest illegally." Lasantha suggests that government training and awareness campaigns are good to better protect the forest. This is consistent with reports from village residents. 
As Mathy, explained to us: "You know, the forest fire things? That people generating forest fires ... to collect Beedi leaves, and sometimes without knowing [it], you know hunters, they just throw their cigarette [butts]. Without knowing [it], [this] is also happening in this area." She described the fact that forest fires are unknowingly caused by hunters who haphazardly toss their cigarettes to the ground and ignite fires without an awareness of doing so. She confirms that the trainings have made a difference:

Now, because of the awareness campaign of IUCN, conducted by IUCN, there are reduced forest fires. People are scared to go [in] to the forest because the villagers have contacts with the Wildlife and Forest Department[s]. -Mathy, female village resident.

Communication between village residents and the Wildlife Department assist regulators in protecting the forests from "outsiders" who wish to exploit the resources that so many residents are dependent on for survival. "There are some meetings and people discuss about this elephant conflict. After the discussion they went for the wildlife department and asked [for] more firecrackers and the Wildlife Department gave more firecrackers." Firecrackers are used to scare away elephants. They make a loud sound and spark. They are considered to be a very effective temporary strategy for chasing elephants out of the paddy fields. (Mathy, female village resident) 
Figure 26. Firecracker Provided by the Wildlife Department

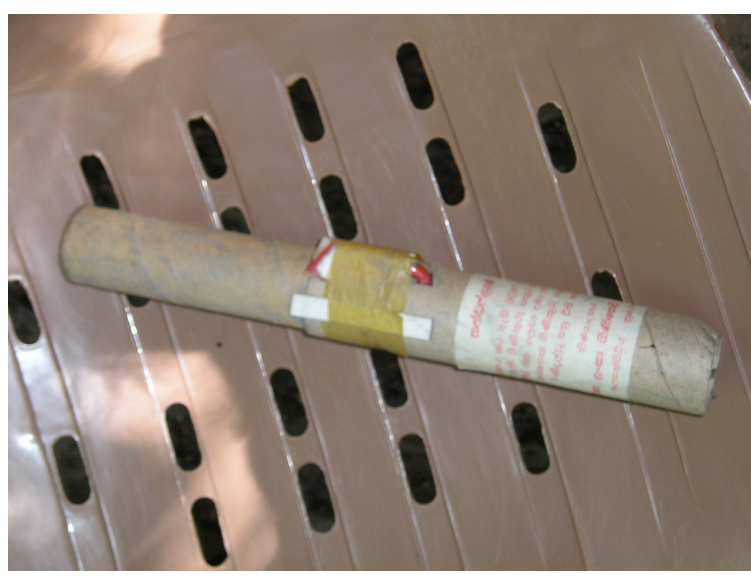

Regarding women's roles, Srihan, generally feels hesitant about the inclusion of gender in his organization's policies. As a supervisor in his organization, his hesitancy may reflect a larger trend to exclude gender initiatives in forest management practices. Srihan's resistance to the mere mention of gender shows that Sri Lankan gender politics may play a role in exclusion of female-centered approaches in HEC mitigating strategies to-date. Hasitha (Male NGO Staff) also acknowledges that his organization has not incorporated gender in its approach:

I think [my NGO] as an institution, has not looked at [gender] very seriously, but it is there. -Hasitha (Male NGO Staff)

In regards to social sustainability, instead of gender, Srihan focuses on a critical take on development as a leading cause in natural resource exploitation:

So maybe with the change in the, say, industrialization or urbanization, people have started getting more out of the nature at a rate where the nature is not in a position to replace or replenish things at the same rate, so then-- where we started seeing the issues. -Srihan (Male NGO Staff) 
A shift to local authority over management had already begun to take place in this research site. Though much of the legislation for protected areas comes from Colombo and national governmental regulations, several "societies," or Community Based Organizations (CBOs), were described by participants. These societies seemed to have a pivotal role in shaping environmental viewpoints and perspectives. Examples of CBOs included the Funeral Society, the Environmental Society, and the Development Society, all of which were local organizations. The Funeral Society was type of CBO formed by villages to help one another with funeral preparation and execution. According to my translator: "if someone die at your home, you will be getting support by others in the village if you are a member of the Funeral Society." The function of these societies seemed to lay the foundations for NGO intervention and poverty alleviation techniques, as well as conservation intervention strategies. CBOs were clearly important sites of communication for residents and outside agencies, including those that were governmentally based.

\section{i. Village Resident Lifestyles}

When asked how much time was spent outside of the village and the home, residents responded that they do not often (if ever) leave their homes and paddy fields and chena farms to visit the city or participate in civic affairs. There seemed to be a discrepancy regarding the notions of "free time". Overwhelmingly village residents reported having "no" free time whatsoever, however many of them were all able to spend over three hours being interviewed by my research team, following us around the villages 
from place to place, trying to see what we were up to, and listening to their neighbors being interviewed.

The key informants also noted that they seemed to have quite a bit of leisure time, especially during the evening after the farming duties were completed. However, the concept of "free time" may have been convoluted during translation and the time spent with us may have been an exception to their daily activities, due to the novelty of our presence in the village.

A few of the villagers had family members living abroad as domestic laborers. One village husband, Baba, describes his household roles when his wife is home. She is currently working and living in Jordan. "She's been gone for two months and will return in two years. "Normally what [I] do is, at the morning, go for animal raising, then go to the farm or chena, again in the evening go for animal husbandry." When his wife is home, "wife and husband both go to do all of the things. The daughter, older one is doing the house things. She is schooling", while his "wife does the shopping". Migrant workers relied on their family members, such as siblings, grandparents, and in-laws to take care of their children. 
Figure 27. Dilhari inspecting village water tank.

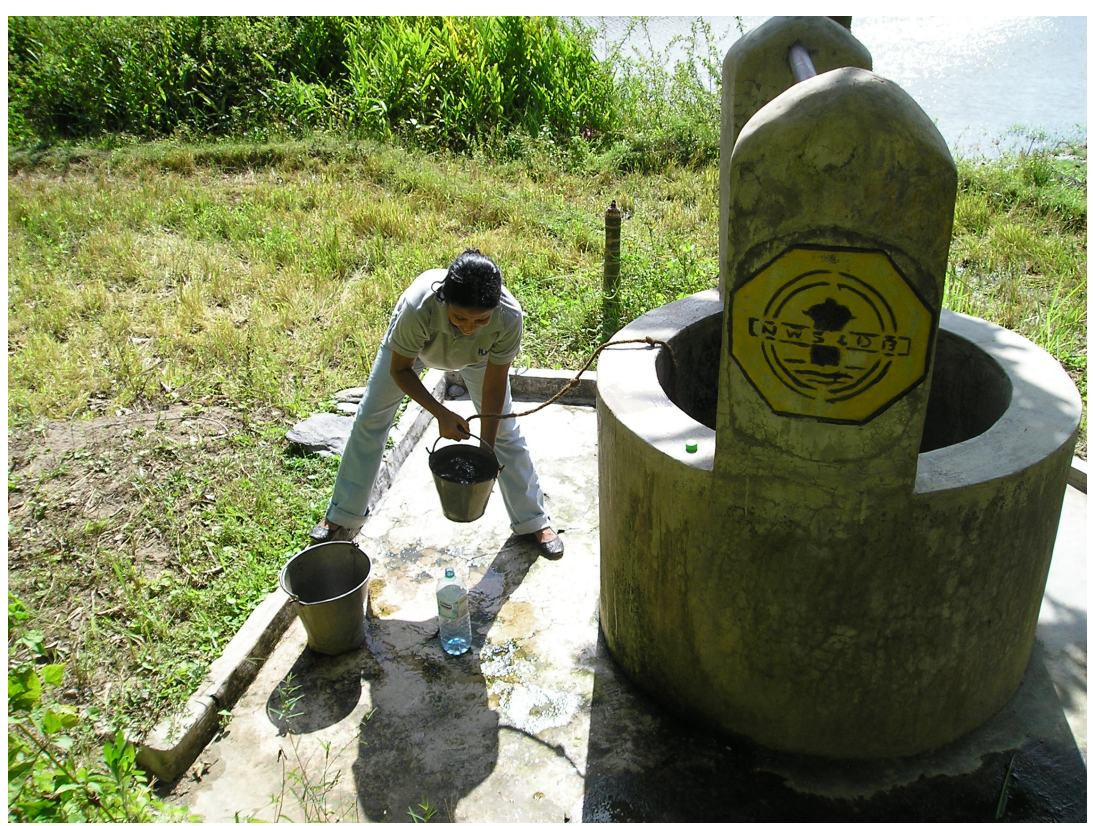

\section{ii. Natural Resource Management and HEC Mitigation in Buffer Zones}

Nearly all twenty villagers expressed the need for a water tank that could allow for decreased forest dependency if it were to provide more sustainable means of survival by allowing them to irrigate their crops without rerouting forest water bodies. The effects of this could be measured through a comparison of another area, which does in fact already have a water tank.

Firecrackers are made available to villagers to scare away intruding elephants. They are inexpensive and effective with little environmental damage. Lasantha, a "range officer" and "game guard" did not allow a recording of the interview with him due to safety reasons, given his position as a government official in the Wildlife Department and the risks he might face as a result of those recorded statements. However, he was willing 
to provide an interview and was very cooperative in answering questions, though much more hesitant than any village participants.

According to him, his responsibilities included animal protection. He claims that it is during "the dry season that elephants come here. Firecrackers and loud noises are used to manage them. No guns are used. They have to chase elephants away two times per week because of the forest fires. The elephants come because they don't have enough food. They cause personal damage and property loss. If they catch people in the demarcated Wildlife Boundary, where people are not allowed to venture, they can charge a very large fine. The minimum fine is 10,000 Rupees. If they are unable to pay such a large fine, they will be sent to jail. No hunting is allowed in this area.

He goes on to relate that recently a man was caught with 2 kilos of meat and was charged a 40,000 Rs fine. The signs are there to make people aware of the boundaries. Those who cross the boundaries are mostly tree cutting and hunting. Some individuals are permitted to watch the wildlife areas but they must go with the officers. They cannot go without the government escorts. Tourists are charged 40 Rs per ticket to go in the National Park. Lasantha notes that as far as women, "No women go in the National Park illegally." The problem in this area is that there is no boundary protection.

Cooperation between the residents and wildlife officials in the buffer zone areas, in addition to full participation of women in both areas, is essential to ensure sustainable village-forest interactions. My key informants provided evidence of resident willingness to plant trees and contribute to conservation efforts and training as time allows. Village residents who felt that wildlife officials were accessible were much more likely to take 
active steps toward increasing the conservation of the forest areas in their respective regions.

According to Lasantha, "there are separate boundaries for the Forest and Wildlife Departments." Yet, this was incredibly unclear to me, and many of the village residents who are not literate might have trouble discerning the content of these signs.

Figure 28. Demarcations of Protected Forest and Wildlife Areas

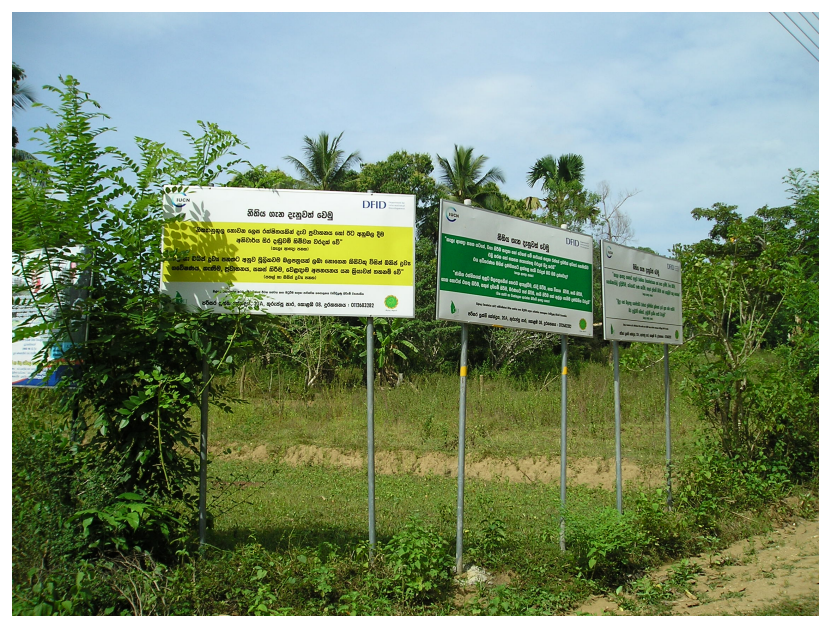

\section{F. Alternative Findings: Female Head of Households \& Indigenous Approaches}

\section{i. Female Headed Households}

Amanthi, a widow, represents one of two female heads of household and had an exceptionally conservation-oriented attitude. Amanthi, in her mid-thirties, but appearing much younger, was the only female head-of-household interviewed who was not living with the influence of a husband or father figure. Amanthi sat for our interview with her hands folded. Sweet, calm and very shy, she offered a particular perspective unlike any others interviewed. Though incredibly quiet at first, throughout the interview her smiles 
grew more frequent, especially when her opinions were elicited. It became clear to her that she was the expert and she gave distinct points of view and suggestions. We asked the others who were listening-in on the conversation to leave the house during the interview. The privacy created a much different environment than any other woman interviewed. Almost all of the other women (i.e. Mathy also was not overshadowed by a male-eavesdropper) had husbands popping in and out of earshot and potentially limiting the views that wives were willing to share with us.

Her house was much sturdier and expensive than the other houses. Amanthi's home was made of bricks, rather than mud, with a clay roof and wooden windows. This was very unusual for this area. There were four rooms in the house, more than any other house we visited. Outside of the home, situated in a larger forest clearing than any other homes visited, were "peanut" shells drying on the stoop on a lark drop cloth. They tasted like raw green beans. Amanthi has felt the effects of environmental degradation and it has affected her income dramatically. Only three years ago she made 7,000 Rs/mo. Unfortunately this has decreased by more than half, as she reported currently to only make 3,000 Rs/mo. Much of this income loss was due to the death of her husband. She is no longer able to go to the market and sell as many vegetables as she was previously able to.

Amanthi cites the issues of forest fires leading to a decline in medicinal plans and reduced water supply. Amanthi claims that women are very upset about this issue. "Most women don't like forest fires because they can collect small things from the forest." When asked if there are gendered activities performed only by men, Amanthi claimed, "Men are the ones who are hunting and tree cutting. Women go to the forest only for 
collection of medicinal things and fire wood." According to Amanthi, Women participate in forest collection of fuel wood, Beedi leaves, and other flora. "Both men and women practice agriculture similarly. Some men participate in forest collection activities, but it is mostly the women." Amanthi states "Men don't have time to do domestic chores, like childcare and cleaning. They are too busy doing Chena farming." She does not personally experience conflict with elephants, though they do come very near to her. She has a very strong awareness of forest dependence. "Many things come from the forest, [and] if they are destroyed, [the villages] will lose everything."

Amanthi has distinct ideas for forest conservation initiatives including using collaborative strategies and working together. She feels that villages should come together to make the decision to stop forest fires. "Both men and women should be involved. Women cannot make decisions without [the aid of] men implementing [them]." The Environmental Protection Society is made up of mostly women. Therefore the Wildlife Department needs to collaborate with them in order to enforce the forest protections by the men and require them to adjust their behaviors. She would like to see tree cutting and hunting stopped. Amanthi said, "Elephants come to the village and destroy everything. However, if the elephants were to become extinct the forests would be destroyed. Because the people are afraid to go into the forests with elephants there, forests are currently protected.

In an interview with Hetuwa, a man living in the village who was permanently injured and unable to walk due to an elephant attack, he shared that: "people [are] generating forest fires. He doesn't know who. ...Sometimes villagers and sometimes 
outsiders. They generate fires for hunting and to collect Beedi leaves. There is a water problem because of the forest fires. They have a well, but in the dry season. They have to walk more than one km to get water." Hetuwa exhibits knowledge of his surrounding ecosystems. This seems to suggest that some of the men are aware of the impact of some of the agricultural activities on the health of the environment and elephants.

In this case, there is strong evidence of a husband supporting conservation efforts with the goal of preserving elephants in spite of the fact that he has become permanently disabled as a result of the attacks. While Hetuwa's wife, Prema, has distain for the elephants who crippled her husband, and wishes to have them all driven away, Hetuwa himself states: "Elephants are an important animal. [There is] no need to kill or destroy [them]." This is a surprising perspective shift and likely has to do with Prema's new role as Head of Household and primary income earner. Because of her husband's injury, Prema must rely on social and financial support from other family and village members. Because she is female, she is not socially permitted to farm. Because of this, their household suffers from a serious income drop as well and livelihood shift to selling handmade and woven goods.

Her husband also demonstrates knowledge of the history of the HEC and has a sense that it is increasing over time. In the words of the translator "Before ten years ago, there was no conflict. When he was young, no elephant conflict was seen here. Because of the forest fires and forest clearance for chena farming, there is elephant conflict now, including crop loss, personal injury and property damage." He takes responsibility for his role in his own injury and recognizes that the destructive practices in the village are 
increasing the conflicts between humans and elephants in this area. He states "Chena farming is the main livelihood here."

ii. Vedda Communities within the Forest Boundaries \& Degradation Awareness

Contrary to my hypothesis, men also emphatically agreed on the importance of ecosystem preservation and habitat management for the well-being of their families. This was particularly expressed by Iranga who is a leader within the Vedda community and the only male we interviewed who did more gathering and forest collecting than chena farming to sustain his family. He was by far the smallest in size and frame of the male participants, exhibited the least amount of shyness. Unlike any other men interviewed, Iranga was seemingly the most confident and comfortable providing information and less awkward in his body language when interviewed by women.

He has four children aged twenty, fifteen, thirteen and ten and has no formal institutional education. Eleven children, a grandmother and two younger women, a cat and a few kittens gathered around us, standing under the roof to avoid the downpour. Many observers stood smiling or sat shelling nuts during the interviews with the husband, and cleared out during the interview with his younger and much shyer wife.

The Veddas are indigenous and are the only group allowed to reside legally within Nilgala Forest, or any protected area. Iranga is the liaison between the group, the NGO, and government representatives to the area. He explained that "Light, electricity provided by an Indian group last year through solar panels. It has been granted through the entire village. This benefits the children for studying, as well as providing access to television and radio." He continues to explain that in this village men often go into the 
forest and stay for three to four days to collect medicinal plants and fruits. They sleep in the forest overnight, while women go into the forests but do not stay since they need to care for the children in the home. Both the men and women in the Vedda community are:

... Not scared of elephants or any animals. The elephants do not do any dangerous things for them. Elephants have always lived here; animals have always lived here. They never scared because always there are living with animals in the forest -Iranga (Male Village Resident)

\section{iii. Other Causes of Forest Fires}

Iranga also claims forest fires are set by other villages. Iranga describes the impact of these fires and how his fellow villagers are affected:

When forest fires are happening in the village they go into the forest and clean it. Some trees are cutting and then they stop the spread of the forest fires. These fires happen one season of the year, during the dry season. Some people do this as entertainment and also do this just to make roads in the forest. All the villagers here are born here and have very much love for the forest. All livelihood, medicinal plants, they getting rain coming from the forest, everything lost because of these forest fires. -Iranga, (Male Village Resident)

Regarding ways to stop these forest fires, Iranga suggests "Government people have, if they want to, if they can do something, to stop these forest fires, it will be better, otherwise they don't come to this area. He will call them, but sometimes they come, sometimes they don't come, officers aren't willing to go into the forest, because of the roads. They don't want to go to the forest, to stop...they don't have any idea to find those people." It is clear that government officials are not enforcing forest and wildlife protection effectively. There are issues, not only with enforcement of habitat protections, but also with corruption within the government. Iranga blamed the police for breaking forest protections. "The police person doing the hunting, they have the guns" (Iranga, Male Village Resident, Vedda). 
Iranga “really like[s] the elephant, and doesn’t find any harm from the elephant to this village... No[t] any damage, no property damage, no damage to the people", Dilhari translates excitedly, “They are living very friendly with the elephant!” When asked for ideas as to why elephants do not cause conflicts in this village, while the surrounding villages are harmed, he replies, "Because they've never done anything damaging to elephants. They have never done harmful things to them." Because they do not harm the elephants, in turn the elephants do not harm them.

This peaceful cohabitation he claims has existed for many generations. As far as elephants invading crops or homes, Iranga maintains that "Around this village, elephant aggression has never happened, he has no experience with this. Elephants are spotted only in the dry season from July to October. They come in herds and as single elephants, both. The single elephants are male." He estimates "One thousand elephants in this forest. They migrate throughout this forest and others. He has noticed that the elephant number is reduced. When he went to the forest with his father, there were more elephants, now he can see their numbers have decreased. Other animals have reduced because of the hunting, deer and wild boars" (Iranga).

Iranga goes on to explain that although water scarcity during the dry season is a problem, the relative isolation of his village, the need to be self-sufficient with food production and their long established appreciation for a healthy forest, conflict with elephants has not been a problem:

Water scarcity is a problem always during the dry season. Degradation, habitat encroachment and pollution not happening in this area. Their life expectancy is high because of the fresh things they are able to get from the forest. This village is far away from the town, so they can't access any of the town facilities, and water, water is the main problem. If they have water, they can plant some vegetables. If 
the forest leaves, the elephants will destroy the village, everything. Until they die they will protect the forest. They don't like the tree cutting. - Iranga

\section{iv. Social Sustainability and Visions for Future Generations}

Iranga was born in this village, and his parents were born five kilometers away, also within the forest area. This household represents one of many that live in harmony with the natural environment. Unlike other groups that have relocated from other areas such as the Kandy region to this area of Bibile, the Vedda are native and have no plans to move. They consider themselves protectors of the forest and the cohabitate peacefully with elephants.

Iranga goes on to express a desire for his children to stay in the village and both he and his wife Nimala maintain that if there were alternative sources to permanent income the amount of tree cutting would be reduced: "If someone can give a permanent income source, they will be able to stop the tree cutting."

When asked for his opinions on ecotourism, Iranga says, "he likes ecotourism, no bad things will happen. The villages don't allow anyone to do any harm to this forest. If they do something, they will take actions against them. They can earn some income from ecotourism. They like to share their knowledge, but they should not do any harmful things to the forest, if so they will share their knowledge. They can show old things, indigenous knowledge to the people coming in, but the tourists need strict rules."

Shoba, a 42-year old woman, who is the financial director of the village, and the volunteer secretary for the Environmental Protection Society, is a mother of two children, a son 18-years-old and a daughter 13-years old. According to her interview, while her 
major method of livelihood involves animal husbandry, poultry and milk, the selling of medicinal plants, bee honey and Beedi leaves, "She likes to see her children given government jobs. She doesn't like to see farming activities [for their future].” This was echoed by many of the wives interviews, and suggests that given other economic opportunities, mothers would prefer to have their children work elsewhere. Chena farming, yielding only 3000 Rs to 5000 Rs annually ( $\sim 30-50$ US \$) for this household, and other agricultural practices are not the preferred livelihood methods. For some of the residents, farming is merely what is available and what they are skilled at doing on the subsistence level.

Though she cares about the forests and the well-being of natural resources, "She says she likes if they are living in the town area, with other facilities." "There is no market to sell their medicinal plants that they gather and they have to throw them away." She, herself, prefers to stay living in the village. "She doesn't have capacity to do jobs in the town, because they can only do farming things, they can only do it in the farm, no?"

\section{G. Elephants, Poverty \& Forest Protection}

As far as the value of wild elephants to Sri Lanka, Mathy maintained that "Elephants are very much a beauty for the forest. Because of elephants, people are scared to enter the forest" (Mathy, Female Village Resident). This statement is fundamental to the case for maintaining elephants for the sake of habitat preservation. Elephants themselves have become a forest protection. As Iranga mentions in translation: "He said that elephants protect the forest lands. People are scared to go into the forest because of 
the elephants, especially outsiders.” Iranga, male Vedda village leader, claimed that elephants protect the forestlands.

Unlike pest or predator species that are far from valued because they threaten agricultural production in other countries, elephants in Sri Lanka are simultaneously seen as a threat and valued. Many villagers, even those who are threatened by the potential for elephant attacks, appreciate the need for elephants to exist. Even though the killings still occur they are also interested in mitigating techniques to reduce HEC. Ruwan attempts to convey the complexities of the situation:

The more poverty there is in a society, the more pressure there is on protecting a natural resource is more. It gets more and more difficult to protect natural resources if there are poverty levels increasing. One thing is, naturally, because when you are driven to a position where you don't have anything to survive, the only thing that is free is the natural resources that surround you. So in the village, or in a rural area where they are close to a natural resource, they would exploit that. That is one thing. The second thing is it becomes a good excuse. Sometimes if you are poor, and there is something you can exploit, if you do it, maybe it's wrong, it becomes a good excuse for the people who are doing it and the politicians who are saying "oh these people are poor, they don't' have any other option." Maybe they do have another option. Or they can be given another option, but it's an excuse they say, they are poor, they can't help it, so they are going to go hunting, or they say "We are poor, there is a forest here, [and] no one is using it, so we can use it." One is the actual need where you have to go, because if you don't have water, say in your village, you would probably go to some other water body, even if it's in a protected area, and you would divert that water towards your village, or toward your farm. The risk of an elephant come and destroying the land is more for the man who is poor, than for a man who could afford to lose part of it. So yes poverty has a significant impact on natural resources and conservation also. -Ruwan (Male NGO Staff)

There are no permanent income sources in this area. That is why they depend on the forests. -Gihan (Male Village Resident)

Hasitha made the point quite clearly:

I don't think I can talk about conservation without talking about a person who is starving, a person who is looking at their kids and thinking how are we going to- 
how can we feed these kids tomorrow. So for those people, it's very difficult to talk [about] conservation. - Hasitha (Male NGO Staff) 


\section{Chapter VI. Discussion}

Utilizing semi-structured in-depth interviews, this study explored the linkages between gender, poverty and use of resources in the buffer zones of protected areas. The examination of women's and men's roles in the household as they relate to the gendered division of labor, revealed that villagers have different environmental views, as well as how they conceptualize issues of environmental degradation, Human Elephant Conflict and projected economic development throughout the country.

The rural population located in the Buffer Zone of Nilgala Forest depended on forest resources out of economic necessity. They experienced strikingly limited mobility and poverty and depended on the forest for survival. Many of the members of the buffer zone community had little hope for their children to advance their socio-economic status. They hoped their children would seize the opportunity to relocate for better livelihood options, especially government jobs.

When people are in poverty, decision-making is limited, and the effects of even small adverse environmental changes can threaten survival rates and health outcomes. A decline in water quality, for example, can devastate the health of an entire community. Under impoverished conditions, there is a greater need for effective problem-solving strategies. Poverty-stricken residents are the most likely to kill elephants to protect their own access to forest resources. They are also the most likely to damage elephant habitat to increase their agricultural yields. The paradox of the situation is that poor residents are dependent on forest resources that are, in turn, dependent on elephants for survival. 
Elephants are integrated into the ecosystem as a keystone species, and forest health depends on them.

Additionally, my findings demonstrated that the very presence of elephants in the forest frightened invaders and encroachers away from entering and exploiting the forest. Thus, the shortsighted killing of elephants by impoverished residents to protect their immediate economic interests and physical safety may ultimately lead to their own demise.

\section{A. Gender \& the Environment}

The residents in the buffer zones of Sri Lankan PAs have gendered relationships to natural resource degradation. The gendered division of tasks in households in Bibile is correlated to role-specific relationships with the environment resources in the buffer zones. This labor division in which men engage in activities such as slash and burn farming while women focus on collection of forest products, fuel collection, cooking and caretaking, exposes women to greater hardship as they seek to fulfill their responsibilities in the face of increasing natural resource degradation.

From the evidence it is clear that the activities men engage in are in part because they require more physical exertion or because women's safety is a concern for farming activities that require overnight stays in the forest. Nonetheless as other research has shown, women do face greater consequences of environmental degradation because their responsibilities for meeting household caretaking needs are adversely affected when they cannot collect the products they rely on or must spend more time in the forest trying to gather them. 
The data from interviews indicate that there is general consensus that women demonstrate greater concern than men for forest protection and connect this concern to future welfare of their families as well as for the elephants. As with other situations in developing countries in which there is a need to protect natural resources even as poor residents need access to them, if women are allowed to influence decisions about how resources are used they can have a potentially significant role to play in environmentally sustainable resource management.

\section{B. Importance of Gender in Natural Resource Management}

Gender equality as well as the inclusion of rural women may be the next step in sustainable resource management to protect Sri Lankan forests and natural habitats. As my theoretical models suggested, women had a greater responsibility for family care giving and other domestic chores, such as providing food for the children and other members of the family. The data suggests that Braidotti's (1994) claim that women also have a specific responsibility for water and food gathering, along with waste disposal, is true in Sri Lanka as well. These roles disproportionately expose women to environmental hazards, thus making women intimately aware of their connection to the health and viability of the ecosystems around them

Given these findings, this research supports inclusion of women in decisionmaking processes related to natural resource management. If women are included in natural resource decision-making, they are likely to have a more responsive, balanced view about how the forests could be used. Effective access to decision making may also 
have ripple effects of ameliorating gender inequities and resource allocation in the household.

It is clear that men and women shared domestic and income earning roles in some ways, while they were stratified in other distinct ways. Men were responsible for farming activities outside of the home, while women functioned in supportive domestic roles, such as providing childcare, preparing of food, and performing other household chores such as shopping and management. While there is a strong promotion of the claim that similar viewpoints are shared between husband and wife, the answers provided do not appear to tell the entire story.

In later questions throughout the interview, when men's understanding of environmental conservation was compared to that of women, it became clear that men and women had different ways of executing forest management. All respondents claimed that men were the sole contributors to environmentally destructive behavior including tree cutting, forest burning and human encroachment.

\section{Uncovering Nuances}

The data also suggests that attitudes may not be stratified strictly by gender. Some men for example — particularly the leader of the Vedda community, the medicine man, and the individual permanently disabled by an elephant attack — had favorable views towards conservation, while many of the other men interviewed were more focused on livelihood development that could yield greater income sources. One woman, on the other hand, had a negative view toward elephant conservation. Her negative attitude 
stemmed from her husband's injury and her consequent new role as sole-income earner. These examples may be the exceptions. This is an ethnographic case study, however, making it difficult to draw generalizations regarding the overall attitudes of men and women from these in-depth interviews. It is universally clear, however, that men and women have distinct roles in the forest.

Environmental trainings and programs conducted by NGOs seemed to show that these types of interventions had major success in mitigating HEC the Bible-Nilgala area. This research found that villagers who have had NGO-sponsored trainings understand the connectivity between the wellbeing of the environment and themselves, as forest dependent residents. So far however, women tend to be the ones who largely attend these events. Finding ways to encourage men to attend these sessions may also enhance their understanding of these environmental health and human well being connections and thereby alter their behavior about natural resource use and management.

Although the research findings indicate that men and women have differential roles, and therefore have differential interactions, the original underlying assumptions about the effects of gender on perception were more complicated than was suggested by the literature. Many men shared supportive environmental attitudes with their female counterparts. A few males even had more favorable and aware environmental perspectives, especially those who attended environmental trainings. This research does demonstrate that successful natural resource management is key to the daily lives of impoverished rural farmers living in buffer zones of nationally protected forest areas. The gendered division of labor in the household significantly impacts the ways men and women utilize and manage natural resources from the forests and surrounding areas. 
Women, as primary domestic caretakers, with duties including cooking and childcare, spend less time focusing on increasing family income and more time on the health, future, and well-being of their children.

\section{Ecotourism \& Community Engagement}

All human societies are resource dependent, however certain impoverished communities rely directly on their local surrounding habitats for survival. There are many communities in Sri Lanka that can be classified in this way. These communities, while impoverished, may enjoy certain benefits as a result of their integrated interactions with nature. Some of these pleasures include: a slower pace associated with a life that regulates around an agricultural time frame. Most of the women, though they wish for better lives for their children, would prefer to stay in the villages, even if their children move to the town areas.

Locally managed and executed ecotourism might provide the rural farmer with an additional source of income. Rural farmers that reside in the buffer zones of protected areas may then potentially discontinue destructive forest interactions by moving away from agricultural profit gains as their only source of income.

It would be unfair to conclude that rural farmers alone are responsible for elephant habitat encroachment. Any governmentally subsidized farming, which would encourage forest degradation and the killing of elephants to protect low yield crops and below standard-of-living wages, would instead move toward profitable habitat preservation, by way of foreign monetary contributions. Ecotourism has high potential in 
the Bibile area. Individuals living near Nilgala forest are very open to a participatory approach involving the development of this industry.

Sri Lanka is in need of coherent strategies to prevent environmental degradation. Rural communities in Sri Lanka are deeply integrated into the day-to-day life of wild elephants. While some villages interact peacefully, it is more common for conflicts to occur between humans and elephants, over the very limited and valuable resources. This human-wildlife conflict is not un-common throughout the world, especially in countries with communities that are natural resource/forest dependent directly.

Ecotourism may be a potential solution to HEC. The Bibile community expressed whole-hearted support for community-centered ecotourist development in Nilgala Forest. Because impoverished buffer-zone residents are in desperate need of permanent income sources, ecotourism has the potential to simultaneously reduce poverty and encourage less destructive habitat uses by forest-dependent families. Village residents, women in particular, were open to alternative livelihood and environmental trainings. In fact they requested additional educational opportunities, citing them as one of the primary needs of village residents. Vedda household members were in support of utilizing their time to share the forest's ecological beauty with visitors, if done with environmental principles and forest-protection.

Combining solutions to the need for (1) household income with the need for (2) habitat and resource conservation, in an integrated and locally relevant ecotourist approach, has the potential to simultaneously (1) reduce poverty levels and (2) reduce environmental hazards including HEC. Poor environmental quality and HEC damage the health and well-being of village households. Ecotourism has the potential to save 
elephant populations and preserve their habitats, while providing viable income sources to villagers. Ecotourism creates a two-fold approach HEC reduction. Elephants are a major attraction for ecotourists, thus incentivizing co-habitation. Also, the alternative income source that would be provided by ecotourism would relieve poverty, freeing residents from exploiting forests to meet basic subsistence needs. Less pressure on forest resources reduces the need for elephants to invade properties looking for food, mitigating HEC. 


\section{Chapter VII. Conclusions}

\section{A. Does Gender Matter? ...A Complicated Story}

The most significant socio-environmental issues in the buffer zone include intentional forest fires, tree cutting by non-residents, unstable income sources, and lack of water. The findings of this case study of Bibile-Nilgala support the postulation that women's participation in natural resource management in the buffer zones with high rates of poverty may be significant in influencing elephant conservation and Human-Elephant Conflict mitigation. This study exposes the complications of the relationships of household members to income earning and gender roles and attitudes to environmental conservation.

The perspectives of female head-of-households reveal the nuances of how decision-making positions and financial responsibilities affect attitudes. Both gender and household position impact conservation attitudes and the options for HEC mitigation strategies. Further complicating the matter is the unique co-habiting situation of the indigenous community living within the forest boundaries. Hunting and gathering family units, such as the Veddas, co-exist with little conflict with elephant populations, while farming households conflict and compete with elephants for land and plant resources, regardless of favorable attitudes toward elephant conservation.

Women have the potential to function in a pivotal and specific role in natural resource management and protection in the context of governance and poverty reduction. While men at-large, were said to be the sole exploiters of natural resources as well as the major decision-makers within households, many male residents shared positive attitudes 
with their wives toward habitat conservation. Women in buffer zones have higher rates of attendance at NGO-provided environmental awareness workshops. Female respondents also universally requested training for alternative ways to earn livelihoods, compared to men who did not. Many men reported not attending environmental trainings due to the "lack of free-time" and their farming duties demands.

The male leader of the indigenous group had the least amount of formal education and yet showed the strongest passion for achieving conservation goals. His role further complicates the findings regarding notions of gender and the role of gender in conservation. In some ways the Veddas as a group, share a value structure with many ecofeminists.

I conclude that due to the unique relationship of women to the environment, specifically to the natural resources in protected forest habitats, their responsibilities in the household and their specific knowledge of the environment they should be allowed greater influence in household decision making processes and community organizing. In addition, the practices of the Veddas and co-existence with elephants should be emulated in order to reduce HEC.

If patriarchal structures remain intact and exist within an unchecked system of capitalist exploitation, it is likely that experiential differences between men and women and Vedda and non-indigenous groups will continue. However, with better understanding of the impact of gender roles and attitudes, it is likely that women may, over time, be included in decision making in ways that reduce HEC and improve the quality of resident life in the buffer zones. Though there is not an 'essential' characteristic of being female which would lead women to have these traits, women's gender specific needs and 
opinions need to be taken into account by development agencies to achieve long-term sustainability.

\section{B. To intervene or not to intervene}

Men and women view ecological management differently due to their historical roles in the social structures in which they live (Martino 2008). The facts of their divided roles and thus differing relationship to natural resources place men and women in different realms of responsibility. This gives them different perspectives and attitudes of environmentalism.

On the national and international levels, this research is relevant to government agencies interested in exploring how gendered policies affect local conservation, economic, and development dynamics. Incorporating women in environmental decisionmaking potential for ripple effects of ameliorating gender inequities in the household as well as potential for increasing the climate of conflict-resolution and grassroots organizing.

Moving forward, how does the social sustainability model offer us a useful framework when discussing gender and Human Elephant Conflict? The framework maintains that economic, environmental, and social processes and institutions are important to achieve human well-being and effective environmental caretaking. Societies look to social institutions to tell them how to balance these needs for the best social, environmental and economic outcomes. The social sustainability framework is about taking care of people, especially those in poverty. 
When people are cared for, especially those dependent directly on natural resources for survival, they are more likely to take care of the environment. Subsequently, taking care of the basic needs of people in the buffer zones of protected areas will, in turn, potentially preserve forest resources and the elephants that are dependent upon them. This project, as it incorporates and focuses in on the element of gender, theorizes that failing to care for people within economic, environmental, and social institutions jeopardizes any attempt to conserve natural resources and mitigate HEC. This includes both the way we think about gender, as well as the way we have constructed gender roles. Gender then becomes a key social institution that can be incorporated in strategies to improve that relationship with nature and to alleviate poverty.

This project incorporates a layered approach for taking care of people and taking care of the environment. This project sought to expand the social sustainability theoretical framework by positing that the social institutions that define gender and gender roles, especially in locations with poverty, are a key leverage point for improving these institutions. Though there is not an 'essential' characteristic of being female which would lead them to have these traits, women's gender specific needs and opinions should be taken into account by development agencies.

Future natural resource management requires attention to gender-specific needs of women in order to successfully meet national conservation goals. Involvement in decision-making and the inclusion of women in environmental education trainings benefit all parties involved. Major stakeholders include the Wildlife and Forest Department government officials, residents in buffer zones of protected areas, Sri Lankan wildlife, national and global environmentalists, and future generations. Recommendations for 
better natural resource governance involve increased environmental awareness trainings (conducted by local environmental NGOs) for both women and men including both alternative livelihoods and environmental conservation awareness as tools for mitigating the effects of poverty and forest resource dependency.

\section{Future Research on Gender and HEC}

In addition to Sri Lanka, multiple case studies across developing countries address environmental impacts in rural farming villages, some include areas similar to Sri Lanka's designated forest buffer zones. Some address a gendered aspect of use and management, including perceptions that are specific to men and women. The transferability of findings in these case studies can be compared through a qualitative investigation of the specific occurrences in Sri Lanka. It may prove to be particularly illuminating to compare villages. A comparison of villages located along the same forest may reveal where successful strategies exist and where and which other strategies have been less successful. Some villages may be experiencing more intra-species violence while others may have developed effective co-habitation strategies.

In addition, the potential transferability of my findings requires more in-depth exploration and place-specific analysis of conditions, including the ways in which women across the global south view the meaning of their particular actions relating to environmental conservation and natural resource management. Because there is some contention surrounding the issue of gender and rural natural resource management, additional empirical studies should be done and participatory action research may be best suited to investigate the issues. 
This leads to questions of future research in Sri Lanka. One relevant research question the findings of this project lead us to ask is: Given the significant presence of NGOs in the buffer zones, how might the programs they implement affect changes in the household division of labor and allow for a shift in the gendered distribution of power in villages to improve environmental and socio-economic outcomes in impoverished areas? 


\section{References}

Agarwal, Bina. 1992. "The Gender and Environment Debate: Lessons from India." Feminist Studies 18: 119-158.

Alaimo, Stacy. 2008. Ecofeminism without Nature? Questioning the Relation Between Feminism and Environmentalism. International Feminist Journal of Politics. 10:3 299-304.

Braidotti, Rosi, Ewa Charkiewicz, Sabine Hausler, and Saskia Wieringa. 1994. Women, the Environment and Sustainable Development: Towards a Theoretical Synthesis. London: INSTRAW.

Bandara, Ranjith. 2009. "The Practice of Ecotourism in Sri Lanka: An Assessment of Operator Compliance towards International Ecotourism Guidelines." South Asia Economic Journal. 10: 471-492.

Bandarage, Asoka. 1998. "Women and Social Change in Sri Lanka: Towards a Feminist Theoretical Framework". Centre for Women's Research (CENWOR). Colombo, Sri Lanka.

Beehner, Lionel et al. 2010. "The 31 Places to Go in 2010." Online Article. Travel. The New York Times. January 2010. (http://www.nytimes.com/2010/01/10/travel/ 10places.html?pagewanted=all\&_r=1\&).

Brechin \& Kempton. 2003. "Global Environmentalism: A Challenge to the Postmaterialism Thesis?" Pp. 326-343 in Environment, Energy, and Society: Exemplary works. Edited by C. Humphrey, T. Lewis and F. Buttel. CA: Wadsworth/Thomson Learning.

Campbell, Lisa. 1999. "Ecotourism in Rural Developing Communities." Annals of Tourism Research. 26: 534-553.

Charmaz, Kathy. 2006. Constructing Grounded Theory: A Practical Guide Through Qualitative Analysis. Sage Publications. Thousand Oaks, CA.

Colombo Telegraph. 2012. "The NY Times has dropped Sri Lanka from the best destinations list." January 2012.

(https://www.colombotelegraph.com/index.php/the-ny-times-has-dropped-srilanka-from-the-best-destinations-list/).

Davis, Coralynn. 1997. "The Politics of Purchasing Power: Feminist Tourism and Women's Development in Nepal.” Michigan Feminist Studies Journal. 12: 26-43

Dillard, J., V. Dujon, and M. King. 2009. Understanding the Social Dimension of 
Sustainability. Routledge/Taylor \& Francis Group.

Duffy, Rosaleen and Lorraine Moore. 2010. "Neoliberal sustainable development? Tourism and the neoliberalisation of nature in Thailand." Development Politics 3: International Actors and Agreements, Political Studies Association Conference, Edinburgh, 29 March-1 April.

Duffy, R. and Moore, L. 2010. "Neoliberalising Nature? Elephant-Back Tourism in Thailand and Botswana." Antipode, 42: 742-766.

FAO, Food and Agriculture Organization (FAO) of the United Nations. Generalized Map of Sri Lanka. "Sri Lankan Women and Men as Managers of Bioresources." Regional Office for Asia and Pacific. Bangkok, Thailand. Retrieved May 7, 2015 (http://www.fao.org/docrep/005/ac791e/AC791E01.htm).

Farmar-Bowers, Quentin \& Ruth Lane. 2009. “Understanding farmers' strategic decisionmaking processes and the implications for biodiversity conservation policy" Journal of Environmental Management. 90: 1135-1144.

Fernando, Prithiviraj et al. 2004."Perceptions and patterns of human-elephant conflict in old and new settlements in Sri Lanka: insights for mitigation and management." Biodiversity and Conservation. 14:2465-2481.

Friends of the Earth Sri Lanka/ Centre for Environmental Justice. 2014. "Sri Lanka: Demand stronger environmental protection for ancient Nilgala forest" Friends of the Earth International. February $4^{\text {th }}, 2014$. Retrieved November 4, 2014 (http://www.foei.org/news/put-pressure-on-sri-lankan-authorities-to-strengthenenvironmental-protection-for-the-ancient-nilgala-forest/).

Gender Across Borders: A Global Voice for Gender Justice. Online Website: "Ecofeminism: Is the Movement Still Relevant?" MARCH 22, 2012 3:00 PM. Retrieved February 17, 2015 (http://www.genderacrossborders.com/2012/03/22/ecofeminism-is-themovement-still-relevant/).

Garcia, Veronica Vazquez. 2001. "Taking Gender into Account: Women and Sustainable Development Projects in Rural Mexico.” Women's Studies Quarterly. 29: 85-98.

Gezon, Lisa. 2002. "Marriage, Kin, and Compensation: A Socio-Political Ecology of Gender in Ankarana, Madagascar.” Anthropological Quarterly. 75: 675-706.

Gerung, Dan \& Klaus Zeeland. 2008. “Ecotourism in Bhutan: Extending its Benefits to Rural Communities" Annals of Tourism Research. 35: 489-508.

Green Belt Movement, The. Official NGO Website. Online. March 16, 2010. Retrieved 
January 2014 (http://gbmna.org/w.php?id=30).

Griffin, Katy and Achala Navaratne. 2005. "Encroaching on the Land of the Elephants." Biosphere 21(3):1-5.

Harding, Sandra. 1998. "Gender, Development, and Post-Enlightenment Philosophies of Science" Hypatia 12: 146-167.

Honey, Martha. 2008. "Ecotourism and Sustainable Development, Second Edition: Who Owns Paradise?" Second Edition. Island Press.

Honey, Martha and Abigail Rome. 2001. "Protecting Paradise: Certification Programs for Sustainable Tourism and Ecotourism." Ecotourism and Sustainable Development Project. Institute for Policy Studies. October 2001.

Hoskins, Janet. 2002.Predatory Voyeurs: Tourists and 'Tribal Violence' in remote Indonesia. American Ethnologist 29(4): 797-828.

Humphrey, Craig R. Tammy L. Lewis, and Frederick H. Buttel. 2002. Environment, Energy, and Society: A New Synthesis. Belmont, CA: Wadsworth Group.

Humphrey et al. 2002. Environment, Energy, and Society: A New Synthesis. Belmont, CA: Wadsworth Group.

IUCN, International Union for Conservation of Nature. 2015. "About IUCN". Headquarters: Switzerland. Sri Lanka Country Office: Colombo 07, Sri Lanka. Retrieved: January 2015 (IUCN.org).

Jain, Devaki. 1990. "Development Theory and Practice: Insights Emerging from Women's Experience.” Economic and Political Weekly 25: 1454-1455.

Jain, Shobita. 1984. "Standing up for trees: Women's role in the Chipko Movement." Unasylva. No. 146. Women in Forestry. An International Journal of Forestry and Forest Industries. Vol. 36. Retrieved: February 10, 2015 (http://www.fao.org/docrep/r0465E/r0465e03.htm).

Janssen, R, Brouwer R, Haider W, Gunaratne LHP, Beardmore B, Ayoni N, Premarathne P, Nan L. 2006. "Human-elephant conflict and rural poverty in Sri Lanka.” Poverty Reduction and Environmental Management: Policy Brief No.11. June 2006.

Jayaneththi, Salila. 2000. "Role of Women in Sustainable Utilization of Forest Resources in the Dry Zone of Sri Lanka; Case Study: Kahatagasdigiliya Divisional Secretariat Division, Anuradhapura District.” Pp 88-101. Gender, Ideology and 
Development in Sri Lanka. Centre for Women's Research (CENWOR). Colombo 05, Sri Lanka.

Jayasuriya, Dinuk S. \& Gibson, John. 2013. "Elephants, tigers and safety in post-conflict Sri Lanka." Development Policy Center. Australian National University. February 2013 (http://devpolicy.anu.edu.au/pdf/papers/DP-27-Elephants-tigers-and-safetyin-post--conflict-Sri-Lanka.pdf).

Jayewardene, Jayantha. 1994. The Elephant in Sri Lanka. Colombo, Sri Lanka.

Jayewardene, Jayantha \& Charles Santiapillai. 1998. Sri Lanka Nature: 1998 Elephant Symposium Special. 1 (4). October 1998.

Katugaha, H.I.E. et al. 1999. "A long-term study on the dynamics of elephant (Elephas maximus) population in Ruhuna National Park, Sri Lanka. Biological Conservation. 89: 51-59.

Lele, Sharachchandra et al. 2010."Beyond exclusion: alternative approaches to biodiversity conservation in the developing tropics." Current Opinion in Environmental Sustainability. 2: 1-7.

Lindström, Sara, Eskil Mattsson, \& S.P. Nissanka. 2012. "Forest cover change in Sri Lanka: The role of small scale farmers." Applied Geography. Elsvier. Peradeniya, Sri Lanka.

Living Heritage Trust. 2015. Sri Lanka's Vedda forest dwelling people "Who are Sri Lanka's Indigenous Wanniya-laeto?” Retrieved March 3, 2015 (http://vedda.org/1-who.htm).

Marshall, Catherine \& Gretchen B. Rossman. 2006. 4th edition. Designing Qualitative Research. Thousands Oaks: Sage Publications. London.

Martino, Diego. 2008. "Gender and Urban Perceptions of Nature and Protected Areas in Banados del Este Biosphere Reserve.” Environmental Management. 41: 654-662.

Mathur, Dr. Deepa. 2001. Women in Transition in South Asia. Mayur Vihar, Delhi: Kalinga Publications.

Mcdermott, M.H. \& K. Schreckenberg. 2009."Equity in community forestry: insights from North and South" International Forestry Review. 11:157-170

McMichael, Philip. 2004. Development and Social Change. Thousand Oaks, CA: Sage Publications, Inc.

Merton, Lisa, Alan Dater, Jim Klein, Mary Lampson, Tom Haneke, and Samite. 2008. 
"Taking Root The Vision of Wangari Maathai" [video recording] Harriman, NY: New Day Films.

Mies, Maria \& Vandana Shiva. 1993. Ecofeminism. Fernwood Publications. Zed Books. New York, NY.

Munasinghe, Mohan. 1993. "Environmental Economics and Biodiversity Management in Developing Countries. Ambio. 22: 126-135.

Naples, Nancy A \& Desai, Manisha. 2002. Women's Activism and Globalization: Linking Local Struggles and Transnational Politics. New York, NY. Routledge.

Narayan, Uma. 1997. Dislocating Cultures: Identities, Traditions and Third World Feminism. New York, NY. Routledge.

Ogra, Monica. 2009. “Attitudes Toward Resolution of Human-Wildlife Conflict Among Forest-Dependent Agriculturalists Near Rajaji National Park, India.” Human Ecology 37: 161-177.

Quisumbing, Agnes. 2003. Household Decisions, Gender and Development: A Synthesis of Recent Research. Washington, D.C.: International Food Policy Research Institute.

Ragin, Charles C. 1994. Constructing Social Research. Thousand Oaks, CA: Pine Forge Press.

Rao, Nitya and Kumar Rana. 1997. "Land Rights and Women: Case of Santhals." Economic and Political Weekly 32 (23): 1307-1309

Rao et al. 2003. “Local Peoples' Knowledge, Aptitude and Perceptions of Planning and Management Issues in Nanda Devi Biosphere Reserve, India.” Environmental Management. 31:168-181.

Ray, Raka and Mary Fainsod Katzenstein. 2005. Social Movements in India: Poverty, Power and Politics. Rowman \& Littlefield Publishers, Inc. Oxford, UK.

Reisinger, Yvette \& Carol Steiner. 2006."Reconceptualising Interpretation: The Role of Tour

Guides in Authentic Tourism." Current Issues in Tourism. 9: 481-498.

Schellhorn, Matthias. 2010. "Development for whom? Social justice and the business of ecotourism” Journal of Sustainable Tourism. 18: 115-135.

Sen, Amartya. 1999. Development as Freedom. Anchor Books. Random House, Inc. New York, NY. 
Seneviratne, Lalith and Greg Rossel. (2004) Lighting up a village: Community RE generating systems for the developing world". Refocus, 5(1): 26-28

Sharma, Kumud. 1994. "Gender, Environment and Structural Adjustment." Economic and Political Weekly 29: WS5-WS11.

Shiva, Vandana. 1991. Ecology and the Politics of Survival: Conflicts Over Natural Resources in India United Nations University Press. Sage Publications.

Shiner, Larry. 1994. "Primitive Fakes," "Tourist Art" and the Ideology of Authenticity. Journal of Aesthetics and Art Criticism 52(2):225-234.

Somasekaram, T. et al. 1997. Arjuna's Atlas of Sri Lanka. Arjuna Consulting Co Ltd, Dehiwala, Sri Lanka.

Trip, Aili Mari. 2006. Global Feminism: Transnational Women's Activism Organizing and Human Rights. "Challenges to Transnational Feminist Mobilization," NY, NYUP.

Vitarana, Kamini Meedeniya. 2000. Environmental Assessment Studies: A Gender Perspective. Colombo, Sri Lanka: Centre for Women's Research

Vitarana, Kamini Meedeniya. 2000. "Women and Environmental Issues". Women in Focus. 13:20-35

Volkman, Toby Alice. 1990. Visions and revisions: Toraja culture and the tourist gaze. American Ethnologist. 17(1): 91-110.

Warren, Karen J. 2000. Ecofeminist Philosophy: A Western Perspective on What it is and Why it Matters. Lanham, Maryland. Rowman \& Littlefield Publishers, Inc.

Weber, Thomas. 1988. Hugging the Trees: The Story of the Chipko Movement. 1988. New York, NY. Viking.

Wickramasinghe, Maithree. 2000. "Gender and Development- A Conceptual Paper.” Pp 1 6-54. Gender, Ideology and Development in Sri Lanka. Centre for Women's Research (CENWOR), Colombo, Sri Lanka.

World Wildlife Fund (WWF). 2015. “Asian Elephant: Sri Lankan Elephant.” WWF. Retrieved January 13, 2015 (http://www.worldwildlife.org/species/sri-lankanelephant).

World Wildlife Fund (WWF Global). 2015. "Sri Lankan elephant” WWF Global. Retrieved May 31, 15 (http://wwf.panda.org/what_we_do/endangered_species/ 
elephants/asian_elephants/sri_lankan_elephant/ 


\section{Appendices}

Appendix A. Obtaining Consent

\section{Oral consent protocol}

"I need to tell you a bit about my research and confirm that you are willing to speak with me today. Please listen carefully for just a few moments.

My name is Katy Griffin, and I am a graduate student in the Sociology Department at Portland State University. I am currently doing an academic study regarding natural resource use in Sri Lanka. [I will then explain the topic of each interview as appropriate to the interview subject.] [For village families:] I would like to ask you how families in this village think about natural resource use. [For NGO staff and volunteers:] I would like to ask you how you analyze problems resulting from increased Human Elephant Conflict in rural villages as it relates to the gendered use of natural resources. [For Department of Wildlife officials:] I would like to ask you about your policies regarding Human Elephant Conflict and rural communities residing in buffer zones of governmentally protected areas.

If you agree to be interviewed, I will ask to speak with you for about an hour on this topic at a location and a time that is convenient for you. I do not foresee any risks or harmful effects befalling you due to this interview. You may not receive any direct benefit from taking part in this study, but the study may help to increase knowledge that may help others in the future.

Any information that is obtained in connection with this study and that can be linked to you or identify you will be kept confidential. In all my publications, I change both the village name and the names of individuals to disguise identity and preserve confidentiality. No one other than myself will have access to this information. My research notebooks are stored in a locked filing cabinet in a locked office at the university where I work, and my computerized notes are stored on a password protected computer, so several safety precautions are in place.

You are under no obligation to speak with me if you do not choose to do so. If you refuse to talk with me, it will not in any way affect your relationship with me. If you do choose to continue with this interview, you are of course free to answer only the questions that you feel comfortable answering. If you do not want to answer a question, please let me know, and we will move on to another topic of discussion.

Do you have any questions?

If you have any questions during our interview, please let me know. If you have questions after our interview is finished, feel free to come talk with me at my local address. [For village interviews:] Please consult the local government administrator, the local monk, or the police if you have any concerns about this research.

If you understand this information and agree to go forward with this interview, please say 'yes' now." 
Appendix B. Environmental Impact Assessment of Rural Villagers based on Gender

Daily Log Sheet

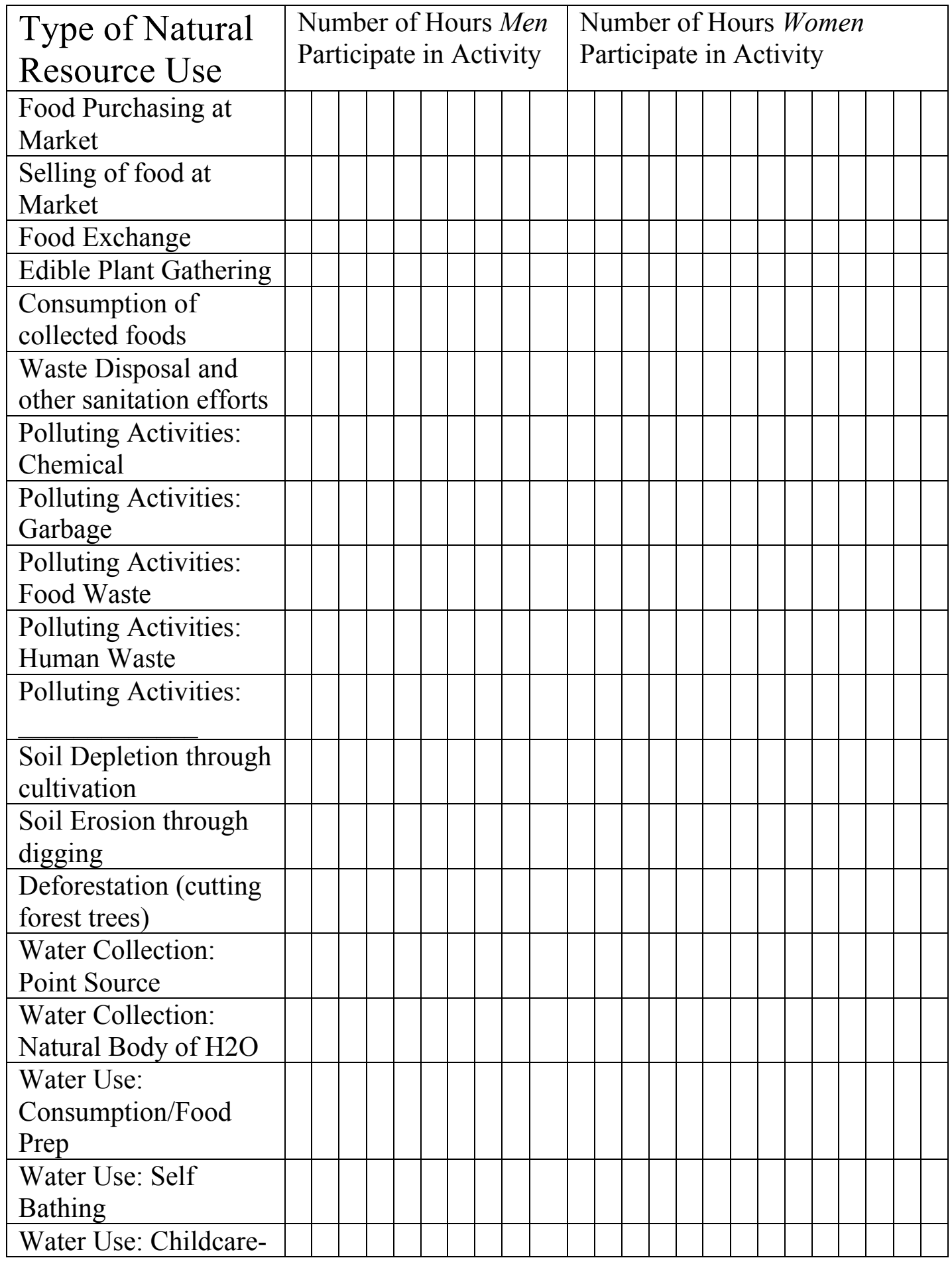




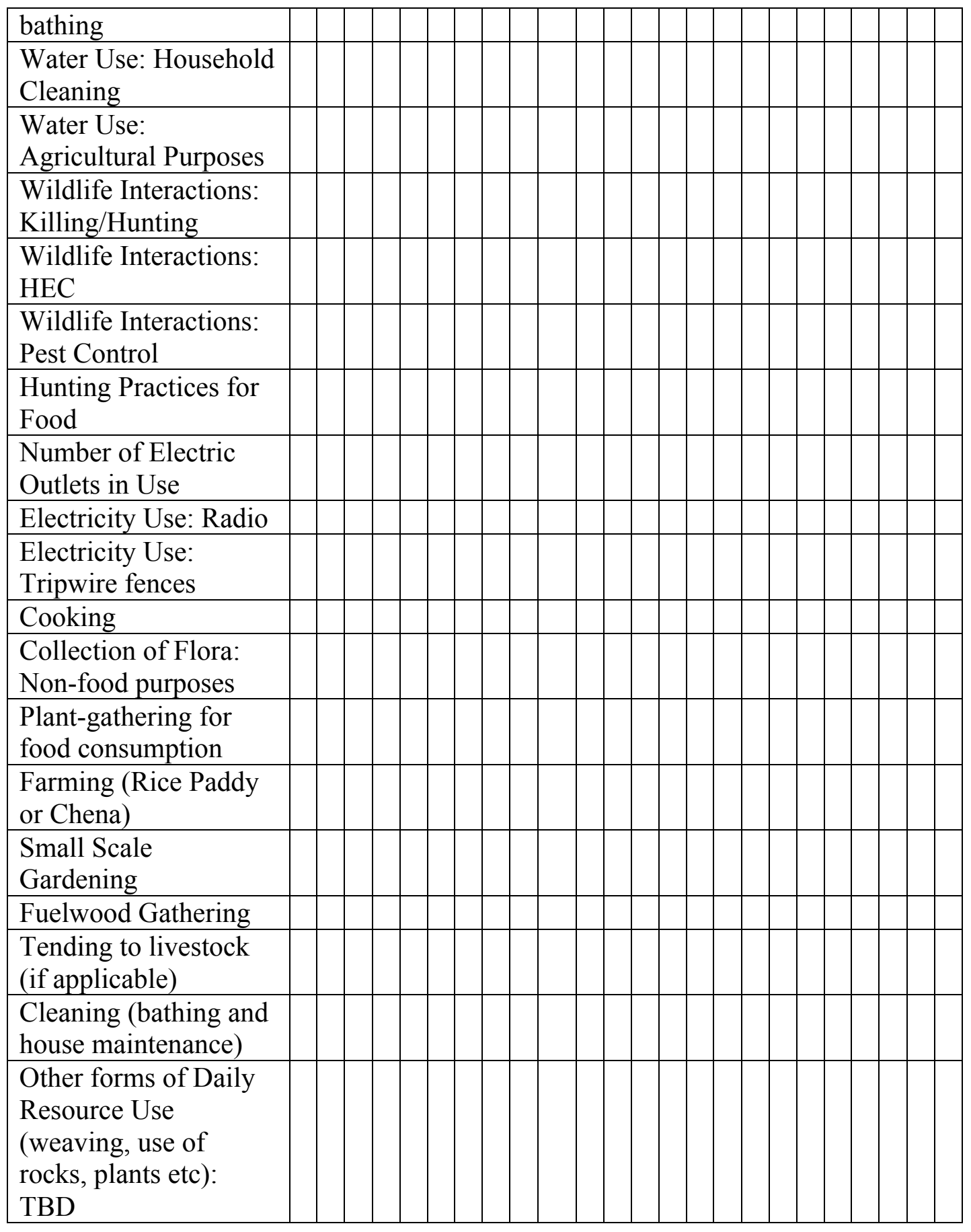


Appendix C. Interview Guide for NGO staff/ volunteers

This interview template serves only as a guide. The technique of guided conversations will be used to prevent imposing the researcher's views on the situation of gender and the environment and how that relates to migrating strategies regarding Human Elephant conflict. Open-ended questions will be utilized to prevent disrupting the openness of the topics discussed. The researcher seeks to understand if there are any current trends in NGO thinking that would support a gendered analysis of Human Elephant Conflict (HEC).

First phase of the interview (these questions situate the interviewee as a representative within the context of their organization)

1) Tell me about your organization.

a. ... in the context of gender roles?

b. ... in the context of wildlife conservation?

c. Probe: What is your mission statement?

2) How does your organization deal with issues of gendered division of labor in the household as they interact with natural resource management?

a. Does gender play a role in Human Elephant Conflict?

b. If so, what role?

c. Can mitigating strategies using gendered differences in natural resource management be utilized?

3) Please describe your organization's views on Human Elephant Conflict.

a. Major causes

b. Mitigating strategies

c. Importance of conservation

d. How well is the government handling HEC?

e. How are NGOs contributing to elephant conservation efforts?

4) Please describe your organization's views on Gender and the Environment.

a. How does gendered division of labor in the rural household relate to:

i. Water

ii. Farming

iii. Food

iv. Wildlife

v. Pollution

vi. Other

5) How do women use natural resources in rural farming villages? 
a. What are the greatest concerns for women in villages regarding natural resource use and management?

6) How do men use natural resources in rural farming villages?

a. What are the greatest concerns for men in villages regarding natural resource use and management?

7) How does your organization perceive local movements to aid in poverty reduction in rural Sri Lankan villages?

Second phase of the interview (these questions ask the interviewee for their personal views on the matter and will be oriented by gender and the context of their role within the organizations they represent)

1) How do you feel the government is handling the situation of Human Elephant Conflict?

a. Are there steps that would improve policy-makers decisions?

b. Are there legislative strategies that would improve policies themselves?

2) What solutions do you personally feel are necessary in Human Elephant Conflict?

a. Probe: Does Ecotourism play a role?

i. How can local communities be included in the development of the ecotourism industry?

ii. How can women be included in the development of the ecotourism industry?

iii. What factors have prevented ecotourism for becoming a significant conservation strategy in the past?

3) Do gender roles impact environmental outcomes?

a. Why or why not?

b. Would a change in the division of labor in the household change environmental outcomes?

4) Do men and women feel differently about environmental conservation? 
Appendix D. Environmental Impact Assessment of Rural Villagers based on Gender

\section{Weekly Log Sheet}

\begin{tabular}{|c|c|c|c|c|c|c|c|c|c|c|c|c|c|c|c|c|c|}
\hline \multirow{2}{*}{$\begin{array}{l}\text { Activity } \\
\text { Interviewee \# }\end{array}$} & \multicolumn{17}{|c|}{$\begin{array}{l}\text { \# Hours Self and Spouse Participate in Activity ( ) per week } \\
(*) \text { per month (@) per day }\end{array}$} \\
\hline & 1 & & 2 & & 3 & & 4 & & 5 & & 6 & & 7 & & 8 & & etc.. \\
\hline Household \# & A & & A & & B & & B & & C & & C & & $\mathrm{D}$ & & $\mathrm{D}$ & & E \\
\hline Gender & $\mathrm{M}$ & F & $\mathrm{M}$ & $\mathrm{F}$ & $\mathrm{M}$ & F & $\mathrm{M}$ & F & $\mathrm{M}$ & $\mathrm{F}$ & $\mathrm{M}$ & $\mathrm{F}$ & $\mathrm{M}$ & $\mathrm{F}$ & $\mathrm{M}$ & & M \\
\hline \multicolumn{18}{|l|}{ Market (total) } \\
\hline \multicolumn{18}{|l|}{ Buy } \\
\hline \multicolumn{18}{|l|}{ Sell } \\
\hline \multicolumn{18}{|l|}{ Forest (total) } \\
\hline \multicolumn{18}{|l|}{ Fuel Col. } \\
\hline \multicolumn{18}{|l|}{ Food Col. } \\
\hline \multicolumn{18}{|l|}{ Med Col. } \\
\hline \multicolumn{18}{|l|}{ Timber } \\
\hline \multicolumn{18}{|l|}{ Hunting } \\
\hline \multicolumn{18}{|l|}{ Other: } \\
\hline \multicolumn{18}{|l|}{ Water } \\
\hline \multicolumn{18}{|l|}{ Well Col. } \\
\hline \multicolumn{18}{|l|}{ River Col. } \\
\hline \multicolumn{18}{|l|}{ Town Activities } \\
\hline \multicolumn{18}{|l|}{ Farming } \\
\hline \multicolumn{18}{|l|}{ Chena } \\
\hline \multicolumn{18}{|l|}{ Paddy } \\
\hline \multicolumn{18}{|l|}{ Anim. Husb. } \\
\hline \multirow{2}{*}{\multicolumn{18}{|c|}{ Home Gardens }} \\
\hline \multicolumn{8}{|l|}{ Domestic } & & & & & & & & & & \\
\hline \multicolumn{18}{|l|}{ Cleaning } \\
\hline \multicolumn{18}{|l|}{ Childcare } \\
\hline Cooking & & & & & & & & & & & & & & & & & \\
\hline Electricity Use & & & & & & & & & & & & & & & & & \\
\hline Temple & & & & & & & & & & & & & & & & & \\
\hline Relatives/Friends & & & & & & & & & & & & & & & & & \\
\hline Weaving/Sewing & & & & & & & & & & & & & & & & & \\
\hline Other: & & & & & & & & & & & & & & & & & \\
\hline
\end{tabular}


Appendix E. Interview Guide for Village Residents

Part 1. Participant's role within household and gendered division of labor:

1- Tell me about your family. (Description of family structure)

a. Who lives in your household and what is their relationship to you?

i. Do you have any children?

ii. Are you married?

2- Please describe what you do at home on a normal/typical day?

3- Tell me about the way work is distributed in your home. (Description of Division of Labor)

a. What are the jobs in your household?

b. How are these jobs distributed?

c. Who is in charge of family chores/jobs?

d. Who generates the external income? (This may be a sensitive question.)

4- Please describe your role in the village? (Description of Village Role)

a. What jobs do you do?

b. Please describe your spouse's role in the household?

\section{Part 2a. Participant's direct relationship to Natural Resources:}

5- How do you interact with natural resources on a day-to-day basis in terms of collection, production, use and marketing?

[See Appendix 1. DAILY LOG SHEET]
a. Water?
i. Irrigation methods
b. Forest Products?
c. Flora?
d. Fauna?

6- How is the forest used in this area?

a. Recourse Collection?

i. Collection of Forest Products throughout the year [See Appendix 2. Forest Collection Table] 

b. Medicinal Plants?
c. Fuel/Energy?
d. Wildlife/Hunting?
e. Food/Cooking?

7- Can you tell me about forest fires in this area?
a. How often (and for how long) do they occur?
b. What are the causes? (Intentional and/or unintentional)
c. What are the effects of forest fires on the forest/village?
d. What motivates intentional forest fires?
i. How do forest fires assist residents?
ii. How do they harm them?
e. What are your views on these forest fires?

i. Are they more often beneficial or harmful and to whom/what?

Part 2b. Participant's description of gendered differences of natural resource use:

8- How do men use natural resources?
a. In your home?
b. In the village?
c. Collection:
d. Use:
e. Disposal:

9- How do women use natural resources?
a. In your home?
b. In the village?
c. Collection:
d. Use:
e. Disposal:

Part 3. Participant's experiences with Human Elephant Conflict:

10- Describe your relationship to elephants:

11- Does your family experience Human Elephant Conflict?

a. If so, what forms?

b. What are mitigating strategies that you (or others in your area) have used to manage elephant conflicts?

i. Barriers: Electric Fences, Ditches, Agro-fences, other fencing?

ii. Trip wires devices or other alarm system?

iii. Community Approach?

iv. Deterrents: Bees, Ultrasound Devices, and/or Chili Peppers?

v. Elephant Drives? Relocation? Culling? 
c. How often do you worry about HEC affecting your livelihood?

d. What do you think should happen to the elephants? Why?

e. How should this solution be implemented? Who should be in charge of managing HEC? Why?

Part 4. Participant's relationship to the socio-economic situation of the village:

12- What are your goals for yourself and your family?

13- Do you expect your children to stay in the village as adults?

a. Why or why not?

14- What do you hope for your children in their future?

a. Sons?

b. Daughters?

15- What do you see/understand as the role of the government in natural resource management?

16- What is the role of NGOs (such as IUCN and the Environmental Foundation) in Natural resource management?

17- Describe any environmental aid (resources or information based) that has been provided to you by outside sources?

a. What effect has this had on your family? Livelihood? Village?

Part 5. Participant's understanding of environmentalism [at-large] and local natural resource conservation:

18- How often do you worry about:

a. Natural resource scarcity?

b. Erosion?

c. Degradation?

d. Habitat encroachment?

e. Pollution?

i. Water

ii. Air

iii. Land

f. Species Extinction?

19- How does the condition and health of the environment around you affect your life every day?
a. Water?
b. Food?
c. Wildlife?
d. Energy?
e. Building materials?

20- How important is natural resource conservation:

(On a scale of 1-5: 5=extremely important, 4= very important 3=neutral, $2=$ somewhat important, $1=$ not important, $0=$ no answer/no opinion) 

a. to you?
b. your family?
c. your livelihood?
d. the village?
e. the forest/protected area?
f. Elephants?
g. Other wildlife species?
h. The country of Sri Lanka?
i. Other countries outside of Sri Lanka?
j. globally?

21- Please describe the role of elephants in Sri Lanka?

22- Describe the importance of clean air, water, and land to you? Family? Village?

23- What kinds of environmental hazards are most worrisome to you/your family?

24- Do you and your spouse share ideas on the importance of natural resource preservation?

a. How do you perceive your values as similar?

b. How do you perceive your values as different?

\section{Part 6. Participant's Understanding of Gendered Perceptions and Differences:}

25- How do you believe your gender (i.e. Being a man or woman in the village) plays a role in your understanding of how men and women use and view natural resources differently or similarly?

26- Have there been any movements in the village to change the way natural resources have been utilized and/or mongered?

a. Who was in charge of these movements?

b. What were the processes involved and the results?

\section{Part 7. Other}

27- Is there anything that you would like to share with me or talk to me about?

28- What have I not included in this interview that you would like me to include and ask in future interviews? 


\section{Appendix F. Map of Primary Research Site}

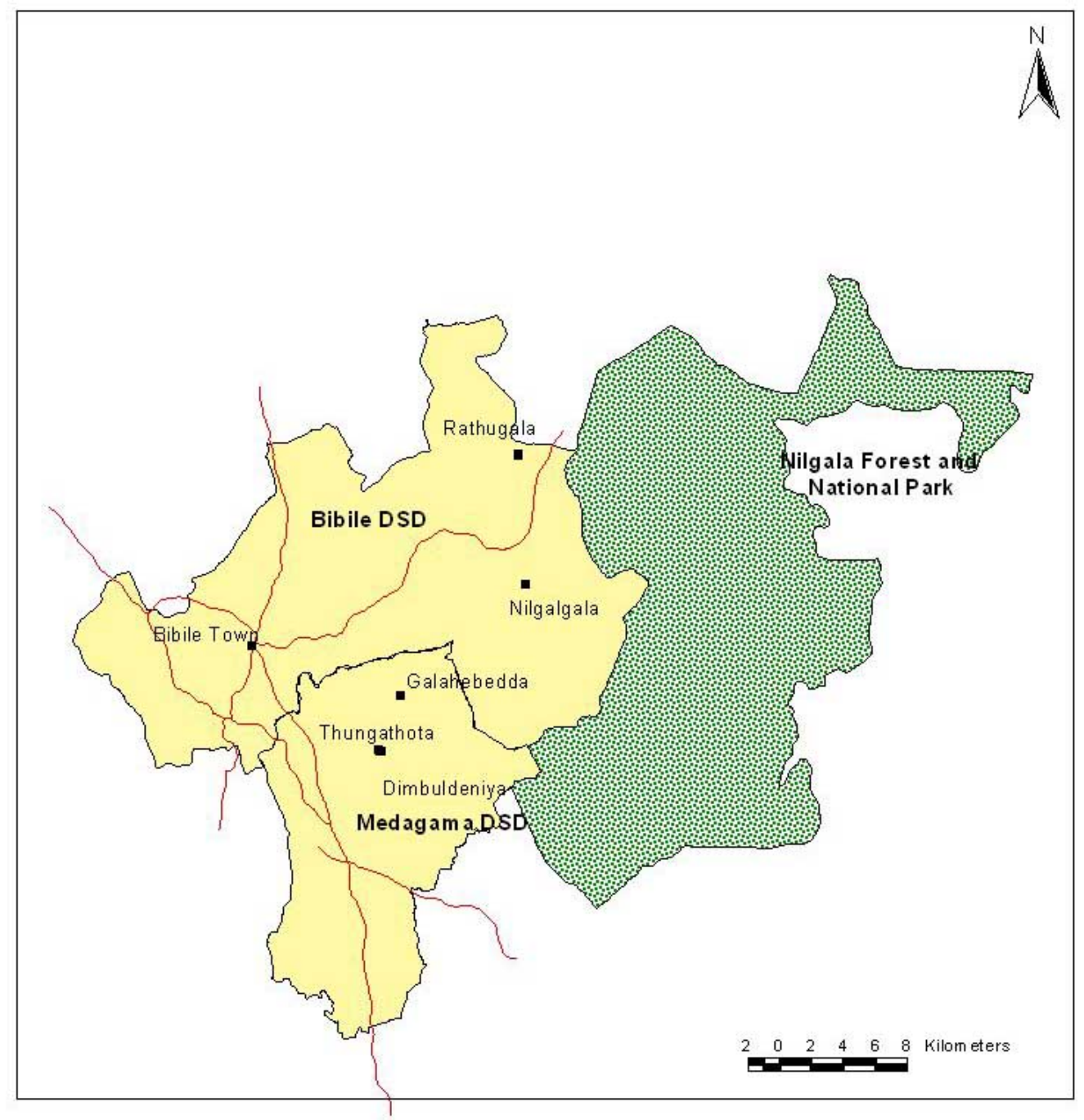

Figure 29. Map Created by Dilhari Weragodathenna (September 2010) 
Appendix G. Village Data Sheet: Annual Forest Product Collection/Services

\begin{tabular}{|l|l|l|l|l|l|l|}
\hline Time/Products/services & $\begin{array}{l}\text { Value } \\
\text { (avg) }\end{array}$ & Jan & Feb & Mar & $\cdots$ & $\begin{array}{l}\text { Engage in } \\
\text { collection? } \\
\text { Men/ Women/ } \\
\text { Total }\end{array}$ \\
\hline Gallnuts (amount) & & & & & & \\
\hline Bulu & & & & & & \\
\hline Nelli & & & & & & \\
\hline Bee honey & & & & & \\
\hline 'Beedi' leaves & & & & & & \\
\hline Fruits & & & & & & \\
\hline Madu & & & & & & \\
\hline Mushrooms & & & & & & \\
\hline Fish & & & & & & \\
\hline Hunting & & & & & & \\
\hline Other foods & & & & & & \\
\hline Timber & & & & & \\
\hline poles & & & & & & \\
\hline Green leaves & & & & & & \\
\hline Grass/Other Services & & & & & & \\
\hline Water for agriculture & & & & & & \\
\hline Water for drinking & & & & & & \\
\hline Grazing animal & & & & & & \\
\hline Religious purposes & & & & & & \\
\hline Leisure activities & & & & & & \\
\hline $\begin{array}{l}\text { Obtain mother seeds and } \\
\text { planting material }\end{array}$ & & & & & & \\
\hline Discharge of human waste & & & & & & \\
\hline Gem mining & & & & & \\
\hline Elephant Encounters & & & & & & \\
\hline
\end{tabular}


Appendix H. Reported Number of People Participating in Forest Collection Activities by Gender

\begin{tabular}{|c|c|c|c|c|c|c|c|c|c|c|c|c|}
\hline \multirow{3}{*}{$\begin{array}{l}\text { Household } \\
\text { Number--> } \\
\text { Collection/Forest } \\
\text { Activity: }\end{array}$} & \multicolumn{6}{|c|}{ Number of Men } & \multicolumn{6}{|c|}{ Number of Women } \\
\hline & \multirow{3}{*}{$\begin{array}{l}\mathrm{D} \\
20 \\
\end{array}$} & \multirow{3}{*}{$\begin{array}{l}\mathrm{F} \\
5\end{array}$} & \multirow[t]{2}{*}{ G } & \multirow[t]{2}{*}{$\mathrm{H}$} & \multirow[t]{2}{*}{ I } & \multirow[t]{2}{*}{ J } & \multirow[t]{2}{*}{ D } & \multirow[t]{2}{*}{$\mathrm{F}$} & \multirow[t]{2}{*}{ G } & \multirow[t]{2}{*}{$\mathrm{H}$} & \multirow[t]{2}{*}{ I } & \multirow[t]{2}{*}{ J } \\
\hline & & & & & & & & & & & & \\
\hline Gallnuts (amount) & & & 25 & 0 & 5 & 25 & 15 & 5 & 20 & 0 & 5 & 25 \\
\hline Bulu & 20 & 0 & 25 & & 5 & 25 & 15 & 0 & 20 & & 5 & 25 \\
\hline Nelli & 20 & 5 & 25 & 15 & 50 & 25 & 15 & 5 & 20 & 3 & 30 & 25 \\
\hline Bee Honey & 20 & 5 & 25 & 15 & 60 & 25 & 15 & 5 & 0 & 0 & 0 & 25 \\
\hline Beedi' leaves & 30 & 5 & 25 & 15 & 50 & 20 & 15 & 5 & 0 & 10 & 50 & 20 \\
\hline Fruits & & 5 & & 15 & & 25 & & 5 & & 10 & & 25 \\
\hline Madu & 10 & 5 & & 15 & & & 15 & 5 & & 10 & & \\
\hline Mushrooms & 30 & & & & & & 25 & & & & & \\
\hline Fish & & & & & 0 & & & & & & 0 & \\
\hline Hunting & & 20 & NA & 5 & & 5 & & 0 & NA & 0 & & 0 \\
\hline \multicolumn{13}{|l|}{ Other foods } \\
\hline Timber & & 0 & & 0 & 0 & 0 & & 0 & & 0 & 0 & 0 \\
\hline poles & & 0 & & & & & & 0 & & & & \\
\hline Green leaves & & 0 & & & & & & 0 & & & & \\
\hline Grass & & 0 & & & & & & 0 & & & & \\
\hline \multirow{2}{*}{\multicolumn{13}{|c|}{$\begin{array}{l}\text { Other services } \\
\text { Water for } \\
\text { Agriculture }\end{array}$}} \\
\hline & & & & & & & & & & & & \\
\hline \multirow{2}{*}{\multicolumn{13}{|c|}{$\begin{array}{l}\text { Grazing anim } \\
\text { Religious } \\
\text { Purposes }\end{array}$}} \\
\hline & & & & & & & & & & & & \\
\hline \multicolumn{13}{|l|}{ Leisure Activities } \\
\hline $\begin{array}{l}\text { Seeds and } \\
\text { planting materials }\end{array}$ & & & & & & 25 & & & & & & \\
\hline \multicolumn{13}{|l|}{$\begin{array}{l}\text { Discharge of } \\
\text { human waste }\end{array}$} \\
\hline Gem mining & & 0 & & & 12 & & & 0 & & & 0 & \\
\hline
\end{tabular}




\begin{tabular}{|c|c|c|c|c|c|c|}
\hline \multirow[b]{2}{*}{ Household Number-- } & \multicolumn{6}{|c|}{ Total Men and Women } \\
\hline & D & $\mathrm{F}$ & G & $\mathrm{H}$ & I & J \\
\hline \multicolumn{7}{|l|}{$\begin{array}{l}\text { Collection/Forest } \\
\text { Activity: }\end{array}$} \\
\hline Gallnuts (amount) & 35 & & 45 & 0 & 10 & 50 \\
\hline Bulu & 35 & & 45 & & 10 & 50 \\
\hline Nelli & 35 & & 45 & 18 & 80 & 50 \\
\hline Bee Honey & 35 & & 25 & 15 & 60 & 50 \\
\hline Beedi' leaves & 45 & & & 25 & 100 & 40 \\
\hline Fruits & & & & 25 & & \\
\hline Madu & 25 & & & 25 & & 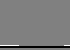 \\
\hline Mushrooms & 55 & & & & & \\
\hline Fish & & & & & 0 & \\
\hline Hunting & & & NA & 5 & & 5 \\
\hline \multicolumn{7}{|l|}{ Other foods } \\
\hline Timber & & & & 0 & - & 0 \\
\hline \multicolumn{7}{|l|}{ poles } \\
\hline \multicolumn{7}{|l|}{ Green leaves } \\
\hline \multicolumn{7}{|l|}{ Grass } \\
\hline \multicolumn{7}{|l|}{ Other services } \\
\hline \multicolumn{7}{|l|}{ Water for Agriculture } \\
\hline \multicolumn{7}{|l|}{ Grazing animal } \\
\hline \multicolumn{7}{|l|}{ Religious Purposes } \\
\hline \\
\hline \multicolumn{6}{|l|}{$\begin{array}{l}\text { Seeds and planting } \\
\text { materials }\end{array}$} & 50 \\
\hline \multicolumn{7}{|l|}{$\begin{array}{l}\text { Discharge of human } \\
\text { waste }\end{array}$} \\
\hline Gem mining & & & & & & \\
\hline
\end{tabular}


Appendix I. Sample of Evolving Log Sheet:

Reported Number of People Participating in Forest Collection Activities by Gender

Weekly Log Sheet

\begin{tabular}{|c|c|c|c|c|c|}
\hline \multirow{2}{*}{$\begin{array}{l}\text { Type of Natural } \\
\text { Resource Use } \\
\text { Gender of } \\
\text { Interviewee (M/F) }\end{array}$} & \multicolumn{5}{|c|}{ Number of Hours Men and Women Participate } \\
\hline & $\mathrm{F}$ & $\mathrm{M}$ & $\mathrm{F}$ & $\mathrm{F}$ & \\
\hline $\begin{array}{l}\text { IndSelf Report (i) } \\
\text { or Spousal Report } \\
\text { (s) }\end{array}$ & s-husband & $\begin{array}{l}\text { I- } \\
\text { husband }\end{array}$ & i-wife & i-wife & \\
\hline Interviewee \# & 1 & 2 & 1 & 3 & \\
\hline $\begin{array}{l}\text { Food Purchasing at } \\
\text { Market }\end{array}$ & 0 & 6 & 4 & 0 & \\
\hline $\begin{array}{l}\text { Selling of food at } \\
\text { Market }\end{array}$ & 0 & & 6 & 0 & \\
\hline Food Exchange & 0 & & 0 & & \\
\hline $\begin{array}{l}\text { Edible Plant } \\
\text { Gathering }=>\text { Forest } \\
\text { Coll }\end{array}$ & 3 & & 3 & 14 & \\
\hline $\begin{array}{l}\text { Consumption of colle } \\
\text { (Cooking) }\end{array}$ & - & & & $*$ & $\begin{array}{l}* 945 / 60=\mathrm{hrs} \\
\text { /week }\end{array}$ \\
\hline $\begin{array}{l}\text { Waste Disposal and } \\
\text { other sanitation } \\
\text { efforts }\end{array}$ & - & & & & \\
\hline $\begin{array}{l}\text { Polluting Activities: } \\
\text { Chemical }\end{array}$ & - & & & & \\
\hline $\begin{array}{l}\text { Polluting Activities: } \\
\text { Garbage }\end{array}$ & - & & & & \\
\hline $\begin{array}{l}\text { Polluting Activities: } \\
\text { Food Waste }\end{array}$ & - & & & & \\
\hline $\begin{array}{l}\text { Polluting Activities: } \\
\text { Human Waste }\end{array}$ & - & & & & \\
\hline Polluting Activities: & - & & & & \\
\hline $\begin{array}{l}\text { Soil Depletion } \\
\text { through cultivation }\end{array}$ & $\begin{array}{l}\text { 8-9 Hours } \\
\text { per day } 7 \\
\text { Days/week }\end{array}$ & & \begin{tabular}{|l}
8 \\
hours \\
a day \\
times \\
4 days \\
per \\
week \\
\end{tabular} & $\begin{array}{l}8 \\
\text { hours } \\
\text { times } \\
\text { four } \\
\text { days }\end{array}$ & \\
\hline Soil Erosion & & 0 & & & \\
\hline
\end{tabular}




\begin{tabular}{|c|c|c|c|c|c|c|}
\hline through digging & & & & & & \\
\hline $\begin{array}{l}\text { Deforestation } \\
\text { (cutting forest } \\
\text { trees) }\end{array}$ & & & & & & \\
\hline $\begin{array}{l}\text { Water Collection: } \\
\text { Point Source (Well) }\end{array}$ & & 14 & & & 7 & \\
\hline $\begin{array}{l}\text { Water Collection: } \\
\text { Natural Body of } \\
\text { H2O (River) }\end{array}$ & & & & & & \\
\hline $\begin{array}{l}\text { Water Use: } \\
\text { Consumption/Food } \\
\text { Prep }\end{array}$ & & & & & & \\
\hline $\begin{array}{l}\text { Water Use: Self } \\
\text { Bathing }\end{array}$ & & & & & & \\
\hline $\begin{array}{l}\text { Water Use: } \\
\text { Child care- bathing }\end{array}$ & & 2 & & & -2 & \\
\hline $\begin{array}{l}\text { Water Use: } \\
\text { Household Cleaning }\end{array}$ & & 14 & & & 3.5 & \\
\hline $\begin{array}{l}\text { Water Use: } \\
\text { Agricultural } \\
\text { Purposes }\end{array}$ & & 42 & & & & \\
\hline $\begin{array}{l}\text { Wildlife } \\
\text { Interactions: } \\
\text { Killing/Hunting }\end{array}$ & & 0 & & & & \\
\hline $\begin{array}{l}\text { Wildlife } \\
\text { Interactions: HEC }\end{array}$ & & 0 & & & & \\
\hline $\begin{array}{l}\text { Wildlife } \\
\text { Interactions: Pest } \\
\text { Control }\end{array}$ & & 0 & & & & \\
\hline $\begin{array}{l}\text { Hunting Practices } \\
\text { for Food }\end{array}$ & & 0 & & & & \\
\hline $\begin{array}{l}\text { Number of Electric } \\
\text { Outlets in Use } \\
\text { (Hours of Use) }\end{array}$ & & 0 & & $\begin{array}{l}200 \mathrm{Rs} \\
/ \\
\text { month }\end{array}$ & & \\
\hline $\begin{array}{l}\text { Electricity Use: } \\
\text { Radio }\end{array}$ & & 0 & & & & \\
\hline $\begin{array}{l}\text { Electricity Use: } \\
\text { Tripwire fences }\end{array}$ & & 0 & & $\mathrm{X}$ & & \\
\hline Cooking & - & $=$ & $=$ & $=$ & $=$ & $=$ \\
\hline $\begin{array}{l}\text { Collection of Flora: } \\
\text { Non-food purposes }\end{array}$ & 0 & & & $\begin{array}{l}1 \text { day } \\
\text { per } \\
\text { month }\end{array}$ & & \\
\hline $\begin{array}{l}\text { Plant-gathering for } \\
\text { food consumption }\end{array}$ & & & & & & \\
\hline $\begin{array}{l}\text { Farming (Rice } \\
\text { Paddy or Chena) }\end{array}$ & & $\begin{array}{l}6 \text { hours } \\
\text { per day }\end{array}$ & & & & \\
\hline
\end{tabular}




\begin{tabular}{|c|c|c|c|}
\hline $\begin{array}{l}\text { Small Scale } \\
\text { Gardening }\end{array}$ & $\begin{array}{l}2 \text { hours } \\
\text { per day }\end{array}$ & & 3.5 \\
\hline $\begin{array}{l}\text { Fuelwood } \\
\text { Gathering }\end{array}$ & & $\begin{array}{l}* 4 \\
\text { hours/ } \\
\text { week }\end{array}$ & \\
\hline $\begin{array}{l}\text { Tending to } \\
\text { livestock (if } \\
\text { applicable) }\end{array}$ & 0 & & \\
\hline $\begin{array}{l}\text { Cleaning (bathing } \\
\text { and house } \\
\text { maintenance) }\end{array}$ & & & \\
\hline $\begin{array}{l}\text { Other forms of } \\
\text { Daily Resource Use }\end{array}$ & & & \\
\hline
\end{tabular}

